\title{
WestVirginiaUniversity
}

THE RESEARCH REPOSITORY @ WVU

Graduate Theses, Dissertations, and Problem Reports

2016

\section{Pigeons and Humans Time Miscued Intervals}

\author{
Shrinidhi Subramaniam
}

Follow this and additional works at: https://researchrepository.wvu.edu/etd

\section{Recommended Citation}

Subramaniam, Shrinidhi, "Pigeons and Humans Time Miscued Intervals" (2016). Graduate Theses, Dissertations, and Problem Reports. 6739.

https://researchrepository.wvu.edu/etd/6739

This Dissertation is protected by copyright and/or related rights. It has been brought to you by the The Research Repository @ WVU with permission from the rights-holder(s). You are free to use this Dissertation in any way that is permitted by the copyright and related rights legislation that applies to your use. For other uses you must obtain permission from the rights-holder(s) directly, unless additional rights are indicated by a Creative Commons license in the record and/ or on the work itself. This Dissertation has been accepted for inclusion in WVU Graduate Theses, Dissertations, and Problem Reports collection by an authorized administrator of The Research Repository @ WVU.

For more information, please contact researchrepository@mail.wvu.edu. 
Pigeons and Humans Time Miscued Intervals

Shrinidhi Subramaniam

Dissertation submitted to the

Eberly College of Arts and Sciences

at West Virginia University

in partial fulfillment of the requirements for the degree of

Doctor of Philosophy

in

Psychology

Elizabeth G. E. Kyonka, Ph.D., Chair

Regina A. Carroll, Ph.D.

Michael Perone, Ph.D.

Julie H. Patrick, Ph.D.

David Smaldone, Ph.D.

Department of Psychology

Morgantown, West Virginia

2016

Keywords: Cue Informativeness; Temporal Discrimination;

Peak-Interval Procedure; Humans; Pigeons; Key Peck

Copyright 2016 Shrinidhi Subramaniam 


\section{ABSTRACT \\ Pigeons and Humans Time Miscued Intervals}

Shrinidhi Subramaniam

Cues signaling time to reinforcer availability can be highly informative, somewhat informative, or uninformative of the specific time to reinforcement. The purpose of this series of studies was to characterize the functional relation between miscues and pigeon and human response patterns in a peak-interval (PI) procedure. In Experiment 1, pigeons pecked keys to earn food in a cued and miscued PI procedure. Each session consisted of fixed-interval (FI) 2-s and 4-s schedules of food and occasional, 12-s PI trials during which pecks had no programmed consequences. The correlation between visual cues (red or green key light colors) and the schedule of reinforcement (FI $2 \mathrm{~s}$ or FI $4 \mathrm{~s}$ ) was manipulated across cue-informativeness conditions and represented by the phi coefficient $(\varphi)$. Different key light colors were either highly $(\varphi=1)$, moderately $(\varphi=0.8,0.6$, 0.4 , or 0.2$)$, or not correlated $(\varphi=0)$ with specific FI schedules. Temporal discrimination in PI trials was accurate; peaks in response distributions occurred at around $2 \mathrm{~s}$ and $4 \mathrm{~s}$. Red and green FI and PI response distributions converged when the correlation between key color and FI was less than $\varphi=0.8$. In Experiments 2 and 3, humans participated in a modified PI procedure. Participants pressed buttons on a computer keyboard to shoot at the center of the screen while a target moved from left to right across the screen. Participants earned points for shots hitting the target (around $2 \mathrm{~s}$ and $4 \mathrm{~s}$ ) and lost points for misses. The target was masked during 12-s PI trials, but participants could still earn and lose points. The correlation between the background color (light or dark green) and time to point availability ( $2 \mathrm{~s}$ or $4 \mathrm{~s}$ ) was manipulated. Different background colors were either highly $(\varphi=1)$, moderately $(\varphi=0.8,0.4)$, or not correlated $(\varphi=0)$ with specific times to point availability. In Experiment 2, each participant experienced all 4 cueinterval correlations and in Experiment 3, participants were randomly assigned to one of the four cue-interval correlations. Consistent with Experiment 1, temporal discrimination in PI trials was accurate, peaks in response distributions occurred at around $2 \mathrm{~s}$ and $4 \mathrm{~s}$. Response distributions in light and dark green PI trials were influenced by cue-informativeness order in Experiment 2 and were converged in groups with cue-interval correlations $\varphi<0.8$ in Experiment 3. Across all experiments, the convergence in PI distributions was not a sign that temporal discrimination accuracy was eliminated (peak times were always stable), but rather an adaptive change in response patterning involving adjustment of the time of abrupt shifts in response rate. 


\section{ACKNOWLEDGMENTS}

This dissertation was supported through doctoral research funds provided by the Eberly College of Arts and Sciences and the Department of Psychology at West Virginia University. I am grateful for the time and helpful suggestions made by my dissertation committee members, Regina Carroll, Julie Patrick, Michael Perone, and David Smaldone. I thank Claire St. Peter and Michael Perone for their helpful discussions about the intricacies of conducting human-operant research. I am especially grateful to Liz Kyonka for serving as chair of the committee and as my adviser and mentor for the past several years. A special thanks to Robert Thiele, Adam Fox, Nathan Rice, Alex Ward, Daniel Bell-Garrison, Matthew Eckard, Jim Cook, Stephanie Kincaid, Meagan Follett, and Tyler Nighbor for general camaraderie, assistance in data analysis, assistance in data collection, or for reviews of my research. 


\section{TABLE OF CONTENTS}

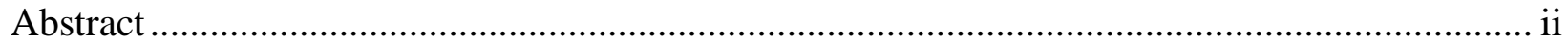

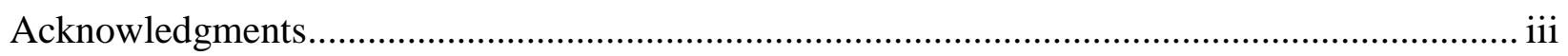

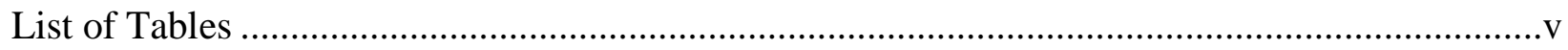

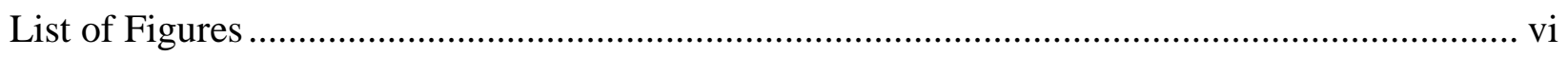

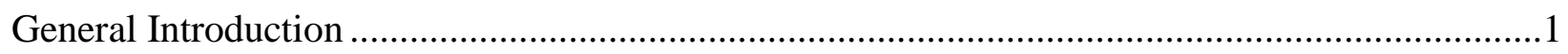

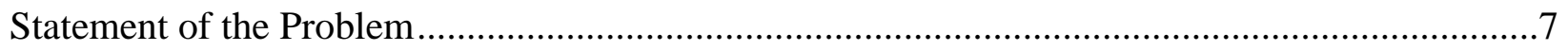

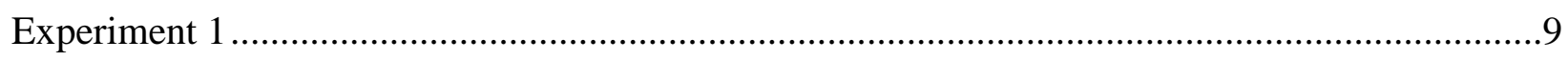

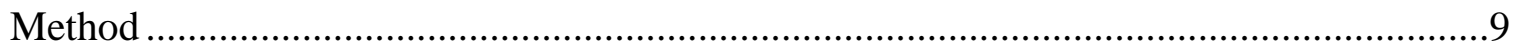

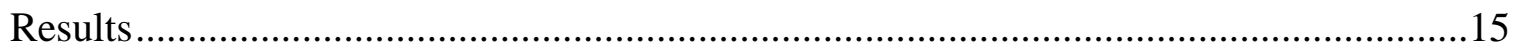

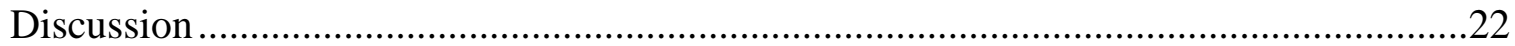

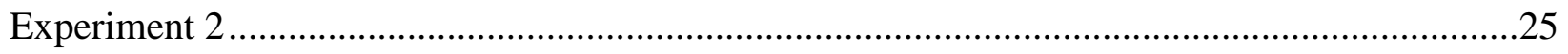

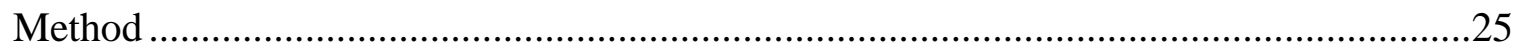

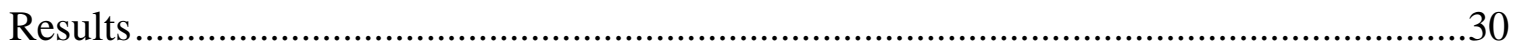

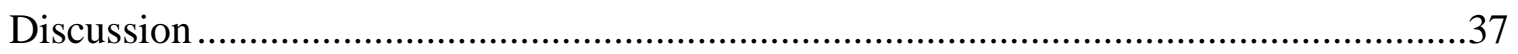

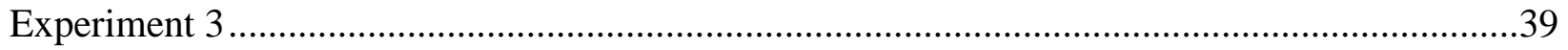

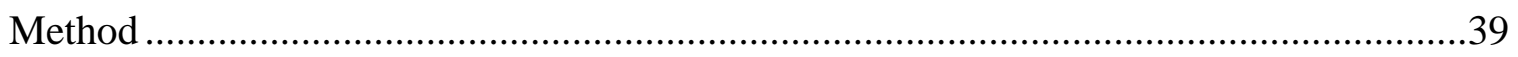

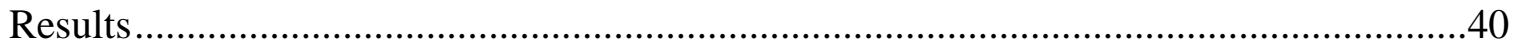

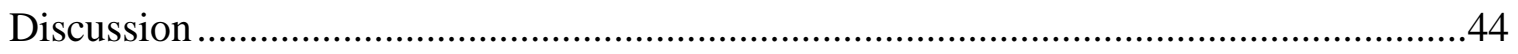

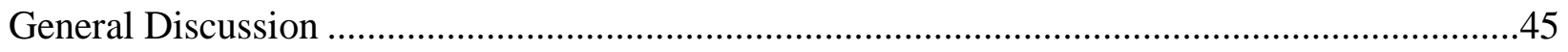

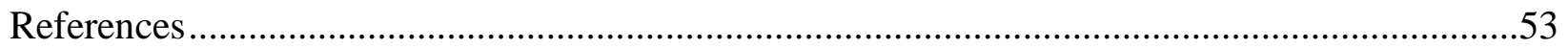

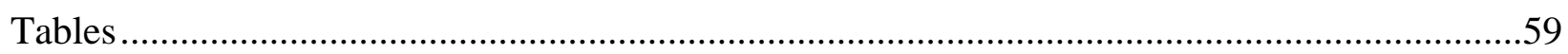

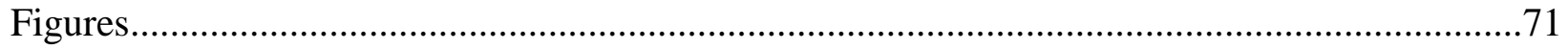




\section{LIST OF TABLES}

Table 1, Experiment 1 Subjects, Condition Order, and Sessions per Condition ...........................59

Table 2, Experiment 1 Number of Miscues per Condition.........................................................6

Table 3, Gaussian Fits to PI Distributions for Pigeons 301, 303, and 403................................61

Table 4, Gaussian Fits to PI Distributions for Pigeons 302, 401, and 402.................................62

Table 5, Experiment 2 Participants, Condition Order, and Trials per Condition........................63

Table 6, Experiment 2 Results of Kolmogorov-Smirnov Tests ...................................................64

Table 7, Gaussian Fits to PI Distributions for Participants H1, H2, and H3 ……......................65

Table 8, Gaussian Fits to PI Distributions for Participants H4, H5, and H6.............................66

Table 9, Gaussian Fits to PI Distributions for Participants in the $\varphi=1$ Group ..........................67

Table 10, Gaussian Fits to PI Distributions for Participants in the $\varphi=0.8$ Group ....................68

Table 11, Gaussian Fits to PI Distributions for Participants in the $\varphi=0.4$ Group .....................69

Table 12, Gaussian Fits to PI Distributions for Participants in the $\varphi=0$ Group .........................70 


\section{LIST OF FIGURES}

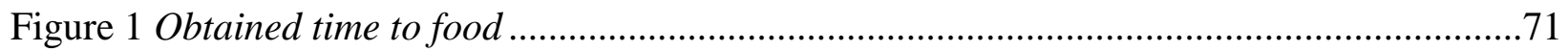

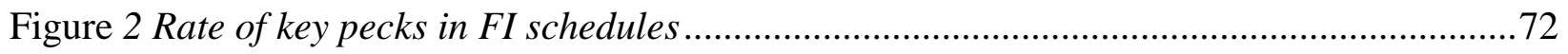

Figure 3 Raster plots of response times in FI schedules for representative pigeons ....................73

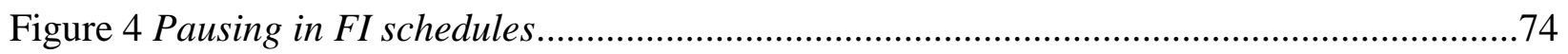

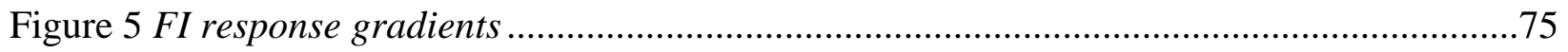

Figure 6 Parameters from FI response gradients ............................................................76

Figure 7 PI response distributions for Pigeons 301, 303, and 403 ........................................77

Figure 8 PI response distributions for Pigeons 302, 401, and 402 ...................................... 78

Figure 9 Parameters from PI response distributions with pigeons .........................................79

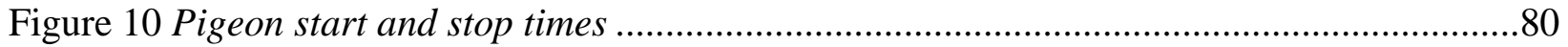

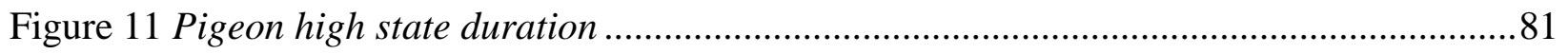

Figure 12 Screenshots of the PI procedure with humans .....................................................82

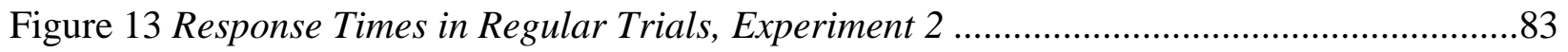

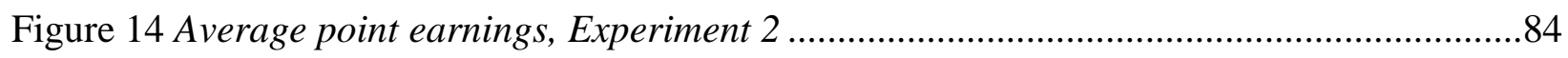

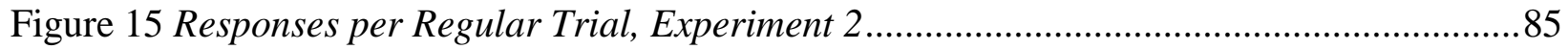

Figure 16 Raster plots of response times in regular trials for $H 1, H 2$, and $H 3$.........................86

Figure 17 Raster plots of response times in regular trials for H4, H5, and H6 ........................87

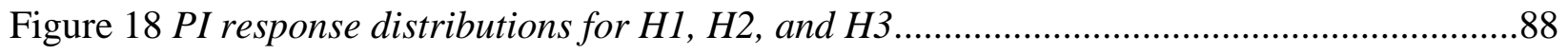

Figure 19 PI response distributions for H4, H5, and H6.................................................89

Figure 20 Parameters from PI response distributions with humans, Experiment 2...................90

Figure 21 Human start and stop time, Experiment 2 ....................................................... 91

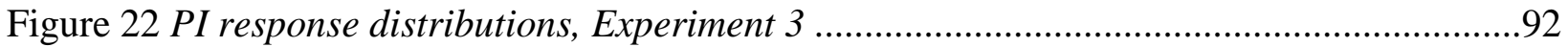


Figure 23 Parameters from PI response distributions with humans, Experiment 3 ....................93

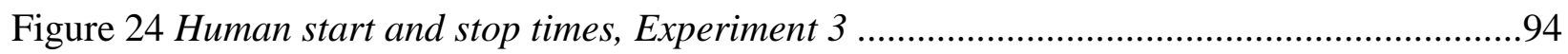

Figure 25 Human high state duration, Experiment 3 ............................................................95 
Pigeons and Humans Time Miscued Intervals

An animal's behavior is often based on informative cues in the environment. When a driver sees a turn signal on the car ahead of them, they usually slow down. Unfortunately, cues are not always perfectly informative. For example, some drivers might use the wrong turn signal or initiate their turn signal at inappropriate times. These miscues, or cues that typically predict one outcome that precede another outcome, might have unique effects on behavior. Miscues are important because the way they are presented and the way animals respond to them can be maladaptive or adaptive. For example, instructors are encouraged to present their students with correct instructions and prompts to be confident that academic interventions are effective (see Hawkins, Morrison, Musti-Rao, \& Hawkins, 2008). At the same time, those instructors might want to "teach loosely" (Stokes \& Baer, 1977) and introduce miscues to encourage generalization of skills across a broad range of contexts. In the former case, steps are taken to preserve high cue informativeness, but in the latter, high cue informativeness during the learning process might hinder the application of skills across different environments.

For the purpose of this investigation, cue informativeness is the extent to which cues signal or miscue the time to reinforcer availability. Decreased cue informativeness disrupts motor-skill learning in rats (Reid, Nill, \& Getz, 2010) and pigeons (Fox, Reid, \& Kyonka, 2014; Reid, Folks, \& Hardy, 2014). When instructions previously predicted reinforcer availability, incorrect instructions disrupted human performance in schedules of reinforcement (Galizio, 1979). When academic interventions were implemented with imprecise cue delivery, or treatment integrity errors, skill acquisition in children with disabilities was slowed (e.g., Carroll, Kodak, \& Fisher, 2013; DiGennaro Reed, Reed, Baez, \& Maguire, 2011). 
Changes in cue informativeness affects a wide range of behaviors. Therefore, a starting point to predicting effects of miscues is to describe the functional relation between cue informativeness and a basic learning process. One such process is temporal discrimination, or differential responding to cues correlated with different times to reinforcement. The passage of time often provides information about the probability of reinforcement for a response (Catania \& Reynolds, 1968). For example, a catcher on a baseball team learns that they have to be ready to catch the ball at some duration after the pitcher winds up. In the natural environment, however, visual dimensions of these cues may not be informative. For example, the catcher signals a change-up, but the pitcher throws a fastball.

A benefit to analyzing the functional relation between cue informativeness and temporal discrimination is that measures of temporal discrimination have been well described through decades of research (see Richelle \& Lejeune, 1980 for a review). Temporal discrimination is often studied using variants of fixed-interval (FI) schedules in which the first response following a fixed period of time since a cue is reinforced. In his multiple cued peak-interval (PI) procedure, Roberts (1981) measured rat lever presses for food in FI $20 \mathrm{~s}$ and FI $40 \mathrm{~s}$ trials. The two FI schedules were differentially cued by light or sound. Occasional "peak-interval" (PI) trials began with the onset of one of the FI cues (light or sound). PI trials were extended in duration (around $80 \mathrm{~s}$ ), and lever presses did not lead to food. Lever presses aggregated across several PI trials took the form of Gaussian curves that reached a maximum, or "peak time," around the time of the FI-schedule duration (20 s or $40 \mathrm{~s}$ ). A Gaussian curve fit to response rate as a function of time provides point estimates characterizing temporal discrimination. The central tendency of the Gaussian curve fit to the PI response distribution, or peak time, serves as a measure of the accuracy of discrimination. Accurate peak times are close to the time of the FI-schedule 
correlated with the PI cue. The standard deviation of the Gaussian curve fit to the PI response distribution, or peak spread, serves as a measure of temporal discrimination precision. In the PI procedure, precise discrimination is indicated by a tight spread in the PI response distribution.

In addition to defining accuracy and precision across several sessions of exposure to the PI procedure, point estimates of temporal discrimination can also be derived on a trial-by-trial basis. Church, Meck, and Gibbon (1994) analyzed rat lever presses in individual PI trials. They found that the rate of lever pressing during PI trials generally followed a low-high-low rate pattern. In other words, the rate of lever presses was low or near zero at the beginning of PI trials, increased to a high rate prior to the FI schedule value, and decreased to a low rate after the time of typical food delivery in FI trials. Two measures of temporal discrimination were calculated from the low-high-low analysis of single PI trials. The start time was the time of the transition from the low to the high state, and the stop time was the time that the high state ended. Start and stop times are measures of temporal discrimination accuracy. The difference between start and stop time, or high state duration, is a measure of the precision of temporal discrimination similar to peak spread.

Much of the research establishing measures of temporal discrimination such as peak, start, and stop times has been conducted with rats, pigeons, and mice. Presenting FI schedules and typical PI procedures to human subjects involves methodological challenges in obtaining stable estimates of discrimination. Indeed, human FI schedule performance is not always similar to that found with rats and pigeons (Hyten \& Madden, 1993). Verbal abilities like chronometric counting and challenges related to the reduction of boredom and attrition may account for differences in temporal discrimination between humans and nonhumans (Wearden \& Lejeune, 2008). Guilhardi, Menez, Caetano, and Church (2010) developed a method to measure temporal 
discrimination that promoted relatively fast acquisition of multiple discriminations without the need to control for chronometric counting. Participants were presented with bull's eye targets that moved at some velocity across a computer screen. The time at which the bull's eye reached the center of the screen was at one of three target durations. These durations were differentially signaled by the background color of the screen. Participants pressed a key on the computer keyboard to shoot at the center of the screen. Shots hitting the target earned points and misses (i.e., shots occurring too early or late) lost points.

Guilhardi and colleagues (2010) manipulated the visibility of the bull's eye target to measure temporal discrimination in humans. Specifically, during occasional PI trials, a white rectangle masked the target from view, while the background color that was previously correlated with the target durations was visible. Participants still responded for points, but momentary feedback about whether shots hit the target was not available. When the three durations were intermixed during training (i.e., presented pseudorandomly), response distributions averaged across PI trials took the form of Gaussian curves that reached a maximum around the time participants earned points in regular trials. Within individual PI trials, responding was continuous such that start and stop times were identifiable using Church, Meck, and Gibbon’s (1994) low-high-low analysis.

Research with nonhumans and humans has indicated two common properties of temporal discrimination: Mean accuracy and scalar variance (see Lejeune \& Wearden, 2006 and Wearden \& Lejeune, 2008 for reviews). Within the PI procedure and its variants, mean accuracy refers to the common finding that peak times and the mean of start and stop times approximate the FI schedule value. Scalar variance is found when peak spread or high state duration increases in proportion to the FI schedule duration. That is, the longer the FI schedule value, the greater the 
peak spread and the longer the range between start and stop times. Functional relations between cue informativeness and mean accuracy and scalar variance can thus be examined using PI procedures.

Other related measures of accuracy and precision of temporal discrimination are sensitive to changes in cue informativeness. When the same cue signals multiple intervals (i.e., cue informativeness is low), both intervals determine characteristics of response distributions. For example, in mixed FI-FI schedules, two intervals (one short and one long) are presented with the same cue. FI response distributions during the longer of the two intervals are a function of both FIs, with high rates of responding at more than one time (Whitaker, Lowe \& Wearden, 2003). In an FI temporal bisection task (Platt \& Davis, 1983), two intervals are associated with the same cue, but different responses (for example, left and right key pecks). When the same cue signaled two FI components that required different responses, Fox, Prue and Kyonka (under review) reported that the central tendency of the short response distribution was independent of long FI duration and vice versa, but that both intervals affected measures of variation in short and long response distributions. By contrast, in multiple schedules in which different cues were perfectly correlated with specific FI schedules (Guilhardi \& Church, 2005), response distributions in the presence of the different cues were independent, even when three intervals were trained simultaneously. In all three arrangements, mixed FI FI schedules, temporal bisection, and multiple cued interval procedures, momentary response rate could be described as a function of the momentary conditional probability of reinforcement in the presence of that cue (e.g., Catania \& Reynolds, 1968).

In most FI schedules, stimulus onset is an optimally informative time marker because food becomes available if and only if stimulus onset happened X s before the response. Further 
evidence of sensitivity of temporal discrimination to cue informativeness is demonstrated when the time marker denoting the start of an interval is a response rather than a visual cue such as stimulus onset (e.g., Caetano \& Church, 2009; Fox \& Kyonka, 2015). Fox and Kyonka (2015) found that distributions of pigeon key pecks in FI schedules were just as accurate, but less precise when the time marker was a key peck rather than a change in key color. They attributed this difference in precision to how predictive a key peck versus a key light was in signaling an interval. In schedules initiated by key pecks, the informativeness of a key peck as a time marker depended upon the number of pecks in each interval. Key pecks were always less informative than changes in key color, but key peck informativeness was determined by the pigeon rather than by the experimenters. Caetano and Church (2009) found that auditory stimuli and nose poke responses functioned as equivalent time markers in FI and differential reinforcement of low rate (DRL) schedules, respectively. Critically, in DRL schedules the two time markers (nose poke responses and auditory stimuli) were procedurally constrained to be equally informative. Manipulating cue informativeness as an antecedent variable would be a direct test of the relation between cue informativeness and patterns of responding in time.

Cue informativeness has been experimentally manipulated using compound stimuli, or simultaneous presentation of more than one cue associated with different intervals. Studies in associative learning have found that animals use a variety of strategies when presented with moderately informative cues as compound stimuli (see McLaren and Mackintosh, 2002 for a review). Swanton, Gooch, and Matell (2009) described three response patterns in the presence of a compound stimulus predicting two different times to food (i.e., one short and one long interval). First, as in long trials of mixed FI-FI schedules (e.g., Leak \& Gibbon, 1995; Whitaker, Lowe, \& Wearden, 2003), animals respond at high rates at the time of the short and the long 
interval. This response pattern is adaptive in instrumental conditioning procedures because responding at short and long intervals maximizes the likelihood of collecting scheduled reinforcers. Second, animals might respond according to temporal biases (e.g., Meck, 1984). Biased responses occur at either the short or the long duration exclusively. Finally, response rates might be noisy such that high rates of response occur at the average of the short and long intervals.

Although a multiple cued PI procedure is most similar to the conditions that promote high rates of responding at both the long and the short intervals, it is possible that intermediate cue informativeness can lead to noisy response distributions. Swanton and colleagues (2009) trained rats to nose poke for food on a multiple cued interval schedule in which the time to food availability was 10 or $20 \mathrm{~s}$. Short and long intervals were differentially signaled by a light or a tone. On occasional, no-food probe trials, the light and tone were presented together and no food was delivered for nose pokes. On the no-food probe trials, nose poke distributions were Gaussian with peaks times (i.e., the highest rates of nose poking) at the average of the two durations. Swanton and Gooch suggested that rats average the speed of their internal clocks when presented with conflicting information about the time to food. If miscues are functionally similar to compound stimuli, then this averaging process might occur at intermediate cue informativeness.

\section{Statement of the Problem}

Cues that provide information about whether and when a response will be reinforced are not always perfectly informative. More research is necessary to describe how the presence of miscues affects temporal discrimination, which is involved in a variety of behavioral and neurological processes (see Buhusi and Meck, 2005 for a review). There are several theories of temporal discrimination spanning different conceptual systems such as behavioral (Killeen \& 
Fetterman, 1988; Machado, 1997), information processing (Gibbon, 1977; Gibbon, Church, \& Meck, 1984), and neurological (Matell \& Meck, 2004; Matell, Meck, \& Nicolelis, 2003; Miall, 1989) frameworks. These theories only generate qualitative predictions about the relation between intermediate levels of cue informativeness and temporal discrimination. Research describing the functional relation between cue informativeness and temporal discrimination can provide data to build a more comprehensive theoretical account of the latter. The purpose of this series of experiments was to use the multiple cued PI procedure to describe the functional relation between cue informativeness and temporal discrimination in pigeons and humans. Previous research (Catania \& Reynolds, 1968; Guilhardi \& Church, 2005; Platt \& Davis, 1983; Whitaker, Lowe, \& Wearden, 2003) suggests that response distributions should be determined by the momentary conditional probability of reinforcement, while other research using compound stimuli varying in informativeness (Swanton, Gooch, \& Matell, 2009) suggests that animals average multiple temporal intervals.

In Experiment 1, pigeons pecked in a multiple-cued PI procedure (Roberts, 1981) with or without miscues. In Experiments 2 and 3, humans pressed computer keys for points in a modified PI procedure (Guilhardi et al., 2010). The time to food or point availability was always around $2 \mathrm{~s}$ and $4 \mathrm{~s}$, but miscues decreased cue informativeness. The primary objectives of these experiments were to determine if cue-informativeness order affected temporal discrimination (Experiments 1 and 2), describe the functional relation between cue informativeness and temporal discrimination, and test the hypothesis that the momentary conditional probability of food or points determined response patterns in PI trials. If this hypothesis was true, then distributions of key pecks and computer key presses in PI trials should be bimodal, rather than having one peak at the average of the two intervals. 


\section{Experiment 1}

Experiment 1 was designed to characterize effects of miscues on temporal discrimination in a multiple cued PI procedure. During FI trials, the time to food availability was always $2 \mathrm{~s}$ and 4 s. Occasional 12-s no-food PI trials were used to gain measures of temporal discrimination. Key light colors (red or green) cued or miscued the FI schedules such that the cue-interval correlation was one, zero, or intermediate. To counterbalance order, three pigeons received cueinformativeness conditions differing in cue-interval correlation in a descending order (i.e., decreasing from one to zero) and the other three pigeons received these conditions in an ascending order (i.e., increasing from zero to one).

\section{Method}

Subjects. Six pigeons (Columba livia) of mixed sex, numbered 301-303 and 401-403, were maintained at $85 \%$ ad libitum weight $\pm 15 \mathrm{~g}$ through postsession feedings, when appropriate. Pigeons were housed individually in a vivarium with a 12:12 hr light/dark cycle with free access to water. All pigeons had experience with FI but not PI schedules.

Apparatus. Experimental sessions were conducted in three standard three-key operant chambers, measuring $25.5 \mathrm{~cm}$ deep and $33.5 \mathrm{~cm}$ high. The keys were spaced $6 \mathrm{~cm}$ apart and were positioned $24 \mathrm{~cm}$ above the floor. A force of approximately $0.15 \mathrm{~N}$ was required to register a response on any key. General illumination was provided by a house light located on the rear wall of the operant chamber. Access to food (Nutriblend Pigeon Chow pellets) was available through a hopper, measuring $5.5 \mathrm{~cm}$ high and $6 \mathrm{~cm}$ wide and located $5.5 \mathrm{~cm}$ above the floor of the chamber. Chambers were housed in sound attenuated boxes with a ventilation fan to mask extraneous noises. Data collection and experimental events were controlled by a MED-PC® program on a computer in an adjacent room. 
Procedure. Pigeons pecked in multiple cued PI procedure with FI 2 and 4 s schedules. At the start of each FI trial, the house light was turned off and the center key illuminated red or green. After the programmed interval elapsed, the first peck to the center key resulted in three, 3s hopper presentations. Three hoppers allowed sufficient opportunity for pigeons to consume most of their daily ration of food. During food delivery, all key lights and the house light were darkened and the hopper was raised and lighted for $3 \mathrm{~s}$. To ensure that pigeons experienced durations similar to the programmed 2-s and 4-s FI schedules, a 1.5-s limited hold was in effect: If no peck occurred within $1.5 \mathrm{~s}$ of the FI schedule value elapsing, the FI trial ended and no food was delivered. During FI trials, pigeons pecked reliably such that food delivery occurred regularly and the limited hold rarely elapsed prior to a peck. Averaged across all FI trials in the last six sessions of each cue-informativeness condition and across pigeons, food delivery occurred in $97 \%$ of trials $(S E=2 \%)$.

To obtain measures of temporal discrimination, peak-interval (PI) trials were programmed to occur during $25 \%$ of trials. On PI trials, the house light was turned off, the center key lighted red or green for $12 \mathrm{~s}$, and no food was delivered. A 12-s PI trial duration was used because PI duration is typically three to four times the FI schedule value (e.g., Catania, 1970; Roberts, 1981).

Sessions consisted of 80 trials (60 FI, 20 PI). All trials were separated by a variable 5-s intertrial interval (ITI) during which the house light was on and all key lights were off. The ITI duration was sampled from a list of 12 intervals constructed from a geometric progression. This ITI ensured that the programmed time marker (i.e., key light onset) was the predictive stimulus rather than food delivery or overall cycle duration. To ensure that FI and PI trials were distributed throughout the session, each session was divided into ten blocks of eight trials. Of the 
eight trials in each block, three were FI 2-s trials, three were FI 4-s trials, one was a red PI trial, and one was a green PI trial. Within each block, the order of FI and PI trials were determined pseudorandomly. Whether red or green was assigned as the short or long key color was counterbalanced across pigeons. The key color correlated with the FI 2-s schedule in the highly correlated conditions (green for Pigeons 401, 402, and 403, red for others) will be referred to as the short key color. The key color correlated with the FI 4-s schedule in the highly correlated conditions (red for Pigeons 401, 402, and 403, green for others) will be referred to as the long key color. Table 1 shows key color arrangements and the order and duration of conditions, described below.

The main independent variable in Experiment 1 was cue informativeness: the programmed cue-interval correlation. Cue informativeness was changed across conditions. Conditions differed in the correlation between the short and long key colors and FI 2- and 4-s schedules. The phi $(\varphi)$ coefficient is a measure of association for two binary variables. Conditions were labeled according to the key color-FI $\varphi$. When $\varphi=1$ (i.e., a multiple schedule), all 30 FI 2-s trials were signaled by the short color and all 30 FI 4-s trials were signaled by the long color. When $\varphi=0$ (functionally, a mixed schedule), half of the FI 2-s trials and half of the FI 4-s trials were initiated by the short key color and the other half were initiated by the long key color. During the intermediate-correlation conditions, occasional FI trials occurred during which the short key color was present, but the long FI schedule was in effect or the long key color was present, but the short FI was in effect. In other words, the intervals were sometimes miscued. Table 2 shows the number of miscues that were programmed to occur in each intermediate cueinformativeness condition and at what point in the session these miscues occurred. To ensure that miscues were distributed throughout the session, the constraints that one-third of the total 
programmed miscues occurred in the first 20 trials were used. The remaining miscues occurred pseudorandomly in every block of 10 FI trials.

Each condition was in effect for a minimum of 20 sessions. Stability criteria were reached when no monotonic trends in stop times, averaged separately for all short and long key PI trials, were present for six consecutive sessions. The number of sessions of each condition is listed in Table 1 for each pigeon. To ensure that effects of cue-informativeness order were captured if they were present, three pigeons began in the $\varphi=1$ condition and the other pigeons began in the $\varphi=0$ condition. During subsequent conditions for the pigeons starting with $\varphi=1$, the cue-interval correlations were decreased in the following order: $\varphi=0.8,0.6,0.4,0.2$, and 0 (i.e., descending cue informativeness). For those three pigeons starting with $\varphi=0$, cue-interval correlations were increased in the following order: $\varphi=0.2,0.4,0.6,0.8$, and 1 (i.e., ascending cue informativeness). The order of cue-informativeness conditions for each individual pigeon are shown in Table 1.

Data Analysis. The functional relation between cue informativeness and temporal discrimination was assessed across several dependent variables in the multiple cued PI procedure. First, measures characterizing the shape of FI response gradients (i.e., slopes and centers) were obtained from the last six sessions of each condition for each individual pigeon and averaged across pigeons. Second, measures of accuracy and precision of temporal discrimination (i.e., peak times and peak spread) were obtained from gradients of responding across short and long key color PI trials in the last six sessions of each condition for each individual pigeon and averaged across pigeons. Finally, similar measures of temporal discrimination were obtained from single PI trials (i.e., start and stop times, high state durations) in each condition for each individual pigeon. 
The functional relation between response rate averaged over several FI trials and time since the beginning of the FI trial is typically characterized by ogives (e.g., Fox \& Kyonka, 2013, 2015; Guilhardi \& Church, 2005). Ogives were fit to normalized response rate (proportion of maximum responses) from the beginning of the FI trial to the time of programmed food delivery averaged across the last six sessions of each condition using Equation 1:

$$
y=\frac{1}{1+e^{-(x-a) / b}},
$$

where $a$ is the center, or time at which response rate reached half of the maximum rate, and $b$ is the slope of the function. When time since the beginning of the FI trial $(x)$ is represented in absolute number of seconds, the center should be earlier and the slope a smaller value for shorter versus longer FI schedules.

Mixed FI-FI schedule arrangements engender multiple temporal discriminations in single trials (e.g., Catania \& Reynolds, 1968; Leak \& Gibbon, 1995; Sanabria \& Oldenburg, 2014; Whitaker, Lowe, \& Wearden, 2003, 2008). One method for identifying peak times in mixed schedules is to fit the sum of two Gaussian curves to response distributions from each condition. Following data analysis procedures used by Whitaker et al. (2003, 2008), the sum of two Gaussian functions with mean $M$ and standard deviation $S D, G(M, S D)$ were fit as such:

$$
f(t)=K_{1} \times G\left(M_{1}, S D_{1}\right)+K_{2} \times G\left(M_{2}, S D_{2}\right),
$$

where $K_{1}$ and $K_{2}$ are scaling constants for the first and second Gaussian, respectively. $M_{1}$ and $M_{2}$ are peak times, and $S D_{1}$ and $S D_{2}$ are peak spreads. Single and summed Gaussian functions were fit to response distributions from each pigeon at each cue-interval correlation. The single Gaussian was defined in terms of two parameters (i.e., $M$ and $S D$ ); the summed Gaussian had seven free parameters (i.e., $M_{1}, M_{2}, S D_{1}, S D_{2}, K_{1}$, Maximum 1, and Maximum 2). Nested model comparison was used such that an $F$ ratio determined whether one or two Gaussians were a better 
fit to response distributions in PI trials. Estimates of parameters were obtained for all conditions and pigeons using a nonlinear optimization procedure (Microsoft Excel Solver). If one Gaussian was a better fit to response distributions, one peak time $(M)$ and spread $(S D)$ are reported. If two Gaussians were a better fit to response distributions, two peak times $\left(M_{1}\right.$ and $\left.M_{2}\right)$ and spreads $\left(S D_{1}\right.$ and $\left.S D_{2}\right)$ are reported.

For estimates of the accuracy and precision of temporal discrimination from each interval, responding in individual PI trials was described using Church and colleagues' (1994) low-high-low analysis. Responding in PI trials typically conforms to a low-high-low rate pattern. Response rate is low at the beginning of a trial during the first break period, increases abruptly and remains high for the duration of the run period and, after the programmed time of food delivery in FI trials, decreases and remains low in the second break period. Low-high-low analysis identified the two most abrupt transitions in response rate during each PI trial: The start time was the time of the transition from a low to a high rate, and the stop time was the time that the high rate ended. The low-high-low algorithm involved an exhaustive search for a best-fitting index. The index, $A$, was maximized using the equation:

$$
A=d_{\mathrm{L} 1}\left(r-r_{\mathrm{L} 1}\right)+d_{\mathrm{H}}\left(r_{\mathrm{H}}-r\right)+d_{\mathrm{L} 2}\left(r-r_{\mathrm{L} 2}\right)
$$

where $r$ was the overall trial response rate, $r_{L 1}$ and $r_{L 2}$ were response rates during the first and second low states, $r_{H}$ was response rate during the high state, and the $d$ s were the durations of those high and low states. The duration of the high state $\left(r_{H}\right)$, or the time between start $\left(d_{L 1}\right)$ and stop $\left(d_{L 1}+d_{H}\right)$ times, serves as a measure temporal discrimination precision. These analyses were conducted without constraints on start and stop time.

Peak times, peak spread, start times, stop times, and high state durations were analyzed separately for PI trials with short and long key colors. In this way, estimates of temporal 
discrimination accuracy and precision were separately obtained for key colors correlated (or uncorrelated) with 2- and 4-s FI schedules.

\section{Results}

The objectives of Experiment 1 were to characterize effects of cue informativeness on temporal discrimination and test the hypothesis that momentary conditional probability of food determined response patterns in PI trials. The results presented: (1) examine whether there were effects of cue-informativeness order on PI response times between pigeons receiving descending or ascending cue informativeness, (2) describe FI response distributions across conditions, (3) describe average PI distributions across conditions, (4) compare measures obtained from singletrial analyses of PI responding across conditions, and (5) determine the cue-interval correlation at which discriminated patterns of key pecking were eliminated.

Order Effects. If the ascending or descending sequence of cue-informativeness conditions affected the accuracy or precision of temporal discrimination, then analyses of cue informativeness should be conducted separately for the two groups of pigeons. KolmogorovSmirnov (KS) tests were computed to determine whether distributions of key pecking in time differed across the six cue-interval correlations depending on the descending or ascending sequence. The time of each key peck in the last 20 PI trials of each of the six cueinformativeness conditions were entered into 2-sample (short versus long key color) KS tests separately for each pigeon. Short and long response distributions were statistically significantly different $(p<.05)$ in ten out of 18 comparisons for pigeons with descending cue informativeness (maximum negative difference $M=-0.08, S E=0.02$; maximum positive difference $M=0.16, S E$ $=0.03$ ). Response distributions were statistically significantly different for pigeons with ascending cue informativeness in eight out of 18 comparisons (maximum negative difference $M$ 
$=-0.08, S E=0.01$; maximum positive difference $M=0.14, S E=0.02$ ). Differences between distributions of key pecking in time as a function of short or long key color were not systematically different across ascending or descending sequences, ruling out durable effects of order. The remaining analyses characterize responding in FI and PI trials collapsed across cueinformativeness order.

FI Schedule Responding. One way to characterize effects of cue informativeness on temporal discrimination is to examine FI schedule responding. Although a 1.5-s limited hold prevented overlapping distributions of obtained time to food in FI 2-s and 4-s schedules, it was possible that obtained time to food could only differ by $0.5 \mathrm{~s}$ in those two schedules (i.e., if pigeons pecked at $3.5 \mathrm{~s}$ in every FI 2-s trial). To ensure that the obtained FI schedules matched the programmed FI schedules, Figure 1 shows the average obtained time to food separately for all FI 2-s and 4-s trials for the last six sessions of each cue-informativeness condition averaged across all pigeons. Pigeons obtained food at times very close to the programmed FI schedule: $2.18 \mathrm{~s}(S E=0.04 \mathrm{~s})$ during FI 2 -s trials and $4.18 \mathrm{~s}(S E=0.04 \mathrm{~s})$ during FI 4-s trials across all conditions. Changes in cue informativeness did not affect the obtained time to food in FI trials. Further, the programmed absolute difference between FI 2-s and 4-s schedules did not differ from the obtained absolute difference of those schedules.

Although the obtained rate of food in FI schedules remained constant across cueinformativeness conditions, the rate of key pecking in FI schedules was free to vary. Figure 2 shows the mean rate of key pecks (per min) in all FI 2- and 4-s trials in the last six sessions of each condition as a function of cue-interval correlation, averaged across pigeons. Key pecking in FI trials occurred at a mean rate of 76.85 pecks per minute ( $S E=11.90$ pecks). There were no monotonic trends in the rate of key pecking across FI 2-s and 4-s schedules and cue- 
informativeness conditions. The presence of miscues did not systematically change global response rates.

Mean rates of key pecking in FI trials did not differ across 2- and 4-s schedule values and cue-informativeness conditions. However, response rates averaged across entire FI trials do not adequately represent performance because FI schedules engender responding conforming to a break-and-run pattern (Schneider, 1969). Figure 3 consists of raster plots for two pigeons (403 and 401) showing every response in every FI trial. Each data point is the time of a single peck in FI trials during the last session of each condition and each row is a single FI trial. In general, each FI trial consisted of a pause followed by a run of key pecks. This pattern persisted across cued (circles) and miscued (blue squares) trials and was generally consistent across all six pigeons.

To demonstrate the "break" in the beginning of trials, Figure 4 shows the mean latency (s) to the first key peck (i.e., pause) in FI trials as a function of cue-interval correlation. Pauses were averaged across all short key or long key color FI trials in the last six sessions of each cueinformativeness condition and across pigeons. Pauses were entered into a 2 x 6 repeatedmeasures analysis of variance (ANOVA) with key color (short or long) and condition $(\varphi=1,0.8$, $0.6,0.4,0.2$, or 0 ) as factors. There was a main effect of condition that was qualified by a statistically significant key-color-by-condition interaction, $F(5,25)=7.65, p<.001, \eta \mathrm{P}^{2}=0.60$. Tukey HSD post-hoc tests revealed that mean pauses diverged with increases in cue informativeness. Pauses to the short key color at $\varphi=1(M=1.11 \mathrm{~s}, S E=0.16 \mathrm{~s})$ and $\varphi=0.8(M$ $=1.12 \mathrm{~s}, S E=0.12 \mathrm{~s}$ ), were statistically significantly shorter than pauses to the long key color at $\varphi=1(M=1.60 \mathrm{~s}, S E=0.24 \mathrm{~s})$ and $\varphi=0.8(M=1.42 \mathrm{~s}, S E=0.15 \mathrm{~s})$, but not in other conditions. Pausing in the presence of the short key color did not change across conditions, while pausing 
monotonically increased with increases in cue informativeness in the presence of the long key color.

The initial break in responding to the long key color decreased as a function of decreases in the cue-interval correlation, suggesting that patterns of responding in FI trials were sensitive to miscues at cue-interval correlations less than $\varphi=0.8$. To demonstrate changes in response patterning, Figure 5 shows response gradients from FI trials in the last six sessions of each cueinformativeness condition averaged across pigeons. The gradients are normalized rate of key pecking (proportion of maximum response rate) as a function of time in 2- and 4-s FI trials. Response rate increased as time to food decreased in an ogive pattern consistent with previous research (e.g., Fox \& Kyonka, 2015; Guilhardi \& Church, 2005). The solid and dashed data paths are best-fitting ogives using Equation 1. By visual inspection, response gradients were different when cues were informative of FI schedules $(\varphi=1)$ and converged with low cue informativeness.

Comparison of center and slope parameters of Equation 1 demonstrate the convergence in FI response gradients. Figure 6 shows center and slope parameters as a function of cue-interval correlation, separately for ogives fit to gradients in FI 2-s and 4-s trials, averaged across pigeons. Centers for each pigeon were entered into a 2 x 6 repeated-measures ANOVA with FI ( 2 s or 4 s) and condition $(\varphi=1,0.8,0.6,0.4,0.2$, or 0$)$ as factors. There were significant main effects of FI and condition qualified by a significant FI $x$ condition interaction, $F(5,25)=5.18, p<.01, \eta_{\mathrm{P}}^{2}=$ 0.51. Tukey HSD post-hoc tests revealed that centers in FI 2-s versus FI 4-s schedules were statistically significantly different at $\varphi=1$ and $\varphi=0.8(p s<.01)$, but not at other cue-interval correlations. Slopes for each pigeon were entered into a 2 x 6 ANOVA with the same factors as the previous test of centers. There were significant main effects of FI and condition qualified by 
a significant $\mathrm{FI} x$ condition interaction, $F(5,25)=3.52, p<.05, \eta \mathrm{P}^{2}=0.41$. Tukey HSD post-hoc tests revealed that centers in FI 2-s versus FI 4-s schedules were statistically significantly different at all cue-interval correlations $(p s<.05)$ except for $\varphi=0$. Centers and slopes of ogives fit to FI response gradients did not change in the FI 2-s schedule, but decreased with decreases in cue-interval correlations for the FI 4-s schedule. The center changes indicate that response rates reached half of maximum earlier for the FI 4-s schedule at low versus high cue-interval correlations. The slope indicates that response rate changes were less abrupt in the FI 4-s schedule at low versus high cue-interval correlations.

PI Distributions. Pausing and the distribution of responses in time during FI trials were sensitive to miscues, but PI response patterns demonstrate accuracy and precision in temporal discrimination when food is not delivered. Figure 7 and Figure 8 shows normalized pecks per minute as a function of time in the presence of the short and long key color PI trials averaged across the last six sessions of each condition for each individual pigeon. The curves are single or summed Gaussians (Equation 2) fit to the distributions (mean $V A C=0.93$, range 0.75 to 0.997 ). By visual inspection, response distributions were more similar when cue-interval correlations were low than when they were high and distributions with low cue informativeness were bimodal.

A quantitative characterization of PI response distributions is shown in Gaussian curves fit to normalized PI distributions in Figures 7 and 8. If one Gaussian was a better fit to response distributions, then a curve with one mean and standard deviation is graphed, if the summed Gaussian (Equation 2) was a better fit, then a curve with two means and standard deviations is graphed. Tables 3 and 4 show parameter estimates for summed and single Gaussians for individual pigeons, and details of model fitting. Table 3 shows estimates for Pigeons 301, 303, 
and 403 and Table 4 shows estimates for Pigeons 302, 401, and 402. The summed Gaussian function was a better fit than the single Gaussian for 119 out of 144 distributions (82.6\%), providing evidence that distributions were mostly bimodal and that the momentary conditional probability of food determined response patterns.

Parameter estimates from Equation $2\left(M_{1}, M_{2}, S D_{1}, S D_{2}\right)$, obtained from PI distributions in the presence of short and long key colors for the last six sessions of each condition for each pigeon, were entered into four paired-samples $t$-tests. Paired-samples $t$-tests revealed that the key color led to no differences in peak times estimated by $M_{2}$ or peak spreads estimated by $S D_{l}$ and $S D_{2}$ (all $p \mathrm{~s}>.05$ ). Peak times estimated by $M_{1}$ were statistically significantly earlier in the presence of the short key color PI ( $M=1.73 \mathrm{~s}, S D=0.40 \mathrm{~s})$ than the long key color PI $(M=2.13$ $\mathrm{s}, S D=0.51 \mathrm{~s}), t(18)=-3.43, p=.003$, but the effect size was quite small $(d=-0.78)$.

Across distributions obtained from the last six sessions of each cue-informativeness condition, key colors, and pigeons, first and second peak times (i.e., $\mathrm{M}_{1}$ and $\mathrm{M}_{2}$ in Equation 2) were $2.05 \mathrm{~s}$ and $4.18 \mathrm{~s}$, respectively. First and second peak spreads (i.e., $\mathrm{SD}_{1}$ and $\mathrm{SD}_{2}$ ) were 0.73 $\mathrm{s}$ and $1.78 \mathrm{~s}$, respectively. Figure 9 shows peak time and peak spread across cue-informativeness conditions, averaged across pigeons. Peak times were entered into a $2 \times 6$ repeated-measures ANOVA with parameter $\left(M_{1}\right.$ or $\left.M_{2}\right)$ and condition $(\varphi=1,0.8,0.6,0.4,0.2$, or 0$)$ as factors. There was a main effect of parameter, $F(1,5)=147.69, p<.001, \eta_{\mathrm{P}}^{2}=0.97$, and no other statistically significant effects $(p s>.05)$. Peak times at $M_{1}$ were earlier than peak times at $M_{2}(p$ $<.001)$. Peak spreads were entered into a 2 x 6 repeated-measures ANOVA with the same factors as described for peak time. There was a main effect of parameter, $F(1,5)=41.86, p<$ $.01, \eta \mathrm{P}^{2}=0.89$, and no other statistically significant tests $(p \mathrm{~s}>.05)$. Peak spread at $S D_{1}$ were 
smaller than peak spread at $S D_{2}(p<.01)$. Despite changes in cue-interval correlations, mean accuracy in peak times and precision in peak spread were stable across conditions.

The relative stability in peak time and spread from PI distributions averaged across multiple sessions demonstrated that mean accuracy and precision maintained across cueinformativeness conditions. Within-trial measures of accuracy (start and stop times) and precision (the difference between start and stop times) are shown for the last six sessions of each condition for each pigeon in Figure 10. Start and stop times were earlier to the short key color and later to the long key color when those cues were correlated with FI schedules and converged when cues were weakly or not correlated. Across pigeons, the difference between mean start times (long- short key color) from the last six sessions of each condition was smaller with lower cue-interval correlations: $M(S E)=0.46 \mathrm{~s}(0.21 \mathrm{~s})$ when $\varphi=1 ; 0.42 \mathrm{~s}(0.15 \mathrm{~s})$ when $\varphi=0.8 ; 0.17$ $\mathrm{s}(0.11 \mathrm{~s})$ when $\varphi=0.6 ; 0.16 \mathrm{~s}(0.10 \mathrm{~s})$ when $\varphi=0.4 ; 0.06 \mathrm{~s}(0.11 \mathrm{~s})$ when $\varphi=0.2 ;$ and $0.11 \mathrm{~s}$ $(0.09 \mathrm{~s})$ when $\varphi=0$. Similarly, the difference between mean stop times (long- short key color) from the last six sessions of each condition was smaller with lower cue-interval correlations: $M$ $(S E)=2.30 \mathrm{~s}(0.24 \mathrm{~s})$ when $\varphi=1 ; 1.57 \mathrm{~s}(0.25 \mathrm{~s})$ when $\varphi=0.8 ; 0.44 \mathrm{~s}(0.29 \mathrm{~s})$ when $\varphi=0.6$; $0.12 \mathrm{~s}(0.16 \mathrm{~s})$ when $\varphi=0.4 ; 0.06 \mathrm{~s}(0.14 \mathrm{~s})$ when $\varphi=0.2$; and $-0.25 \mathrm{~s}(0.18 \mathrm{~s})$ when $\varphi=0$.

Mean start and stop times were sensitive to miscues. This finding implies that the difference between start and stop times, or high state duration, may detect changes in precision of temporal discrimination as a function of cue informativeness. Figure 11 shows the high state duration, or within-trial precision of temporal discrimination, averaged across all pigeons and PI trials in the last six sessions of each cue-informativeness condition. High state durations for the short and long key color were entered into a 2 x 6 repeated-measures ANOVA with color (short or long) and condition ( $\varphi=1,0.8,0.6,0.4,0.2$, or 0$)$ as factors. There were main effects of color 
and condition qualified by a color $\mathrm{x}$ condition interaction, $F(5,25)=16.52, p<.001, \eta_{\mathrm{P}} 2=0.77$. Tukey HSD post-hoc tests revealed differences between high state durations in the presence of the short versus long key at $\varphi=1$ and $\varphi=0.8$ ( $p$ s $<.001)$, but not at other cue-interval correlations. There were no monotonic trends in high state durations to the long key color across condition, but high state durations to the short color decreased across increases in cue informativeness. In other words, within-trial precision to the short key color decreased when the cue-interval correlation was $\varphi<0.8$.

Discriminated Patterns of Responding. Across multiple measures of temporal discrimination (i.e., pausing, centers and slopes of FI gradients, start and stop times, and high state durations), patterns of responding converged at intermediate cue informativeness. A comparison of PI distributions in the presence of short or long key colors permit further identification of the point at which miscues eliminated discriminated patterns of pecking. Nonnormalized PI response rate distributions averaged across all pigeons at each condition were used in the analysis. PI response rate distributions were entered into a two-sample Mann Whitney U test (short versus long key) separately for each cue-interval correlation. Response distributions in the presence of the short and long key color were statistically significantly different at $\varphi=1.0(U$ $=188.00, p=.04)$ and at $\varphi=0.8(U=187.50, p=.04)$, but were not significantly different at $\varphi=$ $0.6,0.2$, or $0(p s>.05)$. Consistent with pauses and centers in FI trials and high state durations in PI trials, average response rate distributions converged when cue-interval correlations were $\varphi<$ 0.8 .

\section{Discussion}

To characterize the relation between cue informativeness and temporal discrimination, pigeons pecked in cued or miscued FI 2 and 4-s schedules with occasional PI trials. Different 
distributions of pecking occurred in short and long key-color FI and PI trials when cue-interval correlations were high and distributions converged when the cue-interval correlation was low. The interesting result was that multiple measures of temporal discrimination revealed that this convergence occurred at $\varphi<0.8$. Thus, miscues that are presented in $20 \%$ or more FI trials $(\varphi \leq$ 0.6) eliminated differential patterns of pecking in the presence of different visual cues. This finding could be conceptualized as shifts in selective attention (e.g., Mackintosh, 1965) toward two cues: Key color and the passage of time. At high cue-interval correlations ( $\varphi=1$ and 0.8$)$, visual and temporal information influenced response patterns. Pigeons attended to key color and the passage of time. At lower cue-interval correlations, response patterns were mostly influenced by temporal information. Pigeons stopped attending to irrelevant visual cues.

If selective attention was shifted by changes in cue informativeness, then order effects should have been evident. That is, learning to ignore previously relevant cues should lead to less converged short and long key color PI distributions than learning to attend to previously irrelevant cues (e.g., Mackintosh, 1975; Sutherland \& Mackintosh, 1971). Response times in PI trials were not, however, significantly affected by the order in which cue-informativeness conditions were presented. There was a small, ordinal difference between response times for pigeons with descending and ascending cue informativeness. Short and long key color PI response times were slightly more converged in the latter than the former, but not to a great extent. Pigeons were exposed to cue-interval correlations for at least 20 sessions. Thus, the extended exposure to cue-interval correlations might have been sufficient to eliminate order effects.

Although response distributions converged in PI trials, the influence of the passage of time as a relevant cue maintained across cue-interval correlations. Temporal discrimination was 
evident in all conditions. PI distributions were well-described by summed Gaussian functions. Peak times (i.e., means of Gaussians), measures of accuracy in temporal discrimination, were constant across cue-informativeness conditions. On average, peak times occurred around $2 \mathrm{~s}$ or 4 s despite changes in cue informativeness. These results are consistent with performance in long trials in mixed FI-FI schedules (Leak \& Gibbon, 1995; Whitaker, Lowe \& Wearden, 2003, 2008). By visual inspection of normalized PI response distributions described by Equation 2, maximum response rates in PI distributions from miscued conditions were usually higher for the first than the second Gaussian. This result is consistent with previous research on performance on mixed FI-FI schedules (Leak \& Gibbon) and with ordinal predictions of scalar expectancy theory. Thus, the momentary conditional probability of food determined response rates.

Fox and Kyonka (2015) suggested that temporal discrimination precision is a function of the correlation between the signal marking the onset of an interval and the duration of the interval. Experiment 1 tested that assertion by manipulating the extent to which key colors signaled specific intervals. Measures of precision were slope parameters of ogives fit to FI response gradients, peak spread in PI response distributions, and high-state durations from individual PI trials. Ogives fit to response gradients in FI trials were more precise in the presence of the long key color as cue informativeness decreased. This increase in precision was adaptive because the probability of the FI 2-s schedule in the presence of that cue increased with decreases in cue informativeness. In PI trials, average peak spread was variable across cueinformativeness conditions, but high state durations in the presence of the short key color increased as the cue-interval correlation decreased. This change in measures of precision of temporal discrimination was consistent with Fox and Kyonka's suggestion that precision is partially determined by cue informativeness. 


\section{Experiment 2}

Pigeons timed miscued intervals given extended exposure to six cue-interval correlations in a multiple cued PI procedure. Visual cues ceased to influence response patterns at cue-interval correlations less than $\varphi=0.8$, accuracy of temporal discrimination was a function of the FI schedules, and temporal discrimination precision was a function of the FI schedules and cue informativeness. Generality of the functional relation between cue informativeness and temporal discrimination has yet to be reported in human participants. Experiment 2 was designed to replicate and extend the results of Experiment 1 with human subjects using a PI procedure designed by Guilhardi et al. (2010). The objectives of Experiment 2 were to describe human performance in the multiple cued PI procedure with miscues, characterize the functional relation between cue informativeness and temporal discrimination, and test the hypothesis that momentary conditional probability of earning points determined response patterns in PI trials. If human response patterns were sensitive to point delivery, then PI distributions should be bimodal as in Experiment 1.

\section{Method}

Participants. Six participants, 3 female (H2, H3, and H6) and 3 male (H1, H4, and H5), participated for research credit and a chance to win a gift card valued at $\$ 50$. All participants completed the four conditions of the experiment within one visit to the laboratory lasting less than 2 hrs.

Setting. Participants were seated at a desk containing one desktop computer with a monitor, keyboard, headphones, and mouse. Auditory stimuli were presented using a pair of stereo headphones. The color monitor presented visual stimuli, and responses on the keyboard were recorded by the computer program. Participants responded using the enter key and the 
spacebar key on the computer keyboard. The custom Microsoft Windows program, written in Microsoft Visual Basic $@$ programming language, timed events with a 1-ms resolution, presented contingencies, and collected real-time experimental data.

Procedure. The six participants responded in the PI procedure individually in a small laboratory. The researcher provided each participant with standard informed consent. After they provided consent, participants received the following instructions displayed on the computer monitor: "During training, a target will move across your screen. You can press the 'enter' key every time you would like to shoot at the middle of the screen. Your goal is to hit the target as much as you can so you maximize your points. Points: -1 for missing the target, +1 for hits anywhere in the target, +5 for the bull's eye. During testing, you won't be able to see the bull's eye but you will be able to shoot at the middle of the screen and score points. You can gain points by shooting the target more than once. You automatically lose 10 points if you do not respond during testing. You can take a break at any time by delaying the start of the trial. Good luck! Click the target on the right to continue." After clicking the target, the instruction, "Press the spacebar to begin," appeared on the top center of the computer screen. Following a spacebar press, the first trial began.

The first 20 trials were regular trials. In regular trials, the target was visible, and moved across the screen from left to right. The target was the same shape and size (relative to the computer monitor) across the entire experiment: Five concentric circles coloring red and white on the outside, and blue in the center, with a diameter $10 \%$ of the width of the computer monitor (102 pixels). During regular trials, the time it took to for the target to reach the center of the screen was either $2 \mathrm{~s}$ or $4 \mathrm{~s}$. These durations were used in a previous experiment (Guilhardi, et al., 2010), and were found to be discriminable with human participants. The background color 
during regular trials was either light or dark green as shown in the top panel of Figure 12. Whether the light or dark green was assigned as the short or long background color was counterbalanced across participants (see Table 5). The background color correlated with 2-s point availability in the $\varphi=1$ condition (light green for participants $\mathrm{H} 1, \mathrm{H} 2, \mathrm{H} 3$, and $\mathrm{H} 5$ ) will be referred to as the short color. The background color correlated with 4-s point availability in the $\varphi$ $=1$ condition (dark green for participants H4 and H6) will be referred to as the long color.

Participants fired shots at the center of the screen with the enter key. Each enter key press resulted in one shot. Each shot resulted in immediate feedback consisting of a yellow square (10 pixels across) visible for $0.1 \mathrm{~s}$ on the center of the screen and a clicking noise. With each shot taken during regular trials, participants could view whether the yellow square hit the target. Participants earned 5 points for each shot hitting the central blue circle ("bulls eye"), one point for each shot hitting other parts of the target, and lost 1 point for each shot missing the target. Participants could hit the bull's eye or sides of the target multiple times in each trial. Points were available for shots between 1.64 and $2.36 \mathrm{~s}$ in 2-s target trials and for shots between 3.27 and $4.73 \mathrm{~s}$ in 4-s target trials.

Once the participant completed the first 20 regular trials, PI trials were programmed to occur pseudorandomly. In each block of 20 trials (following the initial exposure to 20 regular trials), six were short background PI and six were long background PI trials. During PI trials, a white rectangle covered the bull's eye target trajectory, but the short or long background color was visible (Figure 12). All PI trials terminated after variable duration averaging $12 \mathrm{~s}$ throughout the session (range $=8 \mathrm{~s}$ to $24 \mathrm{~s}$ ). Pilot data revealed that when all PI trials were $12 \mathrm{~s}$, response latencies were disrupted on the subsequent trial. Therefore, a variable rather than a fixed, 12-s duration was used to promote attending to the task. During PI trials, enter-key presses resulted in 
visual and auditory feedback as in regular trials, but the position of the yellow square (i.e., visual feedback of the shot) relative to the target was not observable. Instead, the yellow square flashed on the center of the screen over the rectangle. In other words, the momentary feedback available during regular trials was not present in PI trials. The identical point contingency as regular trials (i.e., 5 points for a bull's eye, 1 point for a hit, -1 point for a miss) was in effect during PI trials to maintain responding when the target was not visible. To promote at least one response per PI trial, participants automatically lost 10 points if they did not respond.

Each regular and PI trial was followed by an ITI. The participant determined the duration of the ITI. During the ITI, the computer screen showed the total points that participants earned on the previous trial and the cumulative points earned across the session as shown in the bottom panel of Figure 12. Points earned in the previous trial were displayed on the top and center of the screen and cumulative points earned across the session were displayed on the top right-hand side of the screen. The instruction, "Press the spacebar to begin," was displayed on the center of the screen below the point feedback. A press to the spacebar began the next trial.

Each session consisted of 60 regular trials and 60 PI trials. The first 20 trials of each session were "exposure trials" in which participants responded in 10, 2-s and 10, 4-s regular trials. This initial exposure to regular trials were programmed to increase the likelihood that participants learned each target duration. The exposure trials were followed by five blocks of 20 trials each. In each of these subsequent blocks, participants were exposed to four 2-s and four 4-s regular trials and six short and six long background color PI trials. The order in which trials were presented was determined by random selection without replacement.

Participants completed at least one session of each of the four cue-informativeness conditions. The difference between conditions was the correlation between the background color 
and target duration, which was manipulated using miscues. A miscue was a regular trial in which the short background was presented during a 4-s regular trial or the long background was presented during the 2-s regular trial.

In the $\varphi=1$ condition, the short background was presented during all 30, 2-s regular trials and the long background during all 30, 4-s regular trials. In the $\varphi=0.8$ condition, three 2 -s and three 4-s regular trials were miscued. To ensure that miscues were distributed throughout the session, one 2-s and one 4-s miscued regular trial occurred during the first 20 trials of the condition; the other four miscues were presented pseudorandomly during the 40 remaining regular trials with the constraint that a maximum of one miscue occurred in each block of 8 regular trials. To ensure that points earned during PI trials did not skew the cue-interval correlation, three short and three long background color PI trials were miscued. In the $\varphi=0.4$ condition, nine 2-s and nine 4-s regular trials were miscued. Six miscues occurred during the first 20 regular trials of the condition (three miscued 2-s and three miscued 4-s regular trials); the other 12 miscues were presented pseudorandomly during the 40 remaining regular trials with the constraint that no more than three miscues occurred in each block. Nine short and nine long background color PI trials were miscued. In the $\varphi=0$ condition, the background colors were not correlated with the short and long targets. Points were available around 2-s and 4-s in the presence of short and long background colors (in other conditions) with equal probability. Thus, in the $\varphi=0$ condition, the background was uninformative of whether a 2-s or 4-s target was more likely to occur.

To test all levels of cue informativeness and potential order effects from repeated exposure to cues, three participants experienced descending cue informativeness: $\varphi=1$ condition first followed by the $\varphi=0.8,0.4$, and 0 cue-interval correlations. Three participants experienced 
ascending cue informativeness: $\varphi=0$ condition first, followed by the $\varphi=0.2,0.4$, and 1 cueinterval correlations. The order of conditions were counterbalanced across participants as illustrated in Table 5.

Stability Criteria. Each condition was in effect until temporal discrimination was stable. The stability criterion was no monotonic trends in stop times during the last six light and dark green PI trials in the last block of a session. Each condition was in effect for 120 trials (i.e., one session), and all participants met these criteria. Participant 3 was exposed to 126 trials due to technical difficulties during the third session. The researcher restarted the session following 43 trials.

\section{Data Analysis}

As with Experiment 1, response distributions were obtained by aggregating enter key presses in PI-trials in the presence of the short and long background colors. Because Guilhardi and colleagues (2010) found that participants responded similarly in the first and last five PI trials in a session, averages were obtained from all 30 short background and all 30 long background PI trials. Summed Gaussian fits for each session and low-high-low analyses for each PI trial were conducted as described for Experiment 1.

\section{Results}

The objectives of Experiment 2 were to describe regular-trial performance in the multiple cued PI procedure with miscues, characterize the functional relation between cue informativeness and temporal discrimination in PI trials, and test the hypothesis that momentary conditional probability of earning points determined response patterns in PI trials. The results presented: (1) examine effects of cue-informativeness order on PI response times between participants receiving descending or ascending cue informativeness, (2) describe responding in 
regular trials, (3) compare measures obtained from average PI distributions across conditions, and (4) compare measures obtained from single-trial analyses of PI responding across conditions.

Order Effects. If the ascending or descending sequence of cue-informativeness conditions affected the accuracy or precision of temporal discrimination, then analyses of cue informativeness should be conducted separately for two groups of participants. KS tests were computed to determine whether distributions of enter key presses in time differed across the four cue-interval correlations for participants receiving those correlations in a descending or ascending sequence. The time of each enter key press in the last 12 PI trials (six short background, and six long background color) of each of the four cue-informativeness conditions were entered into 2-sample (short versus long background color) KS tests separately for each participant. Table 6 shows the test statistics obtained from KS tests: Participants with descending cue informativeness had stable differences in response-time distributions across conditions ( $83 \%$ of comparisons were significantly different), while those with ascending cue informativeness had similar response-time distributions across conditions (only $42 \%$ of comparisons were significantly different). Cue-interval correlation order had a substantial impact on participants' response patterns in PI trials. The remaining analyses characterize responding in regular and PI trials separately for participants with descending or ascending cue-informativeness order.

Regular Trial Responding. One objective of Experiment 2 was to describe performance in regular trials of the multiple cued PI procedure. The top panel of Figure 13 shows the mean time of enter key presses separately for short (2-s) and long (4-s) regular trials as a function of cue-interval correlation for participants with descending and ascending cue informativeness. Averaged across all regular trials, participants, and cue-informativeness conditions, mean response times to the 2 -s target were $2.05 \mathrm{~s}(S E=0.11 \mathrm{~s})$ and were $3.63 \mathrm{~s}(S E=0.16 \mathrm{~s})$ to the $4-\mathrm{s}$ 
target. Mean response times were later for the long than the short trials, similar across levels of cue informativeness, and did not differ as a function of cue-informativeness order. Furthermore, participants pressed the enter key most frequently when points were available; $90.08 \%$ (SE $=$ $0.46 \%$ ) of responses in regular trials earned points when averaged across all participants and all regular trials.

Although participants earned points for most enter key presses, the number of points earned might have differed as a function of cue informativeness and trial type. Figure 14 shows the number of points participants earned at each cue-interval correlation. The left panel shows points earned by participants with descending cue informativeness and the right panel shows points earned by participants with ascending cue informativeness. Total points earned per session were entered into a mixed 2 x 4 ANOVA with cue-informativeness order (descending or ascending $)$ as the between-subjects factor and condition $(\varphi=0,0.4,0.8$, or 1$)$ as the withinsubjects factor. There were no statistically significant differences in overall points earned based on cue-informativeness order or condition and there was no significant interaction $(p s>.05)$. Although the overall mean number of points was lower for participants with ascending $(M=$ 514.25, $S E=57.65)$ than descending $(M=778.00, S E=60.33)$ cue informativeness, the difference was not statistically significant.

Points did not differ as a function of cue-informativeness condition, but points were available at a longer window of time in 4-s than in 2-s regular trials and participants could not see whether each response earned points in PI trials. To test whether trial type affected the number of points participants earned, mean points earned in each trial type across all sessions and conditions were entered into a mixed $2 \times 4 \times 4$ ANOVA with cue-informativeness order (descending or ascending) as the between-subjects factor. Cue-informativeness condition $(\varphi=0$, 
0.4, 0.8, or 1) and trial type (2-s, 4-s, short background color PI, or long background color PI) were within-subjects factors. There was a condition $\mathrm{x}$ trial type $\mathrm{x}$ order interaction, $F(9,36)=$ $3.25, p<.01, \eta \mathrm{P}^{2}=0.45$, which qualified a main effect of condition and other interaction effects. Of note was that Tukey HSD post-hoc tests indicated that participants earned more points in 4-s $(M=14.00, S E=0.78)$ than they did in $2-\mathrm{s}(M=6.85, S E=0.45)$ regular trials, and that participants with descending cue informativeness earned points in long background color PI trials $(M=3.57, S E=0.95)$, while those with ascending cue informativeness lost points in long background color PI trials $(M=-3.25, S E=0.32)$.

Another aspect of regular-trial responding that might have been affected by the presence of miscues was the mean number of responses per trial. Figure 15 shows the mean number of responses per trial in all 2-s and 4-s regular trials as a function of cue-interval correlation for participants with descending cue informativeness (left panel) and ascending cue informativeness (right panel). Consistent with results from Experiment 1, the number of enter key presses per trial did not change systematically as a function of cue informativeness.

Although mean responses per trial did not differ as a function of cue informativeness, response patterns in regular trials might have been sensitive to miscues. Figures 16 and 17 are raster plots that represent every response participants made in regular trials. The time of each enter key press is shown as a function of time since the beginning of the regular trial for each individual regular trial (row). Figure 16 shows raster plots from participants with descending cue informativeness and Figure 17 shows raster plots from participants with ascending cue informativeness. Cued and miscued trials are shown as circles and blue squares, respectively. Each horizontal panel shows response times in a different cue-informativeness condition for individual participants. The shaded area shows the time in which points were available for enter 
key presses. Visual inspection of the raster plots in Figures 16 and 17 indicates that changes in cue informativeness did not affect response patterns in regular trials.

PI Distributions. Regular-trial performance in the multiple cued PI procedure did not measure temporal discrimination per se because participants could always see the target, but PI response patterns demonstrate accuracy and precision in temporal discrimination because participants did not receive momentary visual feedback about whether shots hit the target. Figures 18 and 19 show normalized enter key presses per minute as a function of time in the presence of the short and long background color averaged across all PI trials of each condition for individual participants. Figure 18 shows PI distributions for participants with descending cueinformativeness order and Figure 19 shows PI distributions for participants with ascending cueinformativeness order. The curves are single or summed Gaussians fit to the distributions (mean $V A C=0.97$, range 0.58 to 0.999$)$. By visual inspection, response distributions were more similar when cue-interval correlations were low than when correlations were high.

A quantitative characterization of PI response patterns is shown in Gaussian curves fit to PI distributions in Figures 18 and 19. Dashed lines show the best-fitting curve for response distributions from PI trials when the short background color was presented. Solid lines show the best-fitting curve for response distributions from PI trials when the long background color was presented. If the summed Gaussian (Equation 2) was a better fit, then a curve with two means and standard deviations is shown, but if a single Gaussian was a better fit to response distributions, then a curve with one mean and standard deviation is shown. Tables 7 and 8 show parameter estimates for summed and single Gaussians and details of model fitting. Table 7 shows estimates for participants with descending cue informativeness $(\mathrm{H} 1, \mathrm{H} 2$, and $\mathrm{H} 3)$ and Table 8 shows estimates for participants with ascending cue informativeness (H4, H5, H6). The 
summed Gaussian function was a better fit than the single Gaussian for 27 out of 48 distributions $(56.25 \%)$, providing evidence that a majority of distributions were bimodal. Parameter estimates from Equation $2\left(M_{1}, M_{2}, S D_{1}, S D_{2}\right)$ obtained from PI distributions in the presence of short and long backgrounds were entered into four paired-samples $t$-tests. Paired-samples $t$-tests revealed that the short or long background color led to no differences in peak times or peak spreads. That is, $M_{1}$ in Equation 2 estimated from response distributions in the short background PI trials was no different from $M_{1}$ estimated from response distributions in the long background PI trials (as were $M_{2} \mathrm{~s}, S D_{1} \mathrm{~s}$, and $\left.S D_{2} \mathrm{~s}\right)$.

Across all participants, background colors, and cue-informativeness conditions, first and second peak times (i.e., $M_{1}$ and $M_{2}$ in Equation 2) were $2.75 \mathrm{~s}$ and $3.49 \mathrm{~s}$, respectively. First and second peak spreads (i.e., $S D_{1}$ and $S D_{2}$ ) were $0.47 \mathrm{~s}$ and $0.62 \mathrm{~s}$, respectively. Figure 20 shows peak time and peak spread across cue-informativeness conditions, averaged across participants separately for those receiving descending (left) and ascending (right) cue-informativeness order. Peak times were entered into a 2 × 2 x 4 mixed ANOVA with cue-informativeness order (descending or ascending) as the between-subjects variable, parameter $\left(M_{1}\right.$ or $\left.M_{2}\right)$ as a withinsubjects variable, and condition $(\varphi=0,0.4,0.8$, or 1$)$ as a within-subjects variable. There was a main effect of parameter that was qualified by a parameter $\mathrm{x}$ order interaction, $F(1,2)=26.34, p$ $<.01, \eta_{\mathrm{P}}{ }^{2}=0.87$. No other effects were statistically significant $(p \mathrm{~s}>.05)$. Although there was a significant interaction term, Tukey HSD post-hoc tests indicated that there was a statistically significant difference between peak times estimated by $M_{1}(M=2.20 \mathrm{~s}, S E=0.02 \mathrm{~s})$ and $M_{2}(M$ $=3.31 \mathrm{~s}, S E=0.12 \mathrm{~s})$ for participants with descending cue informativeness $(p<.01)$, and a statistically significant difference between $M_{1}(M=3.48 \mathrm{~s}, S E=0.94 \mathrm{~s})$ and $M_{2}(M=3.91 \mathrm{~s}, S E=$ $0.86 \mathrm{~s})$ for participants with ascending cue informativeness $(p=.03)$. Peak spreads were entered 
into a $2 \times 2 \times 4$ ANOVA with the same factors used in the peak time ANOVA. There was a main effect of order, $F(1,4)=16.31, p<.05, \eta \mathrm{P}^{2}=0.80$, a main effect of parameter, $F(1,4)=10.35, p$ $<.05, \eta \mathrm{P}^{2}=0.72$, and no other statistically significant effects $(p \mathrm{~s}>.05)$. Statistically significant ( $p$ s $<.05)$ Tukey HSD post-hoc tests indicated that participants with descending cue informativeness had smaller mean peak spreads $(M=0.43 \mathrm{~s}, S E=0.03 \mathrm{~s})$ than participants with ascending cue informativeness $(M=0.74 \mathrm{~s}, S E=0.07 \mathrm{~s})$, and that mean peak spreads estimated by $S D_{1}(M=0.49 \mathrm{~s}, S E=0.07 \mathrm{~s})$ were shorter than peak spreads estimated by $S D_{2}(M=0.68 \mathrm{~s}$, $S E=0.09 \mathrm{~s})$. Despite changes in cue-interval correlations, mean accuracy in peak times and precision in peak spread were stable across conditions and only differed across cueinformativeness order and background color.

The relative constancy in peak time and spread from PI distributions averaged across multiple PI trials demonstrates that mean accuracy and precision maintained across cueinformativeness conditions. Within-trial measures of accuracy (start and stop times) and precision (the difference between start and stop times) averaged across blocks of six PI trials within sessions of each condition for each participant are shown in Figure 21. Start times were generally earlier than stop times and start and stop times did not change systematically over the course of the condition. Start times were entered into a 2 × 2 x 4 mixed ANOVA with cueinformativeness order (descending or ascending) as the between-subjects factor, background color (short or long) as a within-subjects factor, and condition $(\varphi=0,0.4,0.8$, or 1$)$ as a withinsubjects factor. There was no main effect of order or condition, no statistically significant interactions ( $p s>.05$ ), but there was a main effect of background color, $F(1,4)=11.09, p<.05$, $\eta \mathrm{P}^{2}=0.74$. Tukey HSD post-hoc tests indicated that start times to the short background color were earlier $(M=2.44 \mathrm{~s}, S E=0.48 \mathrm{~s})$ than start times to the long background color $(M=2.81 \mathrm{~s}$, 
$S E=0.43$ s). A $2 \times 2 \times 4$ mixed ANOVA with the same factors was conducted with stop times with the same result: No statistically significant effects except for a main effect of background color, $F(1,4)=17.04, p<.05, \eta_{\mathrm{P}}^{2}=0.81$. Tukey HSD post-hoc tests indicated that stop times to the short background color were earlier $(M=3.34 \mathrm{~s}, S E=0.43 \mathrm{~s})$ than stop times to the long background color $(M=3.84 \mathrm{~s}, S E=0.37 \mathrm{~s})$. Like peak time and spread, start and stop times remained relatively constant across conditions.

\section{Discussion}

Experiment 2 was conducted to characterize the relation between cue informativeness and temporal discrimination in humans using a systematic replication of a multiple cued PI procedure (Guilhardi et al., 2010). Participants pressed keys in cued or miscued 2- and 4-s schedules with occasional PI trials. For three participants, cue-interval correlations were $\varphi=1$ and cue informativeness decreased across conditions. For the other three participants, initial cueinterval correlations of $\varphi=0$ increased across conditions. Participants' response patterns were strongly influenced by cue-informativeness order. That is, response times in short and long background color PI trials were more similar across conditions for participants with ascending than descending cue-informativeness order.

Despite order effects on PI trial response times, regular-trial performance was consistent across participants and cue-informativeness conditions. A substantial majority of enter key presses earned points and the number of enter key presses per regular trial was stable across cueinterval correlations. Taken together, these results suggest that the visibility of the target, rather than the background color, controlled response times in regular trials. One aspect of regular-trial performance that requires further investigation is that participants earned more points in 4-s regular trials than they did in 2-s regular trials. This difference in the magnitude of points earned 
might have led to biases to respond late in PI trials for two out of three participants with ascending cue informativeness. In other words, if both background colors are initially correlated with point availability at $2 \mathrm{~s}$ and $4 \mathrm{~s}$, then a history with a larger point magnitude at $4 \mathrm{~s}$ might influence response times when the only other information available is the background color.

Consistent with the results of Experiment 1, participants with descending cue informativeness had different distributions of key presses in time in the presence of short and long background color PI trials when the cue-interval correlation was $\varphi=1$. Short and long background color PI distributions became more similar when correlations decreased to $\varphi=0.8$, 0.4 , and 0 for all three of those participants $(\mathrm{H} 1, \mathrm{H} 2$, and $\mathrm{H} 3)$. In contrast, participants with ascending cue informativeness had similar distributions of key presses in short- and longbackground PI trials at all cue-interval correlations. Participants experienced each cue-interval correlation in a single session and four sessions occurred consecutively in one, 2-hr laboratory visit. Thus, effects of order were not washed out by extended exposure as they might have been with pigeons in Experiment 1.

The fact that participants with ascending cue informativeness had PI response distributions that did not adjust across conditions is consistent with theories of attention (Mackintosh, 1975; Sutherland \& Mackintosh, 1971) that suggest that a learning rate parameter (alpha) or analyzer is decreased in strength with each invalid presentation of a cue. Miscues constituted invalid presentations of the background color. At the end of each intermediate cueinformativeness condition, the learning rate parameter or analyzer should have been lower or weaker with ascending cue informativeness over descending cue informativeness leading to more converged PI response distributions in the former. 
Cue-informativeness order influenced PI trial response times, but there was evidence that participants learned the temporal discrimination within the first condition and that the passage of time influenced responding across cue-informativeness conditions. For participants with descending cue informativeness, average peak times were around the time of point availability in the presence of short and long background colors. In addition, peak spread increased linearly with peak time. Across participants, peak response distributions were mostly bimodal, suggesting that humans are sensitive to the momentary conditional probability of earning points.

\section{Experiment 3}

In Experiment 2, participants timed miscued intervals in the first condition of a multiple cued PI procedure, but temporal discrimination in intermediate cue-informativeness conditions was affected by initial exposure to cue-interval correlation of $\varphi=1$ or $\varphi=0$. Experiment 3 was a between-subjects design that was used to assess effects of cue informativeness on temporal discrimination while ruling out effects of order. The objectives of Experiment 3 were to characterize the functional relation between cue informativeness and temporal discrimination, and test the hypothesis that momentary conditional probability of earning points determined response patterns in PI trials across all cue-interval correlations.

\section{Method}

Participants. Forty eight participants, 38 females and 10 males, participated for research credit and a chance to win a gift card valued at $\$ 50$. All participants completed one condition of the experiment within one visit to the laboratory lasting less than $1 \mathrm{hr}$.

Setting. Participants were run in groups in a 10-station classroom or a 2-station computer laboratory. Each participant sat at a desk or station containing one desktop computer with a monitor, keyboard, headphones, and mouse. Auditory stimuli were presented using a pair of 
stereo headphones. The color monitor presented visual stimuli, and responses on the keyboard were recorded by the computer program. Participants responded using the down arrow key and the spacebar key on the computer keyboard. The custom Microsoft Windows program, written in Microsoft Visual Basic (C) programming language, timed events with a 1-ms resolution, presented contingencies, and collected real-time experimental data.

Procedure. Participants responded in the same PI procedure as Experiment 2. Participants responded using the down arrow key rather than the enter key. The researcher provided participants with standard informed consent individually or in groups. Following consent, participants received the same instructions and program as Experiment 1.

Participants completed one session of one of the four cue-informativeness conditions. Conditions were randomly assigned to participants. For participants in groups receiving correlations $\varphi>0$, whether the light or the dark green background color was correlated with point availability at 2 or $4 \mathrm{~s}$ was determined by randomly assigned participant numbers. Oddnumbered participants had dark green as the short background and even numbered participants had light green as the short background color. Participant numbers for groups receiving cueinterval correlations of $\varphi=1,0.8,0.4$, and 0 are listed in Table 9, 10, 11 and 12, respectively. The difference between groups was the correlation between the background color and target duration (cue informativeness), which was manipulated using miscues as described in Experiment 2.

Data Analysis. As in Experiments 1 and 2, peak times, peak spread, start times, stop times, and high state durations were calculated for individual participants and averaged across participants.

\section{Results}


The objectives of Experiment 3 were to characterize the functional relation between cue informativeness and temporal discrimination in PI trials and test the hypothesis that momentary conditional probability of earning points determined response patterns in PI trials. The results presented compare measures of temporal discrimination obtained from average PI distributions between groups of participants receiving different cue-interval correlations and from single-trial analyses of PI responding between those groups.

Figure 22 shows normalized rate of down arrow key presses as a function of time in the presence of the short and long background color PI trials averaged across all PI trials in a session and across groups of 12 participants in each cue-informativeness condition. The curves are single or summed Gaussians fit to the distributions (mean $V A C=0.91$, range 0.17 to 0.999 ). By visual inspection, response distributions were more similar when cue-interval correlations were low than when they were high.

A quantitative characterization of PI response distributions is shown in single or summed Gaussian (Equation 2) curves fit to PI distributions. If one Gaussian was a better fit to response distributions, then a curve with one mean and standard deviation is graphed, if the summed Gaussian was a better fit, then a curve with two means and standard deviations is graphed. Table 9, 10, 11, and 12 show parameter estimates and details of model fitting for individual participants in cue-informativeness groups with cue-interval correlations of $\varphi=1,0.8,0.4$, and 0 , respectively. Across individual participants, the summed Gaussian function was a better fit than the single Gaussian for 35 out of 96 distributions (36.46\%), providing evidence that a majority of distributions had single peaks.

Parameter estimates from Equation $2\left(M_{1}, M_{2}, S D_{1}, S D_{2}\right)$ obtained from PI distributions in the presence of short and long backgrounds were entered into four paired-samples $t$-tests. 
Consistent with Experiment 2, paired-samples $t$-tests revealed that the background color led to no differences in peak times and peak spreads (all $p s>.05$ ). Across all participants, background colors, and cue-informativeness conditions, first and second peak times (i.e., $M_{1}$ and $M_{2}$ in Equation 2 or $M$ from the single Gaussian) were $3.03 \mathrm{~s}(S E=0.14 \mathrm{~s})$ and $4.00 \mathrm{~s}(S E=0.08 \mathrm{~s})$, respectively. First and second peak spreads (i.e., $S D_{1}$ and $S D_{2}$ or $\left.S D\right)$ were $0.67 \mathrm{~s}(S E=0.07 \mathrm{~s})$ and $0.95 \mathrm{~s}(S E=0.11 \mathrm{~s})$, respectively. Figure 23 shows peak time and peak spread across cueinformativeness conditions averaged across groups of 12 participants in each condition. Peak times were entered into a 2 × 4 mixed ANOVA with parameter $\left(M_{1}\right.$ or $\left.M_{2}\right)$ as the within-subjects factor and condition group $(\varphi=1,0.8,0.4$, or 0$)$ as the between-subjects factor. There was a main effect of parameter, $F(1,44)=71.37, p<.001, \eta_{\mathrm{P}}{ }^{2}=0.62$, and no other significant effects ( $p$ s $>.05)$. Tukey HSD tests confirmed that $M_{1}$ was significantly earlier than $M_{2}$ collapsed across all conditions $(p<.001)$. Peak spreads were entered into a 2 x 4 mixed ANOVA with the same factors as described for peak time. There was a main effect of parameter, $F(1,44)=6.55, p=$ $.01, \eta_{\mathrm{P}}{ }^{2}=0.13$, and no other significant effects $(p \mathrm{~s}>.05)$. Tukey HSD tests confirmed that $S D_{1}$ was significantly smaller than $S D_{2}$ collapsed across all conditions $(p<.05)$. Despite differences in cue-interval correlations, mean accuracy in peak times and precision in peak spread were relatively stable across groups.

Peak times and peak spreads from PI distributions averaged across multiple PI trials were comparable across conditions. This finding provides additional evidence that mean accuracy and precision can be maintained at different levels of cue informativeness. Within-trial measures of accuracy (start and stop times) and precision (the difference between start and stop times) are shown averaged across all PI trials for individual participants and across the groups of 12 participants in each cue-informativeness condition in Figure 24. Average start and stop times 
were used because estimates did not change systematically over the course of a condition in Experiment 2. Start and stop times were entered into a $2 \times 2 \times 4$ mixed ANOVA with time (start or stop) and background color (short or long) as the within-subjects factors and condition group $(\varphi=0,0.4,0.8$, or 1$)$ as the between-subjects factor. There was a main effect of time, $F(1,44)=$ 162.21, $p<.001, \eta_{\mathrm{P}}^{2}=0.79$. Start times $(M=2.72 \mathrm{~s}, S E=0.08)$ were significantly earlier than stop times $(M=4.18 \mathrm{~s}, S E=0.14 \mathrm{~s})$. There was a main effect of background color that was qualified by a color $\mathrm{x}$ condition interaction, $F(3,44)=7.94, p<.001, \eta \mathrm{P}^{2}=0.35$. Tukey HSD post-hoc tests revealed that average start and stop times were significantly earlier to the short than the long background color at $\varphi=1(p<.001)$ and $\varphi=.8(p<.05)$, but not in other conditions. Start times to the long background were at the same time as stop times to the short background for participants in the $\varphi=1$ group. Across decreasing cue informativeness, start times to the long background occurred earlier and stop times to the short background occurred later such that the estimates converged with other start and stop times.

The times of abrupt shifts in responding during individual PI trials were sensitive to miscues. This finding implies that the difference between start and stop times, or high state duration, might detect changes in precision of temporal discrimination as a function of cue informativeness. Figure 25 shows the high state duration, or within-trial precision of temporal discrimination, averaged across all PI trials per session and across 12 participants in each cueinformativeness condition group. High state durations for the short and long background color were entered into a 2 x 4 repeated-measures ANOVA with color (short or long) and condition group $(\varphi=1,0.8,0.4$, or 0$)$ as factors. Although there was a monotonically decreasing trend in high state duration across cue-interval correlations, there were no statistically significant 
differences in high state duration based on background color or condition and no statistically significant interactions between the factors $(p s>.05)$.

\section{Discussion}

Experiment 3 was conducted to characterize the relation between cue informativeness and temporal discrimination in human participants using a between-subjects design to rule out order effects found in Experiment 2. Participants pressed keys in cued or miscued FI 2- and 4-s schedules of points with occasional PI trials. For groups of 12 participants each, cue-interval correlations were either $\varphi=1, \varphi=0.8, \varphi=0.4$, or $\varphi=0$. Consistent with the results of Experiments 1 and 2 (participants with descending cue informativeness), different distributions of key presses in time occurred in the presence of short and long background color PI trials when the cue-interval correlation was $\varphi=1$. Short and long background color PI distributions were more similar at intermediate correlations, and were overlapping when $\varphi=0$. The time of abrupt shifts in responding in individual PI trials were earlier to the short than long background color for cue-informativeness groups with cue-interval correlations of $\varphi=1$ and 0.8 , but not for other groups.

In contrast with Experiments 1 and 2, a majority of PI distributions were characterized by single Gaussian functions. Rather than estimating the momentary conditional probability of points, participants were likely to respond at times between 2 and 4 s. Perhaps the single, 120 trial session was insufficient exposure to contingencies for participants to learn that points were always lost for responses between $2.36 \mathrm{~s}$ and $3.27 \mathrm{~s}$. PI response distributions for participants with descending cue informativeness in Experiment $2(\mathrm{H} 1, \mathrm{H} 2, \mathrm{H} 3)$ were mostly characterized by single Gaussians in the $\varphi=1$ condition. More than 120 trials might be necessary to promote patterns of responding that are similar to the key pecking distributions obtained in Experiment 1. 
Nevertheless, participants learned the temporal discrimination within the 120 trials of the multiple cued PI procedure. Average peak times were around the time of point availability in the presence of short and long background colors and peak spread increased linearly with peak time. Peak times and spreads did not differ as a function of cue-informativeness group. Start times were consistently earlier than stop times, and high-state durations did not differ as a function of cue-informativeness group.

\section{General Discussion}

Animals are often faced with cues that vary in informativeness about the time to reinforcer availability. Experiments 1, 2 and 3 arranged cued or miscued 2- and 4-s schedules of food or points with occasional PI trials to permit a description of the functional relation between cue informativeness and temporal discrimination. Different distributions of pecking (Experiment 1) and key presses (Experiments 2 and 3) were observed in short and long cue PI trials when cueinterval correlations were high and those distributions converged at low cue-interval correlations. Across pigeons and humans, this convergence generally occurred at cue-interval correlations less than $\varphi=0.8$. In Experiment 1, pausing in FI schedules, slope parameters in FI gradients, high state durations in single PI trials, and average PI response distributions converged at correlations less than $\varphi=0.8$. This finding generalized to human participants in Experiment 3. Average start and stop times and PI distributions in the presence of short and long background colors converged at cue-interval correlations less than $\varphi=0.8$.

The fact that multiple measures of temporal discrimination converged at cue-interval correlations below $\varphi=0.8$ for pigeons and humans has implications for research on skill acquisition. When training instructors to administer behavioral treatments, treatment integrity failures are conceptually similar to miscues. Researchers measuring effects of programmed 
treatment integrity failures in clients' skill acquisition found that discrete-trial instruction (see Smith, 2001) is less effective when treatment integrity is low than when it is high (Carroll, Kodak, \& Fisher, 2013; DiGennaro Reed, Reed, Baez, \& Maguire, 2011). Procedures employed in this research usually arrange for conditions with $100 \%, 50 \%$, and $0 \%$ treatment integrity for particular components of an intervention. In the current experiments, PI distributions in the presence of different cues converged when cue-interval correlations were lower than $\varphi=0.8$, which are akin to treatment integrity values of less than $90 \%$ in a given session. This analysis suggests that the mastery criteria in training practitioners to conduct skill-acquisition procedures should be carefully assigned. The criterion for acceptable treatment integrity should be set at $90 \%$ or greater for optimal response differentiation, at least for antecedent instructions or prompts that signal when clients' responses will be reinforced.

There are situations in which a tolerance for misinformation during skill acquisition and maintenance is optimal. For example, teachers might want to use uninformative, misleading, or ambiguous stimuli to encourage generalization (e.g., Stokes \& Baer, 1977), to reduce the influence of periodically misleading stimuli (e.g., in defensive driving simulations), or to promote endurance of skills across a variety of stimulus conditions. When using these strategies, it might be beneficial to program variability in controlling stimuli in no more than $10 \%$ of presentations of those stimuli.

In addition to determining when response gradients converged, which has relevance to skill acquisition, Experiments 1, 2, and 3 permitted a test of the theoretical hypothesis that response patterns in PI trials are based on the momentary conditional probability of reinforcement. Previous research indicated that response patterns are sometimes based on the reinforcer probability (Catania \& Reynolds, 1968; Leak \& Gibbon, 1995; Whitaker, Lowe, \& 
Wearden, 2003, 2008), temporal biases (Meck, 1984), or averaging of temporal information (Swanton, Gooch, \& Matell, 2009). In Experiments 1 and 2, a majority of response distributions were well-characterized by summed Gaussian functions, suggesting that the momentary conditional probability of food or points determined response patterns. These results are consistent with performance in long trials in mixed FI-FI schedules (Leak \& Gibbon, 1995; Whitaker, Lowe \& Wearden, 2003, 2008). Careful examination of the bimodal PI distributions in Experiment 1 indicates that normalized response rate was generally higher in the first than the second peaks, consistent with previous research on performance on mixed FI-FI schedules (Leak \& Gibbon, 1995) and with ordinal predictions of the scalar expectancy theory of temporal discrimination.

In contrast to Experiments 1 and 2, a majority of individual participants' response distributions were well-characterized by single Gaussian functions in Experiment 3. These results indicate that the momentary conditional probability of points failed to determine response patterns. The fact that PI response distributions had single peaks might be consistent with previous research suggesting that response gradients are a function of averaging temporal memories (e.g., Swanton, Gooch, \& Matell, 2009). An alternative explanation is that responding eventually comes under the control of the momentary conditional probability of points with increased exposure to contingencies. Pigeons pecked in the PI procedure for a minimum of 9680 trials, with a majority of PI distributions (83\%) characterized as bimodal. Participants in Experiment 2 were exposed to a minimum of 480 trials, and a majority of PI distributions (56\%) were bimodal. Participants in Experiment 3 only responded in 120 trials, and their response patterns were sometimes bimodal (36\%), but were well described by single Gaussians. These participants might have eventually responded in a pattern described by bimodal distributions if 
exposed to more sessions of the multiple cued PI procedure. Future research can be used to evaluate whether the emergence of bimodal distributions occurs after extended exposure to contingencies or whether initial exposure to the extremes of cue informativeness $(\varphi=1$ or $\varphi=0)$ is necessary to develop bimodal distributions in intermediate cue informativeness.

Taken together, results from Experiments 1, 2, and 3 support the notion that certain response patterns in PI trials are affected by cue informativeness. A low-high-low analysis (Equation 3), identified that this change in response patterning involved a convergence in the average times of abrupt shifts in response rate in PI trials. For pigeons, high state duration for the short key color increased with decreases in cue informativeness. Inspection of start and stop times suggested that this change was a function of start times to the long key color occurring earlier and stop times to the short key color occurring later as cue informativeness decreased. A similar pattern was observed with humans. For participants in Experiment 3, start and stop times in the presence of short and long background colors were more similar at lower than higher cueinterval correlations. For participants with cue-interval correlations of $\varphi=1$, start times to the long background color were identical to stop times to the short background color. Start times to the long background color monotonically decreased (i.e., were earlier) at lower cue-interval correlations. Stop times to the short background color monotonically increased (i.e., were later) as cue-interval correlations were lower.

Changes in start and stop time were consistent across pigeons in Experiment 1 and groups of participants in Experiment 3. Start and stop times for participants in Experiment 2, however, were influenced by the order in which cue-informativeness conditions were presented. This finding is consistent with attentional theories suggesting that initially invalid cue presentations affect subsequent learning. Participants in Experiment 2 completed all conditions in one, 2-hr 
visit to the laboratory. Future research can be used to determine whether more sessions of exposure to contingencies or a change in background colors along with a change in condition would eliminate the observed order effects. Participants in the present investigation did not experience more than one session in each cue-informativeness condition. Thus, it is impossible to determine whether responding eventually comes under the control of informative cues or how much exposure to cue-informativeness conditions is necessary to wash out order effects using the existing data. There is evidence that initially high cue informativeness leads to a greater adjustment of response distributions than initially low cue informativeness.

Previous research with human participants (e.g., Hirst, DiGennaro Reed, \& Reed, 2013; St. Peter Pipkin, Vollmer, \& Sloman, 2010) found order effects when the informativeness of consequent events was manipulated. For example, St. Peter Pipkin and colleagues (2010) provided participants with points for every response to an initial stimulus on a computer screen. Next, points were contingent on responses to an alternative stimulus and not provided for the initial stimulus (i.e., differential reinforcement of alternative behavior or DRA). In a subsequent phase, responses to the alternative stimulus were maintained on the same schedule, but responses to the initial stimulus were occasionally reinforced according to several probabilities (range 0.20.8). These constant probabilities of reinforcement were conceptualized as treatment integrity failures, or commission errors, in the DRA procedure. The result germane to the current investigation was that participants who first received relatively low probabilities of commission errors responded at a low rate when those probabilities increased. In contrast, participants who first received relatively high probabilities of commission responded at a higher rate toward the initial stimulus when those probabilities decreased. If commission errors are misinformation, then the order effects reported by St. Peter Pipkin et al. are consistent with the present 
Experiment 2 results from participants with descending versus ascending cue informativeness, respectively. Recently, Hirst and colleagues (2013) presented feedback to participants who responded to arbitrary stimuli on a computer screen. The feedback provided information about whether responses were correct or incorrect. When participants received inaccurate feedback, subsequent accurate feedback was less likely to influence responding than initially accurate feedback. Taken together, these studies indicate that invalid consequent events might affect response adaptation through similar attentional processes (e.g., Mackintosh, 1975) as antecedent miscues.

Future research using the multiple cued PI procedure with pigeons and humans can be used to characterize other forms of invalid stimulus presentations to determine whether there are functional classes of misinformation. Previous research on invalid consequent events such as incorrect feedback or point delivery (Hirst, DiGennaro Reed, \& Reed, 2013; St. Peter Pipkin, Vollmer, \& Sloman, 2010) suggest that contingent, discrete miscues might be functionally similar to the antecedent miscues manipulated in the current investigation. Deviation from the modal outcome cued by a particular stimulus could also be described as noise. When signals are noisy, stimuli may predict variable-interval schedules in which the time to reinforcer availability varies along a distribution. Catania and Reynolds (1968) described response rates in these VI schedules as dependent on the momentary conditional probability of reinforcement. If miscues and noise are functionally equivalent, then response distributions in PI trials following exposure to increasingly (or decreasingly) noisy intervals might converge at cue-interval correlations of $r$ $<0.8$.

The present examination of the functional relation between cue informativeness and temporal discrimination has theoretical relevance and has the potential to inform model building. 
In the present investigation, temporal discrimination was evident through stable peak times and peak spread across all levels of cue informativeness for pigeons and humans. Peak times, measures of accuracy, and peak spread, a measure of precision, were constant across cueinformativeness conditions and groups. On average, peak times occurred around $2 \mathrm{~s}$ or $4 \mathrm{~s}$, despite differences in cue-interval correlations. Theories of temporal discrimination such as scalar expectancy theory (Gibbon, Church, \& Meck, 1984), the behavioral estimation theory (Killeen \& Fetterman, 1988), and learning to time theory (Machado, 1997) would all account for this finding, albeit through different mechanisms. However, those theories do not make specific predictions about patterns of responding in time at intermediate levels of cue informativeness. Killeen and Fetterman (1988) proposed that the behavioral estimation theory and scalar expectancy theory lead to different predictions about responding when cues are not predictive of the time to reinforcer availability. Specifically, cues present during long trials of mixed FI-FI schedules, much like the $\varphi=0$ condition of the present experiment, do not differentially signal two intervals and are a critical test of the difference between behavioral estimation and scalar expectancy theories (Leak \& Gibbon, 1995).

According to the behavioral estimation theory, the response rate at the time of the short FI should be lower than the response rate at the time of the end of the trial because reinforcement always follows the long duration and only follows the short duration in half of trials. This prediction is also supported by the learning to time theory (Machado, 1997). Scalar expectancy theory makes the opposite prediction: That response rate at the time of the short FI duration should be higher than response rate at the time of the long FI duration due to scalar variance holding during simultaneous temporal discrimination. Response rate during the time of the long and short FI durations during PI trials in the current experiment supported predictions of scalar 
expectancy theory; response rate was higher at $2 \mathrm{~s}$ than at $4 \mathrm{~s}$ in most of the bimodal response distributions in Experiment 1. Scalar variance, as measured by peak spread, was constant throughout all cue-informativeness conditions. There were several procedural differences between PI schedules and mixed FI-FI schedules, and our use of two different colors as visual cues might lead to attentional differences compared to mixed FI-FI schedules using the same visual cue with two schedule values. Temporal discrimination theories, however, should account for differences in timing performance as a function of the type of cues (e.g., Fox \& Kyonka, 2015) and attentional processes (e.g., Mackintosh, 1975) to be comprehensive accounts of learning and performance. 


\section{References}

Buhusi, C. V., \& Meck, W. H. (2005). What makes us tick? Functional and neural mechanisms of interval timing. Nature Reviews Neuroscience, 6(10), 755-765. doi: 10.1038/nrn1764

Caetano, M. S., \& Church, R.M. (2009). A comparison of responses and stimuli as time markers. Behavioural Processes, 81, 298-302. doi: 10.1016/j.beproc.2009.01.014

Carroll, R. A., Kodak, T., \& Fisher, W. W. (2013). An evaluation of programmed treatmentintegrity errors during discrete-trial instruction. Journal of Applied Behavior Analysis, 46(2), 379-394. doi: 10.1002/jaba.49

Catania, A. C. (1970). Reinforcement schedules and psychophysical judgments. In W. N. Schoenfeld (Ed.), Theory of reinforcement schedules (pp. 1-42). New York: AppletonCentury- Crofts.

Catania, A. C., \& Reynolds, G. S. (1968). A quantitative analysis of the responding maintained by interval schedules of reinforcement. Journal of the Experimental Analysis of Behavior, 11(32), 327-383. doi: 10.1901/jeab.1968.11-s327

Church, R. M., Meck, W. H., \& Gibbon, J. (1994). Application of scalar timing theory to individual trials. Journal of Experimental Psychology: Animal Behavior Processes, 20 (2), 135-155. doi: 10.1037/0097-7403.20.2.135

DiGennaro Reed, F. D., Reed, D. D., Baez, C. N., \& Maguire, H. (2011). A parametric analysis of errors of commission during discrete-trial training. Journal of Applied Behavior Analysis, 44(3), 611-615. doi: 10.1901/jaba.2011.44-611

Fox, A. E., \& Kyonka, E. G. (2013). Pigeon responding in fixed-interval and response-initiated fixed-interval schedules. Journal of the Experimental Analysis of Behavior, 100(2), 187197. doi: $10.1002 /$ jeab.38 
Fox, A. E., \& Kyonka, E. G. E. (2015). Timing in response-initiated fixed intervals. Journal of the Experimental Analysis of Behavior, 103(2), 375-392. doi: 10.1002/jeab.120

Fox, A. E., Prue, K. E., \& Kyonka, E. G. E. (2016). What is timed in a fixed-interval temporal bisection procedure? Manuscript under review.

Fox, A. E., Reid, A. K., \& Kyonka, E. G. E. (2014). Behavioral history and pigeons' "guiding cues” performance. The Psychological Record. doi: 10.1007/s40732-014-0060-9

Galizio, M. (1979). Contingency-shaped and rule-governed behavior: Instructional control of human loss avoidance. Journal of the Experimental Analysis of Behavior, 31, 53-70. doi: 10.1901/jeab.1979.31-53

Gibbon, J. (1977). Scalar expectancy theory and Weber's law in animal timing. Psychological Review, 84, 279-325. doi: 10.1037/0033-295X.84.3.279

Gibbon, J., Church, R. M., \& Meck, W. H. (1984). Scalar timing in memory. Annals of the New York Academy of sciences, 423(1), 52-77. doi: 10.1111/j.1749-6632.1984.tb23417.x

Guilhardi, P., \& Church, R. M. (2005). Dynamics of temporal discrimination. Learning and Behavior, 33, 399-416. doi: 10.3758/BF03193179

Guilhardi, P., Menez, M., Caetano, M. S., \& Church, R. M. (2010). The effect of stimulus discriminability on strategies for learning multiple temporal discriminations. Behavioural processes, 84(1), 476-483. doi: 10.1016/j.beproc.2010.01.004

Hawkins, R. O., Morrison, J. Q., Musti-Rao, S., \& Hawkins, J. A. (2008, July). Treatment integrity for academic interventions in real-world settings. School Psychology Forum, $2(3), 1-15$. 
Hirst, J. M., DiGennaro Reed, F. D. D., \& Reed, D. D. (2013). Effects of varying feedback accuracy on task acquisition: A computerized translational study. Journal of Behavioral Education, 22(1), 1-15. doi: 10.1007/s10864-012-9162-0

Hyten, C., \& Madden, G. J. (1993). The scallop in human fixed-interval research: A review of problems with data description. The Psychological Record, 43(3), 471-500.

Killeen, P. R., \& Fetterman, J. G. (1988). A behavioral theory of timing. Psychological Review, 95, 274-295. doi: 10.1037/0033-295X.95.2.274

Leak, T. M., \& Gibbon, J. (1995). Simultaneous timing of multiple intervals: Implications of the scalar property. Journal of Experimental Psychology: Animal Behavior Processes, 21(1), 3. doi: $10.1037 / 0097-7403.21 .1 .3$

Lejeune, H., \& Wearden, J. H. (2006). Scalar properties in animal timing: Conformity and violations. The Quarterly journal of experimental psychology, 59(11), 1875-1908. doi: $10.1080 / 17470210600784649$

Machado, A. (1997). Learning the temporal dynamics of behavior. Psychological review, 104(2), 241. doi: 10.1037/0033-295X.104.2.241

Mackintosh, N. J. (1965). Selective attention in animal discrimination learning. Psychological Bulletin, 64(2), 124-150. doi: 10.1037/h0022347

Mackintosh, N. J. (1975). A theory of attention: variations in the associability of stimuli with reinforcement. Psychological Review, 82(4), 276-298. doi: 10.1037/h0076778

Matell, M. S., \& Meck, W. H. (2004). Cortico-striatal circuits and interval timing: coincidence detection of oscillatory processes. Cognitive Brain Research, 21(2), 139-170. doi: 10.1016/j.cogbrainres.2004.06.012 
Matell, M. S., Meck, W. H., \& Nicolelis, M. A. (2003). Interval timing and the encoding of signal duration by ensembles of cortical and striatal neurons. Behavioral neuroscience, 117(4), 760. doi: 10.1037/0735-7044.117.4.760

McLaren, I. P. L., \& Mackintosh, N. J. (2002). Associative learning and elemental representation: II. Generalization and discrimination. Animal Learning \& Behavior, 30(3), 177-200. doi: 10.3758/BF03192828

Meck, W. H. (1984). Attentional bias between modalities: Effect on the internal clock, memory, and decision stages used in animal time discrimination. Annals of the New York Academy of Sciences, 423(1), 528-541. doi: 10.1111/j.1749-6632.1984.tb23457.x

Miall, C. (1989). The storage of time intervals using oscillating neurons. Neural Computation, 1(3), 359-371. doi: 10.1162/neco.1989.1.3.359

Platt, J. R., \& Davis, E. R. (1983). Bisection of temporal intervals by pigeons. Journal of Experimental Psychology: Animal Behavior Processes,9(2), 160-170. doi: 10.1037/00977403.9.2.160

Reid, A. K., Folks, N., \& Hardy, J. (2014). On the dynamics of stimulus control during guided skill learning in nonhumans. Behavioural Processes, 104, 72-83. doi: 10.1016/j.beproc.2014.01.017

Reid, A. K., Nill, C. A., \& Getz, B. R. (2010). Changes in stimulus control during guided skill learning in rats. Behavioural Processes, 84, 511-515. doi: 10.1016/j.beproc.2010.01.001

Richelle, M., \& Lejeune, H. (1980). Time in animal behaviour. Oxford, United Kingdom: Pergamon Press.

Roberts, S. (1981). Isolation of an internal clock. Journal of Experimental Psychology: Animal Behavior Processes, 7(3), 242. doi: 10.1037/0097-7403.7.3.242 
Sanabria, F., \& Oldenburg, L. (2014). Adaptation of timing behavior to a regular change in criterion. Behavioural processes, 101, 58-71. doi: 10.1016/j.beproc.2013.07.018

Schneider, B. A. (1969). A two-state analysis of fixed-interval responding in the pigeon. Journal of the Experimental Analysis of Behavior, 12(5), 677-687. doi: 10.1901/jeab.1969.12677

Smith, T. (2001). Discrete trial training in the treatment of autism. Focus on Autism and Other Developmental Disabilities, 16, 86-92. doi: 10.1177/108835760101600204

St. Peter Pipkin, C. C., Vollmer, T. R., \& Sloman, K. N. (2010). Effects of treatment integrity failures during differential reinforcement of alternative behavior: A translational model. Journal of Applied Behavior Analysis, 43(1), 47-70.

Stokes, T. F. \& Baer, D. M. (1977). An implicit technology of generalization. Journal of Applied Behavior Analysis, 10, 349-367.

Sutherland, N. S., \& Mackintosh, N. J. (1971). Mechanisms of animal discrimination learning. Academic Press.

Swanton, D. N., Gooch, C. M., \& Matell, M. S. (2009). Averaging of temporal memories by rats. Journal of Experimental Psychology: Animal Behavior Processes, 35(3), 434-439. doi: $10.1037 / \mathrm{a} 0014021$

Wearden, J. H., \& Lejeune, H. (2008). Scalar properties in human timing: Conformity and violations. The Quarterly Journal of Experimental Psychology, 61(4), 569-587. doi: $10.1080 / 17470210701282576$

Whitaker, S., Lowe, C. F., \& Wearden, J. H. (2003). Multiple-interval timing in rats: Performance on two-valued mixed fixed-interval schedules. Journal of Experimental Psychology: Animal Behavior Processes, 29(4), 277. doi: 10.1037/0097-7403.29.4.277 
Whitaker, S., Lowe, C. F., \& Wearden, J. H. (2008). When to respond? And how much?:

Temporal control and response output on mixed-fixed-interval schedules with unequally probable components. Behavioural Processes,77(1), 33-42. doi:

10.1016/j.beproc.2007.06.00 
Table 1

Experiment 1 Subjects, Condition Order, and Sessions per Condition

\begin{tabular}{cccccccc}
\hline \multirow{2}{*}{ Pigeon } & Short Key Color & 1 & 2 & 3 & 4 & 5 & 6 \\
\hline 301 & Red & $\varphi=1$ & $\varphi=0.8$ & $\varphi=0.6$ & $\varphi=0.4$ & $\varphi=0.2$ & $\varphi=0$ \\
& & $(20)$ & $(21)$ & $(20)$ & $(23)$ & $(20)$ & $(20)$ \\
303 & Red & $\varphi=1$ & $\varphi=0.8$ & $\varphi=0.6$ & $\varphi=0.4$ & $\varphi=0.2$ & $\varphi=0$ \\
& & $(20)$ & $(21)$ & $(20)$ & $(20)$ & $(22)$ & $(20)$ \\
403 & Green & $\varphi=1$ & $\varphi=0.8$ & $\varphi=0.6$ & $\varphi=0.4$ & $\varphi=0.2$ & $\varphi=0$ \\
& & $(20)$ & $(20)$ & $(20)$ & $(20)$ & $(20)$ & $(21)$ \\
302 & Red & $\varphi=0$ & $\varphi=0.2$ & $\varphi=0.4$ & $\varphi=0.6$ & $\varphi=0.8$ & $\varphi=1$ \\
& & $(20)$ & $(20)$ & $(21)$ & $(21)$ & $(21)$ & $(20)$ \\
401 & Green & $\varphi=0$ & $\varphi=0.2$ & $\varphi=0.4$ & $\varphi=0.6$ & $\varphi=0.8$ & $\varphi=1$ \\
& & $(20)$ & $(20)$ & $(21)$ & $(20)$ & $(21)$ & $(21)$ \\
402 & Green & $\varphi=0$ & $\varphi=0.2$ & $\varphi=0.4$ & $\varphi=0.6$ & $\varphi=0.8$ & $\varphi=1$ \\
& & $(20)$ & $(20)$ & $(21)$ & $(20)$ & $(21)$ & $(21)$ \\
\hline
\end{tabular}

Note. Short key color represents the color of the key during the short FI schedule trials when intervals were not miscued. Phi correlations are used to label cue-informativeness conditions. Number of sessions in each condition are included in parentheses. 
Table 2

Experiment 1 Number of Miscues per Condition

\begin{tabular}{lcccccc}
\hline Cue & $\begin{array}{c}\text { Total } \\
\text { Informativeness } \\
\text { of }\end{array}$ & $\begin{array}{c}\text { Intervals } \\
1-20\end{array}$ & $\begin{array}{c}\text { Intervals } \\
21-30\end{array}$ & $\begin{array}{c}\text { Intervals } \\
31-40\end{array}$ & $\begin{array}{c}\text { Intervals } \\
41-50\end{array}$ & $\begin{array}{c}\text { Intervals } \\
\text { Miscues }\end{array}$ \\
\hline$\varphi=0.8$ & 6 & 2 & 1 & 1 & 1 & \\
$\varphi=0.6$ & 12 & 4 & 2 & 2 & 2 & 2 \\
$\varphi=0.4$ & 18 & 6 & 3 & 3 & 3 & 3 \\
$\varphi=0.2$ & 24 & 8 & 4 & 4 & 4 & 4 \\
\hline
\end{tabular}

Note. Intermediate cue informativeness is expressed in phi correlations. The total number of miscues is presented, but an equal number of miscues occurred for short and long FIs across the session and in intervals 1-20. "Intervals" denotes the FI trials within the session. 
Table 3

Gaussian Fits to PI Response Distributions for Pigeons 301, 303, and 403

\begin{tabular}{|c|c|c|c|c|c|c|c|c|c|}
\hline Pigeon & $\varphi$ & Color & $\mathrm{K}_{1}$ & $\mathrm{M}_{1}$ & $\mathrm{SD}_{1}$ & $\mathrm{~K}_{2}$ & $\mathrm{M}_{2}$ & $\mathrm{SD}_{2}$ & VAC \\
\hline \multirow[t]{12}{*}{301} & \multirow[t]{2}{*}{1} & Red & 0.73 & 1.6 & 0.51 & 0.27 & 5.5 & 5.85 & 0.84 \\
\hline & & Green & 0 & - & - & 1 & 4 & 1.92 & 0.87 \\
\hline & \multirow[t]{2}{*}{0.8} & Red & 0.44 & 1.63 & 0.53 & 0.56 & 4.69 & 2.95 & 0.84 \\
\hline & & Green & 0.53 & 2.9 & 0.77 & 0.47 & 5.5 & 2.31 & 0.96 \\
\hline & \multirow[t]{2}{*}{0.6} & Red & 0.42 & 1.47 & 0.43 & 0.58 & 4.67 & 2.14 & 0.92 \\
\hline & & Green & 0.49 & 2.62 & 0.79 & 0.51 & 5.5 & 2.35 & 0.92 \\
\hline & \multirow[t]{2}{*}{0.4} & Red & 0.5 & 1.65 & 0.54 & 0.5 & 4.46 & 2.21 & 0.93 \\
\hline & & Green & 0.5 & 2.28 & 0.84 & 0.5 & 4.84 & 1.69 & 0.96 \\
\hline & \multirow[t]{2}{*}{0.2} & Red & 1 & 3.72 & 2.49 & 0 & - & 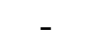 & 0.75 \\
\hline & & Green & 0 & - & - & 1 & 3.93 & 2.12 & 0.87 \\
\hline & \multirow[t]{2}{*}{0} & Red & 0.45 & 1.64 & 0.51 & 0.55 & 4.35 & 2.11 & 0.95 \\
\hline & & Green & 0.45 & 1.8 & 0.55 & 0.55 & 4.16 & 1.61 & 0.96 \\
\hline \multirow[t]{12}{*}{303} & \multirow[t]{2}{*}{1} & Red & 1 & 2.81 & 1.23 & 0 & - & - & 0.79 \\
\hline & & Green & 0 & - & - & 1 & 4.16 & 1.85 & 0.90 \\
\hline & \multirow[t]{2}{*}{0.8} & Red & 1 & 2.87 & 1.25 & 0 & - & - & 0.79 \\
\hline & & Green & 0.57 & 3.32 & 1.07 & 0.43 & 5.50 & 1.98 & 0.97 \\
\hline & \multirow[t]{2}{*}{0.6} & Red & 1 & 3.86 & 2.03 & 0 & - & - & 0.84 \\
\hline & & Green & 0 & - & - & 1 & 4.31 & 1.81 & 0.92 \\
\hline & \multirow[t]{2}{*}{0.4} & Red & 0.44 & 2.29 & 0.53 & 0.56 & 4.98 & 1.77 & 0.93 \\
\hline & & Green & 0.52 & 2.88 & 0.79 & 0.48 & 5.06 & 1.02 & 0.99 \\
\hline & \multirow{2}{*}{0.2} & Red & 0.52 & 2.55 & 0.84 & 0.48 & 5.50 & 1.18 & 0.95 \\
\hline & & Green & 0 & - & - & 1 & 4.08 & 1.87 & 0.90 \\
\hline & \multirow[t]{2}{*}{0} & Red & 0.49 & 2.46 & 0.86 & 0.51 & 5.25 & 1.28 & 0.95 \\
\hline & & Green & 0 & - & - & 1 & 4.28 & 1.67 & 0.93 \\
\hline \multirow[t]{12}{*}{403} & \multirow[t]{2}{*}{1} & Green & 1 & 2.09 & 0.87 & 0 & - & - & 0.94 \\
\hline & & Red & 0.40 & 1.94 & 0.70 & 0.60 & 4.06 & 1.24 & 0.99 \\
\hline & \multirow[t]{2}{*}{0.8} & Green & 1 & 2.07 & 0.89 & - & - & - & 0.91 \\
\hline & & Red & 0 & - & 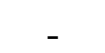 & 1 & 3.24 & 1.79 & 0.93 \\
\hline & \multirow[t]{2}{*}{0.6} & Green & 0.42 & 1.72 & 0.57 & 0.58 & 4.01 & 1.75 & 0.96 \\
\hline & & Red & 0 & - & - & 1 & 3.16 & 1.65 & 0.94 \\
\hline & \multirow{2}{*}{0.4} & Green & 0.34 & 1.67 & 0.66 & 0.66 & 4.00 & 1.48 & 0.98 \\
\hline & & Red & 0.43 & 1.71 & 0.68 & 0.57 & 3.75 & 1.17 & 0.98 \\
\hline & \multirow[t]{2}{*}{0.2} & Green & 0.44 & 1.65 & 0.57 & 0.56 & 3.86 & 1.34 & 0.97 \\
\hline & & Red & 0.41 & 1.51 & 0.52 & 0.59 & 3.52 & 1.30 & 0.98 \\
\hline & \multirow[t]{2}{*}{0} & Green & 0.47 & 1.70 & 0.67 & 0.53 & 4.05 & 1.41 & 0.97 \\
\hline & & Red & 0.41 & 1.60 & 0.52 & 0.59 & 3.66 & 1.39 & 0.98 \\
\hline
\end{tabular}

Note. Means (M) and standard deviations (SD) are listed with subscripts denoting Gaussian (1 or 2) by key colors correlated with short and long intervals. 
Table 4

Gaussian Fits to PI Response Distributions for Pigeons 302, 401, and 402

\begin{tabular}{|c|c|c|c|c|c|c|c|c|c|}
\hline Pigeon & $\varphi$ & Color & $\mathrm{K}_{1}$ & $\mathrm{M}_{1}$ & $\mathrm{SD}_{1}$ & $\mathrm{~K}_{2}$ & $\mathrm{M}_{2}$ & $\mathrm{SD}_{2}$ & VAC \\
\hline \multirow[t]{12}{*}{302} & \multirow[t]{2}{*}{1} & Red & 0.47 & 1.23 & 0.42 & 0.53 & 2.83 & 0.91 & 0.997 \\
\hline & & Green & 0.59 & 2.05 & 0.71 & 0.41 & 4.58 & 1.54 & 0.97 \\
\hline & \multirow{2}{*}{0.8} & Red & 0.56 & 1.20 & 0.19 & 0.44 & 3.22 & 1.65 & 0.97 \\
\hline & & Green & 0.54 & 2.37 & 0.80 & 0.46 & 4.97 & 1.72 & 0.98 \\
\hline & \multirow[t]{2}{*}{0.6} & Red & 0.60 & 1.22 & 0.20 & 0.40 & 3.61 & 2.06 & 0.92 \\
\hline & & Green & 0.39 & 2.27 & 0.75 & 0.61 & 4.74 & 1.82 & 0.96 \\
\hline & \multirow[t]{2}{*}{0.4} & Red & 0.48 & 1.58 & 0.67 & 0.52 & 4.33 & 1.56 & 0.93 \\
\hline & & Green & 0.54 & 1.92 & 0.69 & 0.46 & 4.65 & 1.66 & 0.98 \\
\hline & \multirow[t]{2}{*}{0.2} & Red & 0.43 & 1.37 & 0.40 & 0.57 & 4.32 & 2.40 & 0.83 \\
\hline & & Green & 0.56 & 2.06 & 0.76 & 0.44 & 4.77 & 2.11 & 0.93 \\
\hline & \multirow[t]{2}{*}{0} & Red & 0.53 & 1.64 & 0.41 & 0.47 & 4.72 & 2.52 & 0.91 \\
\hline & & Green & 0.43 & 1.74 & 0.60 & 0.57 & 4.47 & 2.12 & 0.93 \\
\hline \multirow[t]{12}{*}{401} & \multirow[t]{2}{*}{1} & Green & 1 & 2.16 & 0.98 & 0 & - & - & 0.96 \\
\hline & & Red & 0 & - & - & 1 & 3.15 & 1.89 & 0.87 \\
\hline & \multirow[t]{2}{*}{0.8} & Green & 0.54 & 1.59 & 0.55 & 0.46 & 3.47 & 1.23 & 0.96 \\
\hline & & Red & 0 & - & - & 1 & 3.29 & 1.80 & 0.90 \\
\hline & \multirow[t]{2}{*}{0.6} & Green & 0.53 & 1.68 & 0.58 & 0.47 & 3.80 & 1.43 & 0.97 \\
\hline & & Red & 0 & - & - & 1 & 3.04 & 1.99 & 0.83 \\
\hline & \multirow[t]{2}{*}{0.4} & Green & 1 & 2.88 & 1.74 & 0 & - & - & 0.87 \\
\hline & & Red & 0 & - & - & 1 & 2.89 & 1.98 & 0.81 \\
\hline & \multirow[t]{2}{*}{0.2} & Green & 0.56 & 1.75 & 0.64 & 0.44 & 3.97 & 1.42 & 0.95 \\
\hline & & Red & 0.57 & 1.21 & 0.20 & 0.43 & 3.51 & 1.87 & 0.93 \\
\hline & \multirow[t]{2}{*}{0} & Green & 0.57 & 1.67 & 0.57 & 0.43 & 4.10 & 1.75 & 0.96 \\
\hline & & Red & 0 & - & - & 1 & 3.17 & 2.09 & 0.78 \\
\hline \multirow[t]{12}{*}{402} & \multirow[t]{2}{*}{1} & Green & 1 & 2.57 & 0.95 & 0 & - & - & 0.97 \\
\hline & & Red & 0 & - & . & 1 & 3.86 & 1.45 & 0.96 \\
\hline & \multirow[t]{2}{*}{0.8} & Green & 0.43 & 1.74 & 0.27 & 0.57 & 3.32 & 1.08 & 0.997 \\
\hline & & Red & 0 & - & - & 1 & 3.86 & 1.58 & 0.98 \\
\hline & \multirow[t]{2}{*}{0.6} & Green & 0.42 & 1.96 & 0.54 & 0.58 & 3.94 & 1.13 & 0.99 \\
\hline & & Red & 0.32 & 2.05 & 0.49 & 0.68 & 4.09 & 1.38 & 0.99 \\
\hline & \multirow[t]{2}{*}{0.4} & Green & 0.36 & 1.93 & 0.53 & 0.64 & 3.78 & 1.18 & 0.99 \\
\hline & & Red & 0 & - & - & 1 & 3.44 & 1.49 & 0.93 \\
\hline & \multirow[t]{2}{*}{0.2} & Green & 0.43 & 2.04 & 0.55 & 0.57 & 3.97 & 1.26 & 0.99 \\
\hline & & Red & 0.43 & 2.06 & 0.61 & 0.57 & 3.95 & 1.42 & 0.99 \\
\hline & \multirow[t]{2}{*}{0} & Green & 0.47 & 2.03 & 0.55 & 0.53 & 4.21 & 1.17 & 0.99 \\
\hline & & Red & 0.51 & 2.22 & 0.66 & 0.49 & 4.39 & 1.27 & 0.99 \\
\hline
\end{tabular}

Note. Means (M) and standard deviations (SD) are listed with subscripts denoting Gaussian (1 or 2) by key colors correlated with short and long intervals. 
Table 5

Experiment 2 Participants, Condition Order, and Trials per Condition

\begin{tabular}{cccccc}
\hline \multirow{2}{*}{ Participant } & Short Color & 1 & 2 & 3 & 4 \\
\hline H1 & Light & $\varphi=1$ & $\varphi=0.8$ & $\varphi=0.4$ & $\varphi=0$ \\
& & $(120)$ & $(120)$ & $(120)$ & $(120)$ \\
H2 & Light & $\varphi=1$ & $\varphi=0.8$ & $\varphi=0.4$ & $\varphi=0$ \\
& & $(120)$ & $(120)$ & $(120)$ & $(120)$ \\
H3 & Light & $\varphi=1$ & $\varphi=0.8$ & $\varphi=0.4$ & $\varphi=0$ \\
& & $(120)$ & $(120)$ & $(126)$ & $(120)$ \\
H4 & Dark & $\varphi=0$ & $\varphi=0.4$ & $\varphi=0.8$ & $\varphi=1$ \\
& & $(120)$ & $(120)$ & $(120)$ & $(120)$ \\
H5 & Light & $\varphi=0$ & $\varphi=0.4$ & $\varphi=0.8$ & $\varphi=1$ \\
& & $(120)$ & $(120)$ & $(120)$ & $(120)$ \\
& Dark & $\varphi=0$ & $\varphi=0.4$ & $\varphi=0.8$ & $\varphi=1$ \\
& & $(120)$ & $(120)$ & $(120)$ & $(120)$ \\
\hline
\end{tabular}

Note. Short color represents the color of the background during 2-s target trials when cueinterval correlations were greater than zero 
Table 6

Experiment 2 Maximum Negative and Positive Difference and p-Values from KolmogorovSmirnov Tests on PI Response-Time Distributions by Background Color

\begin{tabular}{|c|c|c|c|c|c|}
\hline \multirow[b]{2}{*}{ Participant } & \multirow[b]{2}{*}{ Order } & \multicolumn{4}{|c|}{ Condition $(\varphi)$} \\
\hline & & 1 & 0.8 & 0.4 & 0 \\
\hline $\mathrm{H} 1$ & Descending & $\begin{array}{c}\mathbf{- 0 . 4 6 , 0} \\
(.007)\end{array}$ & $\begin{array}{c}-0.26,0.12 \\
(.182)\end{array}$ & $\begin{array}{c}-\mathbf{- 0 . 0 7 , 0 . 3 3} \\
(.037)\end{array}$ & $\begin{array}{c}-0.03,0.25 \\
(.254)\end{array}$ \\
\hline $\mathrm{H} 2$ & Descending & $\begin{array}{c}-0.90,0 \\
(<.001)\end{array}$ & $\begin{array}{l}-\mathbf{- 0 . 8 3 , 0} \\
(<.001)\end{array}$ & $\begin{array}{c}-0.44,0.10 \\
(.003)\end{array}$ & $\begin{array}{c}-\mathbf{0 . 5 8 , 0 . 0 6} \\
(<.001)\end{array}$ \\
\hline $\mathrm{H} 3$ & Descending & $\begin{array}{c}-1.00,0 \\
(<.001)\end{array}$ & $\begin{array}{l}-0.73,0 \\
(<.001)\end{array}$ & $\begin{array}{c}-0.48,0 \\
(.005)\end{array}$ & $\begin{array}{c}-0.45,0 \\
(.012)\end{array}$ \\
\hline $\mathrm{H} 4$ & Ascending & $\begin{array}{l}-\mathbf{- 0 . 5 8 , 0} \\
(<.001)\end{array}$ & $\begin{array}{c}-0.34,0 \\
(.024)\end{array}$ & $\begin{array}{c}-\mathbf{0 . 3 1 , 0} 0 \\
(.049)\end{array}$ & $\begin{array}{c}-\mathbf{0 . 0 8 , 0 . 4 1} \\
(<.001)\end{array}$ \\
\hline H5 & Ascending & $\begin{array}{c}-0.04,0.13 \\
(.992)\end{array}$ & $\begin{array}{c}-0.14,0.12 \\
(.985)\end{array}$ & $\begin{array}{c}-0.04,0.22 \\
(.649)\end{array}$ & $\begin{array}{c}-0.04,0.13 \\
(.942)\end{array}$ \\
\hline H6 & Ascending & $\begin{array}{c}-0.32,0.14 \\
(.679)\end{array}$ & $\begin{array}{c}-0.16,0.24 \\
(.960)\end{array}$ & $\begin{array}{c}-0.04,0.52 \\
(<.001)\end{array}$ & $\begin{array}{c}-0.19,0.07 \\
(.744)\end{array}$ \\
\hline
\end{tabular}

Note. Maximum negative difference is to the left of maximum positive difference and $p$-values are in parentheses. Maximum difference and $p$-values that are $p<.05$ are in bold. 
Table 7

Gaussian Fits to PI Response Distributions for Participants with Descending Cue Informativeness

\begin{tabular}{|c|c|c|c|c|c|c|c|c|c|}
\hline Participant & $\varphi$ & Color & $\mathrm{K}_{1}$ & $\mathrm{M}_{1}$ & $\mathrm{SD}_{1}$ & $\mathrm{~K}_{2}$ & $\mathrm{M}_{2}$ & $\mathrm{SD}_{2}$ & VAC \\
\hline \multirow[t]{8}{*}{ H1 } & 1 & Short & 1 & 2.09 & 0.46 & 0 & - & - & 0.998 \\
\hline & & Long & 0 & - & - & 1 & 3.06 & 0.55 & 0.998 \\
\hline & 0.8 & Short & 0.52 & 2.14 & 0.34 & 0.48 & 3.22 & 0.54 & 0.997 \\
\hline & & Long & 0 & - & - & 1 & 3.20 & 0.60 & 0.98 \\
\hline & 0.4 & Short & 0.22 & 2.13 & 0.13 & 0.78 & 3.26 & 0.91 & 0.99 \\
\hline & & Long & 0.47 & 2.72 & 0.32 & 0.53 & 3.27 & 0.72 & 0.998 \\
\hline & 0 & Short & 0.47 & 2.21 & 0.39 & 0.53 & 3.31 & 0.81 & 0.99 \\
\hline & & Long & 0.50 & 1.81 & 0.12 & 0.50 & 3.37 & 0.68 & 0.998 \\
\hline \multirow[t]{8}{*}{$\mathrm{H} 2$} & 1 & Short & 1 & 2.25 & 0.47 & 0 & - & - & 0.97 \\
\hline & & Long & 0 & - & - & 1 & 3.41 & 0.68 & 0.97 \\
\hline & 0.8 & Short & 1 & 2.00 & 0.36 & 0 & - & - & $>0.999$ \\
\hline & & Long & 0.18 & 3.13 & 0.67 & 0.82 & 3.25 & 0.19 & $>0.999$ \\
\hline & 0.4 & Short & 0.70 & 1.94 & 0.37 & 0.30 & 3.16 & 0.30 & $>0.999$ \\
\hline & & Long & 0.00 & - & - & 1.00 & 2.76 & 0.56 & 0.99 \\
\hline & 0 & Short & 0.81 & 2.19 & 0.34 & 0.19 & 2.84 & 0.21 & $>0.999$ \\
\hline & & Long & 0.44 & 1.80 & 0.20 & 1 & 3.17 & 0.36 & $>0.999$ \\
\hline \multirow[t]{8}{*}{ H3 } & 1 & Short & 0.68 & 2.14 & 0.36 & 0.32 & 3.39 & 0.38 & 0.999 \\
\hline & & Long & 0 & - & - & 1 & 3.96 & 0.53 & 0.96 \\
\hline & 0.8 & Short & 0.65 & 1.92 & 0.08 & 0.35 & 2.51 & 0.59 & 0.98 \\
\hline & & Long & 0.17 & 2.26 & 0.19 & 0.83 & 3.57 & 0.47 & 0.998 \\
\hline & 0.4 & Short & 0.62 & 2.16 & 0.24 & 0.38 & 3.46 & 0.58 & $>0.999$ \\
\hline & & Long & 0.54 & 2.23 & 0.34 & 0.46 & 3.95 & 0.45 & 0.98 \\
\hline & 0 & Short & 0.43 & 2.50 & 0.41 & 0.57 & 3.80 & 0.37 & $>0.999$ \\
\hline & & Long & 0.42 & 2.60 & 0.35 & 0.58 & 3.81 & 0.40 & $>0.999$ \\
\hline
\end{tabular}

Note. Means (M) and standard deviations (SD) are listed with subscripts denoting Gaussian (1 or 2) by background colors correlated with short and long intervals. 
Table 8

Gaussian Fits to PI Response Distributions for Participants with Ascending Cue Informativeness

\begin{tabular}{|c|c|c|c|c|c|c|c|c|c|}
\hline Participant & $\varphi$ & Color & $\mathrm{K}_{1}$ & $\mathrm{M}_{1}$ & $\mathrm{SD}_{1}$ & $\mathrm{~K}_{2}$ & $\mathrm{M}_{2}$ & $\mathrm{SD}_{2}$ & VAC \\
\hline \multirow[t]{8}{*}{$\mathrm{H} 4$} & 1 & Short & 1 & 4.46 & 0.73 & 0 & - & - & 0.998 \\
\hline & & Long & 0 & - & - & 1 & 3.86 & 0.88 & 0.98 \\
\hline & 0.8 & Short & 1 & 4.41 & 1.01 & 0 & - & - & 0.96 \\
\hline & & Long & 0.60 & 3.17 & 0.52 & 0.40 & 4.64 & 0.92 & 0.99 \\
\hline & 0.4 & Short & 1 & 4.66 & 0.80 & 0 & - & - & 0.96 \\
\hline & & Long & 0.40 & 2.58 & 0.49 & 0.60 & 4.28 & 0.72 & 0.99 \\
\hline & 0 & Short & 1 & 3.78 & 0.93 & 0 & - & - & 0.99 \\
\hline & & Long & 0.43 & 2.60 & 0.38 & 0.57 & 4.14 & 1.00 & 0.99 \\
\hline \multirow[t]{8}{*}{ H5 } & 1 & Short & 1 & 1.81 & 0.78 & 0 & - & - & 0.96 \\
\hline & & Long & 0.54 & 1.26 & 0.25 & 0.46 & 2.16 & 0.55 & $>0.999$ \\
\hline & 0.8 & Short & 0.61 & 1.64 & 0.42 & 0.39 & 2.64 & 0.35 & $>0.999$ \\
\hline & & Long & 0.21 & 1.42 & 0.35 & 0.79 & 2.24 & 0.69 & 0.99 \\
\hline & 0.4 & Short & 0.53 & 1.66 & 0.49 & 0.47 & 2.60 & 0.54 & $>0.999$ \\
\hline & & Long & 0 & - & - & 1 & 1.93 & 0.70 & 0.97 \\
\hline & 0 & Short & 1 & 2.16 & 0.81 & 0 & - & - & 0.93 \\
\hline & & Long & 0 & - & - & 1 & 2.27 & 0.92 & 0.84 \\
\hline \multirow[t]{8}{*}{ H6 } & 1 & Short & 1 & 5.99 & 0.63 & 0 & - & - & 0.58 \\
\hline & & Long & 0 & - & - & 1 & 5.63 & 1.05 & 0.89 \\
\hline & 0.8 & Short & 1 & 6.74 & 0.98 & 0 & - & - & 0.97 \\
\hline & & Long & 0 & - & - & 1 & 5.72 & 1.02 & 0.86 \\
\hline & 0.4 & Short & 1 & 5.03 & 1.13 & 0 & - & - & 0.94 \\
\hline & & Long & 0.47 & 2.79 & 0.18 & 0.53 & 5.18 & 1.17 & 0.99 \\
\hline & 0 & Short & 0.37 & 3.18 & 0.42 & 0.63 & 4.56 & 0.52 & 0.96 \\
\hline & & Long & 0 & - & - & 1 & 4.20 & 0.83 & 0.97 \\
\hline
\end{tabular}

Note. Means (M) and standard deviations (SD) are listed with subscripts denoting Gaussian (1 or 2) by background colors correlated with short and long intervals. 
Table 9

Gaussian Fits to PI Response Distributions for Participants in the $\varphi=1$ Cue-Informativeness Group

\begin{tabular}{|c|c|c|c|c|c|c|c|c|c|}
\hline Participant & $\varphi$ & Color & $\mathrm{K}_{1}$ & $\mathrm{M}_{1}$ & $\mathrm{SD}_{1}$ & $\mathrm{~K}_{2}$ & $\mathrm{M}_{2}$ & $\mathrm{SD}_{2}$ & $\mathrm{VAC}$ \\
\hline \multirow[t]{2}{*}{174} & 1 & Short & 0.91 & 2.18 & 0.43 & 0.09 & 3.16 & 0.32 & $>0.999$ \\
\hline & 1 & Long & 0 & - & - & 1 & 3.57 & 0.56 & 0.99 \\
\hline \multirow[t]{2}{*}{106} & 1 & Short & 1 & 2.01 & 0.39 & 0 & - & - & $>0.999$ \\
\hline & 1 & Long & 0 & - & - & 1 & 3.30 & 0.50 & 0.98 \\
\hline \multirow[t]{2}{*}{113} & 1 & Short & 0.76 & 2.34 & 0.34 & 0.24 & 3.04 & 0.56 & $>0.999$ \\
\hline & 1 & Long & 0 & - & - & 1 & 3.85 & 0.58 & 0.97 \\
\hline \multirow[t]{2}{*}{119} & 1 & Short & 0.75 & 2.01 & 0.46 & 0.25 & 3.37 & 0.88 & 0.99 \\
\hline & 1 & Long & 0 & - & - & 1 & 3.72 & 0.85 & 0.97 \\
\hline \multirow[t]{2}{*}{137} & 1 & Short & 1 & 3.61 & 0.65 & 0 & - & - & 0.84 \\
\hline & 1 & Long & 0 & - & - & 1 & 5.14 & 0.75 & 0.97 \\
\hline \multirow[t]{2}{*}{142} & 1 & Short & 1 & 5.56 & 1.27 & 0 & - & - & 0.93 \\
\hline & 1 & Long & 0 & - & - & 1 & 4.54 & 0.73 & 0.62 \\
\hline \multirow[t]{2}{*}{154} & 1 & Short & 0.61 & 2.33 & 0.47 & 0.39 & 3.54 & 1.06 & 0.98 \\
\hline & 1 & Long & 0 & - & - & 1 & 5.26 & 1.11 & 0.94 \\
\hline \multirow[t]{2}{*}{156} & 1 & Short & 0.67 & 2.25 & 0.29 & 0.33 & 2.86 & 0.58 & $>0.999$ \\
\hline & 1 & Long & 0 & - & - & 1 & 3.73 & 0.63 & 0.99 \\
\hline \multirow[t]{2}{*}{158} & 1 & Short & 0.69 & 2.31 & 0.23 & 0.31 & 3.14 & 0.25 & $>0.999$ \\
\hline & 1 & Long & 0 & - & - & 1 & 3.74 & 0.69 & 0.99 \\
\hline \multirow[t]{2}{*}{159} & 1 & Short & 1 & 1.96 & 0.27 & 0 & 4.00 & 0.89 & $>0.999$ \\
\hline & 1 & Long & 0 & - & - & 1 & 3.97 & 0.64 & 0.99 \\
\hline \multirow[t]{2}{*}{160} & 1 & Short & 0.77 & 2.24 & 0.46 & 0.23 & 3.60 & 1.01 & $>0.999$ \\
\hline & 1 & Long & 0 & - & - & 1 & 3.70 & 0.59 & $>0.999$ \\
\hline \multirow[t]{2}{*}{175} & 1 & Short & 0.52 & 2.13 & 0.39 & 0.48 & 3.68 & 0.56 & 0.99 \\
\hline & 1 & Long & 0.34 & 2.20 & 0.45 & 0.66 & 3.47 & 0.57 & $>0.999$ \\
\hline
\end{tabular}

Note. Means (M) and standard deviations (SD) are listed with subscripts denoting Gaussian (1 or 2) by background colors correlated with short and long intervals. 
Table 10

Gaussian Fits to PI Response Distributions for Participants in the $\varphi=0.8$ Cue-Informativeness Group

\begin{tabular}{|c|c|c|c|c|c|c|c|c|c|}
\hline Participant & $\varphi$ & Color & $\mathrm{K}_{1}$ & $\mathrm{M}_{1}$ & $\mathrm{SD}_{1}$ & $\mathrm{~K}_{2}$ & $\mathrm{M}_{2}$ & $\mathrm{SD}_{2}$ & VAC \\
\hline \multirow[t]{2}{*}{102} & 0.8 & Short & 1 & 3.81 & 0.68 & 0 & $\begin{array}{l}- \\
-\end{array}$ & - & 0.46 \\
\hline & 0.8 & Long & 0 & - & - & 1 & 4.64 & 0.86 & 0.53 \\
\hline \multirow[t]{2}{*}{105} & 0.8 & Short & 0.79 & 2.36 & 0.47 & 0.21 & 3.51 & 0.89 & 0.99 \\
\hline & 0.8 & Long & 0 & $\begin{array}{l}- \\
-\end{array}$ & - & 1 & 4.87 & 0.91 & 0.96 \\
\hline \multirow[t]{2}{*}{115} & 0.8 & Short & 0.90 & 3.07 & 0.59 & 0.10 & 4.67 & 1.06 & $>0.999$ \\
\hline & 0.8 & Long & 0 & - & - & 1 & 4.84 & 1.60 & 0.90 \\
\hline \multirow[t]{2}{*}{117} & 0.8 & Short & 0.74 & 2.63 & 0.53 & 0.26 & 3.57 & 0.81 & 0.99 \\
\hline & 0.8 & Long & 0 & - & - & 1 & 4.22 & 0.80 & 0.99 \\
\hline \multirow[t]{2}{*}{120} & 0.8 & Short & 0.56 & 2.80 & 0.19 & 0.44 & 4.26 & 1.37 & 0.96 \\
\hline & 0.8 & Long & 0 & - & $\begin{array}{l}- \\
-\end{array}$ & 1 & 5.35 & 1.36 & 0.78 \\
\hline \multirow[t]{2}{*}{124} & 0.8 & Short & 0.60 & 3.14 & 1.06 & 0.40 & 5.50 & 10.01 & 0.57 \\
\hline & 0.8 & Long & 0 & - & - & 1 & 3.77 & 1.10 & 0.86 \\
\hline \multirow[t]{2}{*}{131} & 0.8 & Short & 1 & 3.17 & 1.06 & 0 & - & - & 0.86 \\
\hline & 0.8 & Long & 0 & - & - & 1 & 3.83 & 1.04 & 0.94 \\
\hline \multirow[t]{2}{*}{136} & 0.8 & Short & 0.74 & 2.98 & 0.84 & 0.26 & 4.81 & 0.20 & 0.99 \\
\hline & 0.8 & Long & 0.58 & 2.48 & 0.55 & 0.42 & 3.52 & 1.10 & $>0.999$ \\
\hline \multirow[t]{2}{*}{146} & 0.8 & Short & 1 & 2.88 & 0.59 & 0 & - & - & $>0.999$ \\
\hline & 0.8 & Long & 0 & - & - & 1 & 3.51 & 0.77 & 0.99 \\
\hline \multirow[t]{2}{*}{151} & 0.8 & Short & 0.54 & 2.07 & 0.29 & 0.46 & 3.78 & 0.48 & 0.99 \\
\hline & 0.8 & Long & 0 & - & - & 1 & 3.92 & 0.45 & 0.99 \\
\hline \multirow[t]{2}{*}{164} & 0.8 & Short & 0.85 & 2.23 & 0.33 & 0.15 & 3.03 & 0.34 & $>0.999$ \\
\hline & 0.8 & Long & 0.47 & 3.15 & 0.78 & 0.53 & 3.85 & 0.44 & $>0.999$ \\
\hline \multirow[t]{2}{*}{165} & 0.8 & Short & 1 & 4.19 & 1.37 & 0 & - & - & 0.55 \\
\hline & 0.8 & Long & 0 & - & - & 1 & 4.67 & 1.23 & 0.76 \\
\hline
\end{tabular}

Note. Means (M) and standard deviations (SD) are listed with subscripts denoting Gaussian (1 or 2) by background colors correlated with short and long intervals. 
Table 11

Gaussian Fits to PI Response Distributions for Participants in the $\varphi=0.4$ Cue-Informativeness Group

\begin{tabular}{|c|c|c|c|c|c|c|c|c|c|}
\hline Participant & $\varphi$ & Color & $\mathrm{K}_{1}$ & $\overline{M_{1}}$ & $\mathrm{SD}_{1}$ & $\mathrm{~K}_{2}$ & $\mathrm{M}_{2}$ & $\mathrm{SD}_{2}$ & VAC \\
\hline \multirow[t]{2}{*}{103} & 0.4 & Short & 0.78 & 3.23 & 0.59 & 0.22 & 5.50 & 1.73 & 0.94 \\
\hline & 0.4 & Long & 0 & - & - & 1 & 3.90 & 0.75 & 0.98 \\
\hline \multirow[t]{2}{*}{108} & 0.4 & Short & 0.58 & 2.07 & 0.34 & 0.42 & 3.01 & 0.75 & $>0.999$ \\
\hline & 0.4 & Long & 0 & - & - & 1 & 3.18 & 0.72 & 0.96 \\
\hline \multirow[t]{2}{*}{114} & 0.4 & Short & 0.83 & 2.30 & 0.39 & 0.17 & 3.24 & 0.31 & $>0.999$ \\
\hline & 0.4 & Long & 0.68 & 2.28 & 0.37 & 0.32 & 3.25 & 0.37 & $>0.999$ \\
\hline \multirow[t]{2}{*}{125} & 0.4 & Short & 1 & 3.11 & 0.85 & 0 & - & - & 0.95 \\
\hline & 0.4 & Long & 0 & - & - & 1 & 4.12 & 0.95 & $>0.999$ \\
\hline \multirow[t]{2}{*}{132} & 0.4 & Short & 0.32 & 2.67 & 0.18 & 0.68 & 3.45 & 0.65 & $>0.999$ \\
\hline & 0.4 & Long & 0 & - & - & 1 & 3.81 & 0.93 & 0.98 \\
\hline \multirow[t]{2}{*}{133} & 0.4 & Short & 0.45 & 1.98 & 0.23 & 0.55 & 3.08 & 0.70 & $>0.999$ \\
\hline & 0.4 & Long & 0.54 & 2.31 & 0.42 & 0.46 & 3.45 & 0.85 & 0.98 \\
\hline \multirow[t]{2}{*}{138} & 0.4 & Short & 1 & 4.01 & 0.85 & 0 & - & - & 0.94 \\
\hline & 0.4 & Long & 0 & - & - & 1 & 3.80 & 0.65 & 0.95 \\
\hline \multirow[t]{2}{*}{147} & 0.4 & Short & 1 & 2.40 & 0.26 & 0 & - & - & 0.99 \\
\hline & 0.4 & Long & 0 & - & - & 1 & 3.10 & 0.26 & 0.99 \\
\hline \multirow[t]{2}{*}{152} & 0.4 & Short & 1 & 3.48 & 0.90 & 0 & - & - & 0.86 \\
\hline & 0.4 & Long & 0 & - & - & 1 & 4.48 & 0.92 & 0.91 \\
\hline \multirow[t]{2}{*}{161} & 0.4 & Short & 1 & 3.67 & 1.15 & 0 & - & - & 0.97 \\
\hline & 0.4 & Long & 0 & - & - & 1 & 3.94 & 1.02 & 0.97 \\
\hline \multirow[t]{2}{*}{166} & 0.4 & Short & 0.57 & 2.37 & 0.31 & 0.43 & 4.28 & 1.18 & 0.92 \\
\hline & 0.4 & Long & 0 & - & - & 1 & 3.74 & 1.41 & 0.74 \\
\hline \multirow[t]{2}{*}{167} & 0.4 & Short & 1 & 5.14 & 2.21 & 0 & - & - & 0.76 \\
\hline & 0.4 & Long & 0 & - & - & 1 & 4.70 & 1.12 & 0.97 \\
\hline
\end{tabular}

Note. Means (M) and standard deviations (SD) are listed with subscripts denoting Gaussian (1 or 2) by background colors correlated with short and long intervals. 
Table 12

Gaussian Fits to PI Response Distributions for Participants in the $\varphi=0$ Cue-Informativeness Group

\begin{tabular}{cccccccccc}
\hline Participant & $\varphi$ & Color & $\mathrm{K}_{1}$ & $\mathrm{M}_{1}$ & $\mathrm{SD}_{1}$ & $\mathrm{~K}_{2}$ & $\mathrm{M}_{2}$ & $\mathrm{SD}_{2}$ & $\mathrm{VAC}$ \\
\hline \multirow{2}{*}{104} & 0 & Short & 1 & 4.35 & 0.66 & 0 & - & - & 0.94 \\
& 0 & Long & 0 & - & - & 1 & 4.21 & 0.79 & 0.83 \\
116 & 0 & Short & 1 & 5.05 & 2.14 & 0 & - & - & 0.48 \\
& 0 & Long & 0 & - & - & 1 & 4.42 & 1.48 & 0.79 \\
122 & 0 & Short & 0.49 & 2.75 & 0.37 & 0.51 & 5.00 & 0.57 & 0.89 \\
& 0 & Long & 0 & - & - & 1 & 3.87 & 0.29 & 0.49 \\
140 & 0 & Short & 1 & 3.45 & 0.64 & 0 & - & - & 0.95 \\
& 0 & Long & 0 & - & - & 1 & 3.38 & 0.61 & 0.99 \\
143 & 0 & Short & 1 & 3.64 & 1.69 & 0 & - & - & 0.85 \\
& 0 & Long & 0 & - & - & 1 & 3.69 & 1.52 & 0.67 \\
144 & 0 & Short & 0.68 & 3.20 & 0.25 & 0.32 & 5.16 & 0.93 & 0.96 \\
& 0 & Long & 0 & - & - & 1 & 4.67 & 2.21 & 0.17 \\
153 & 0 & Short & 0.44 & 3.46 & 0.95 & 0.56 & 4.87 & 1.51 & 0.99 \\
& 0 & Long & 0 & - & - & 1 & 4.21 & 1.53 & 0.98 \\
155 & 0 & Short & 0.54 & 1.89 & 0.58 & 0.46 & 4.29 & 1.16 & 0.94 \\
& 0 & Long & 0.60 & 2.29 & 0.69 & 0.40 & 5.11 & 0.81 & 0.92 \\
157 & 0 & Short & 0.38 & 2.73 & 0.51 & 0.62 & 4.75 & 0.32 & 0.90 \\
& 0 & Long & 0 & - & - & 1 & 3.11 & 0.55 & 0.76 \\
162 & 0 & Short & 0.26 & 2.48 & 0.24 & 0.74 & 3.72 & 0.73 & $>0.999$ \\
& 0 & Long & 0 & - & - & 1 & 3.32 & 0.98 & 0.97 \\
163 & 0 & Short & 1 & 3.63 & 0.75 & 0 & - & - & 0.98 \\
& 0 & Long & 0 & - & - & 1 & 3.73 & 1.06 & 0.98 \\
171 & 0 & Short & 1 & 3.73 & 0.63 & 0 & - & - & 0.96 \\
& 0 & Long & 0.47 & 2.49 & 0.47 & 0.53 & 3.92 & 0.41 & 0.99 \\
\hline \multirow{4}{*}{163}
\end{tabular}

Note. Means (M) and standard deviations (SD) are listed with subscripts denoting Gaussian (1 or 2) by background colors correlated with short and long intervals. 


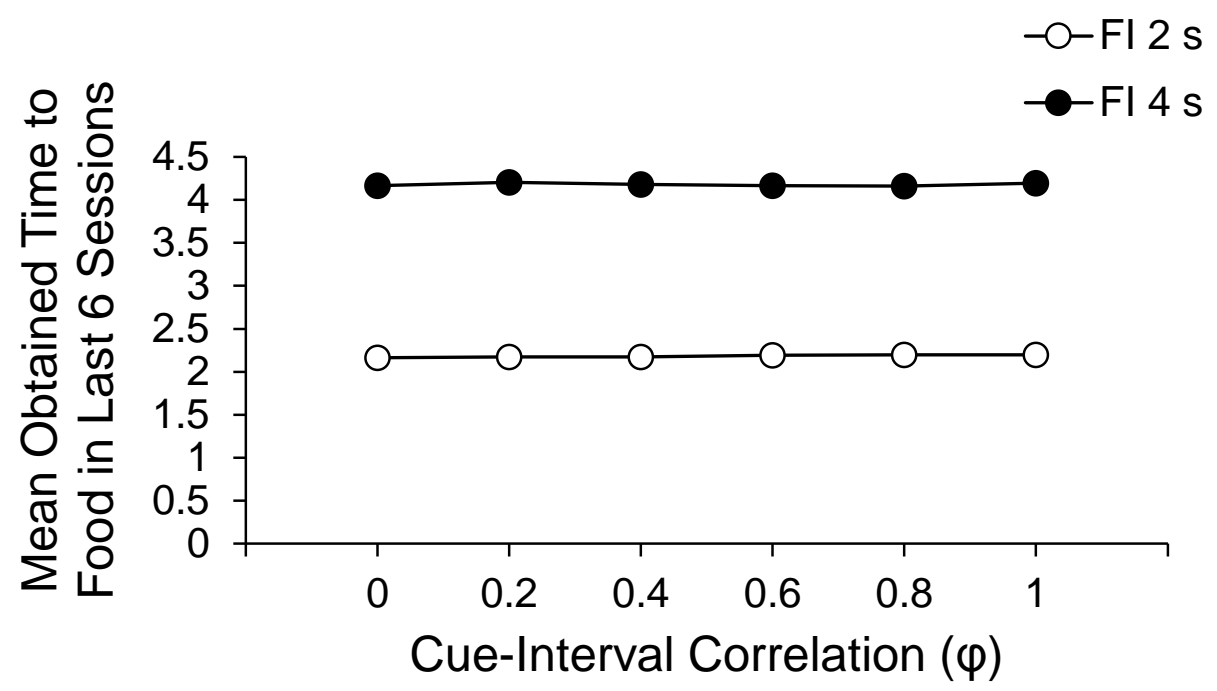

Figure 1. Mean obtained time to food in the FI 2-s (open circles) and FI 4-s (closed circles) schedules as a function of cue-interval correlation. Obtained time to food is averaged across the last six sessions of each cue-informativeness condition and across pigeons. Error bars are not shown because data points mask standard error of the mean (range 0.03-0.05). 


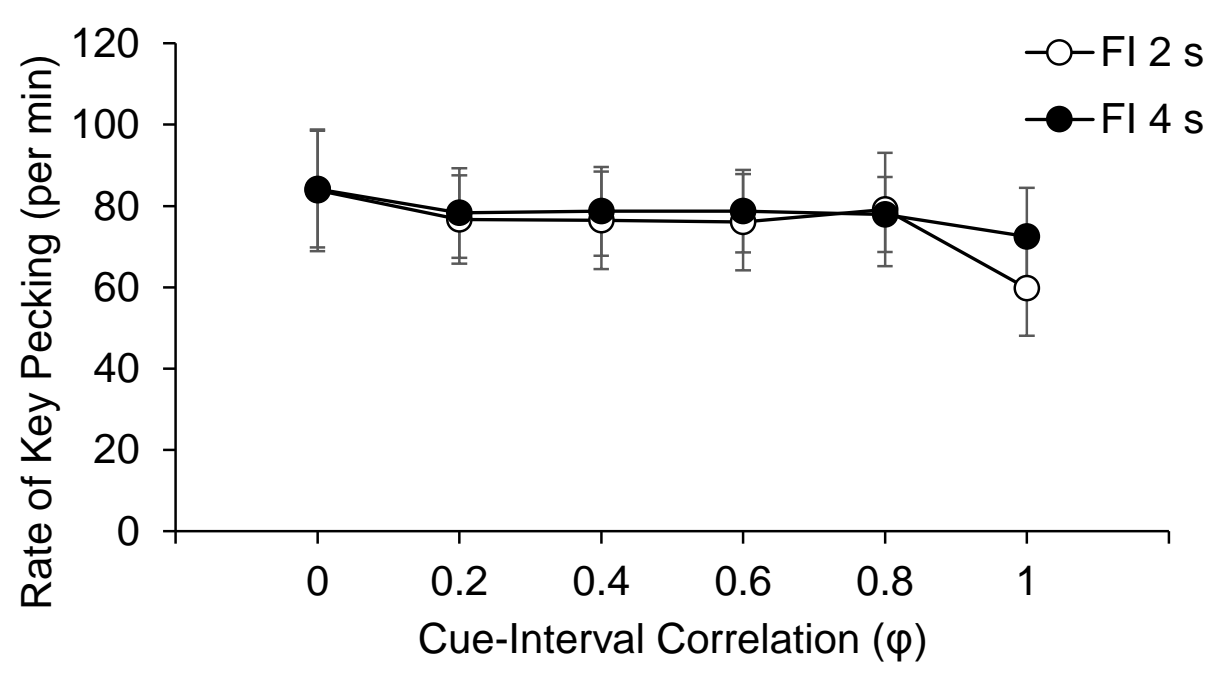

Figure 2. Mean rate of key pecking (per min) in the FI 2-s (open circles) and FI 4-s (closed circles) schedules as a function of cue-interval correlation. Rate of key pecking is averaged across the last six sessions of each cue-informativeness condition and across pigeons. Error bars are standard error of the mean. 


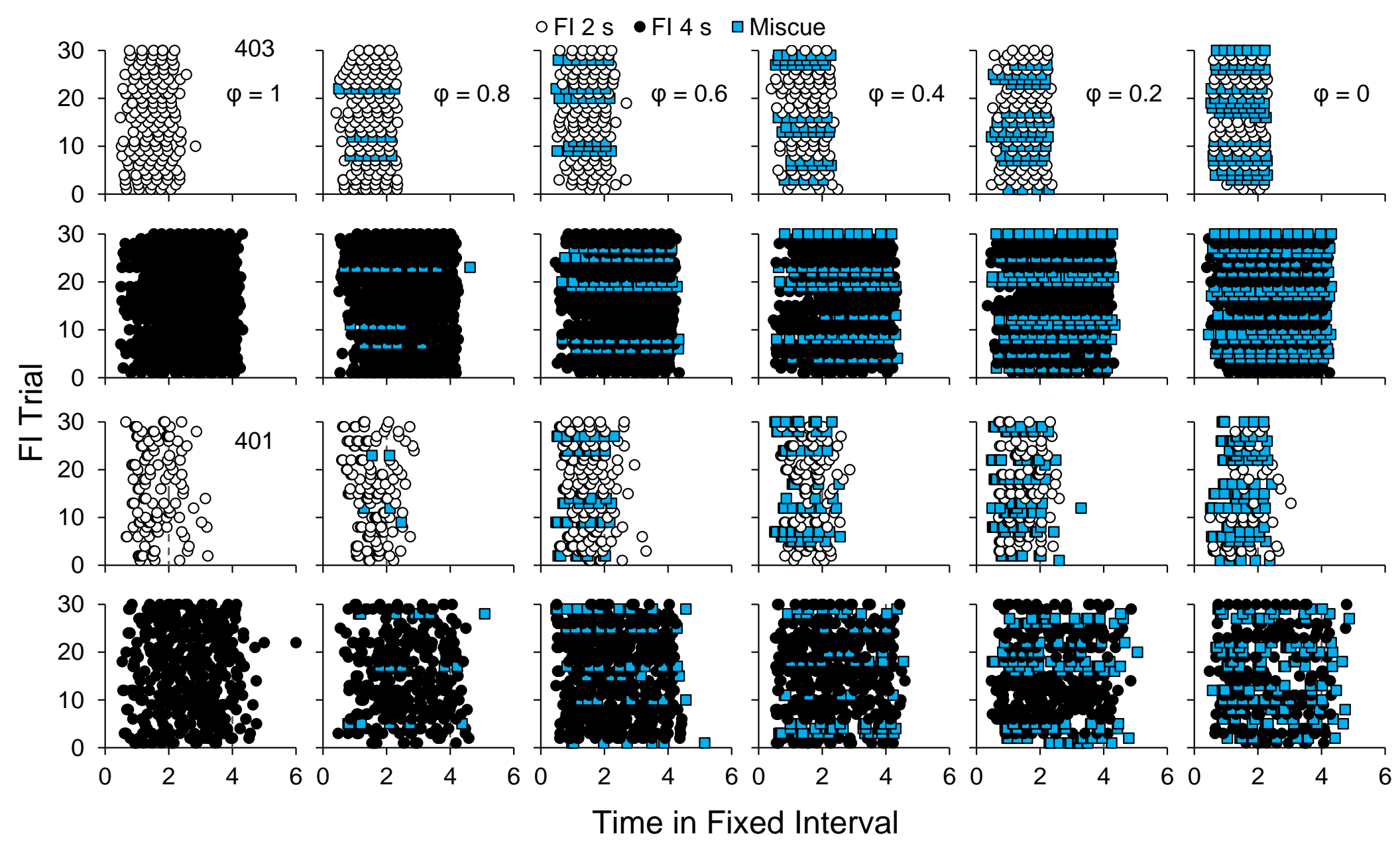

Figure 3. Each data point is the time of a response in every FI 2- (open circles) and FI 4-s (closed circles) trial of the last session of each condition for representative pigeons (403 and 401). FI 2- and 4-s trials from the session are shown separately. Circles are signaled and blue squares are miscued intervals. Each column is a different cue-informativeness condition labeled by phi coefficient. 


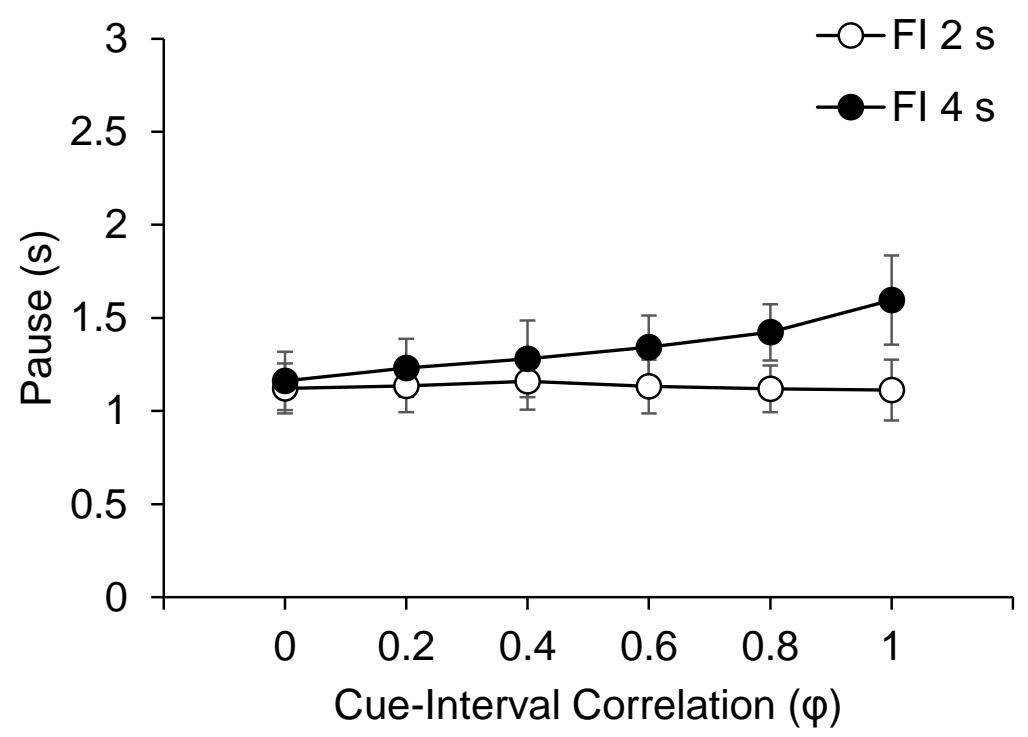

Figure 4. Latency to first response (i.e., pausing) as a function of cue-interval correlation in the FI 2-s and FI 4-s trials. Pauses are averaged across the last six sessions of each cueinformativeness condition and across pigeons. Error bars show standard error of the mean. 


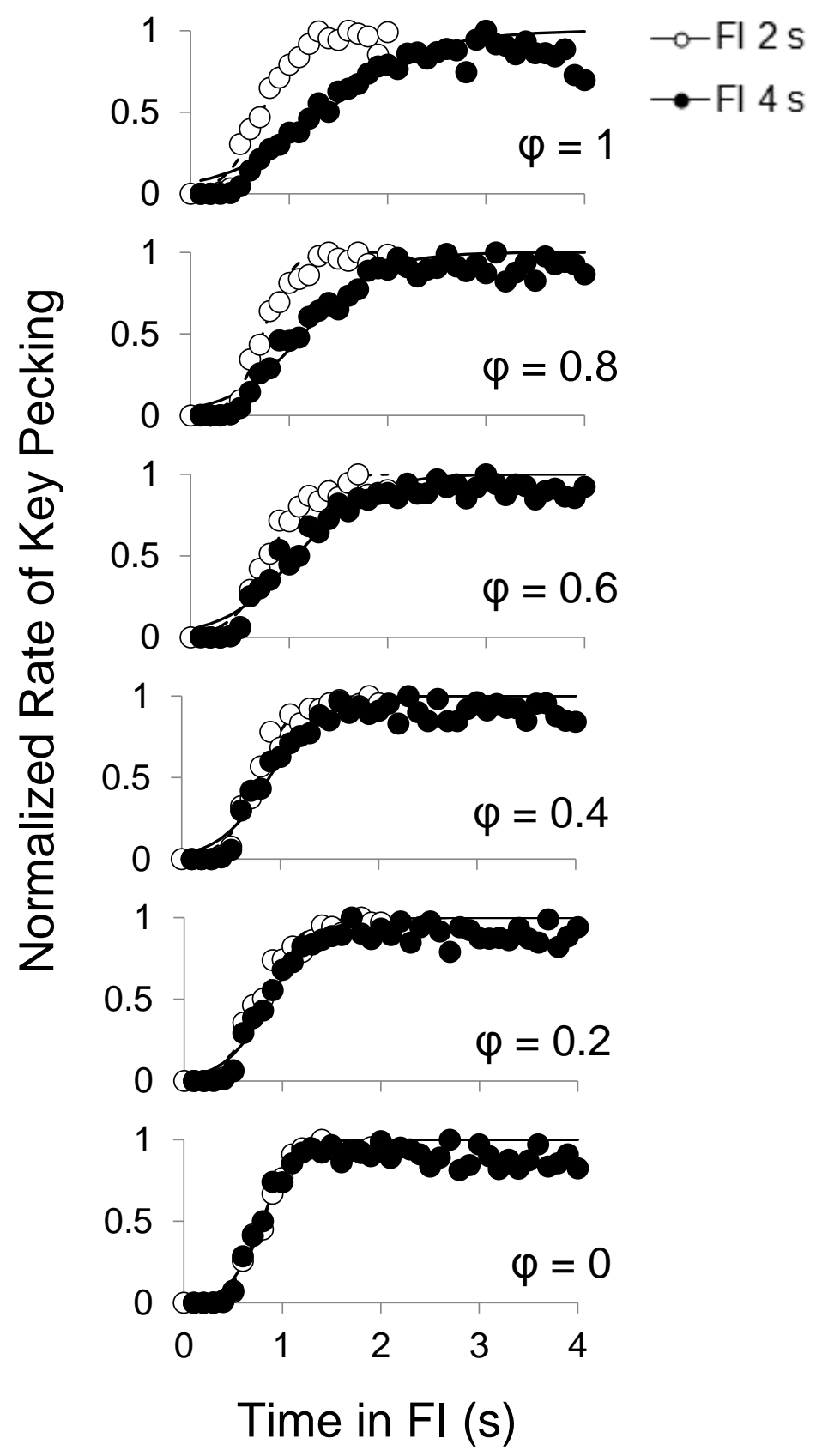

Figure 5. Normalized rate of key pecking (proportion of maximum key pecks) as a function of time in FI $2 \mathrm{~s}$ (unfilled circles) and FI $4 \mathrm{~s}$ (filled circles) trials collapsed across cues and miscues. Response gradients are averaged across pigeons and across the last six sessions of each cueinformativeness condition, shown as the phi correlation between cue and interval. Ogives fit to the response gradients are dashed (FI $2 \mathrm{~s}$ ) and solid (FI $4 \mathrm{~s}$ ) lines. 

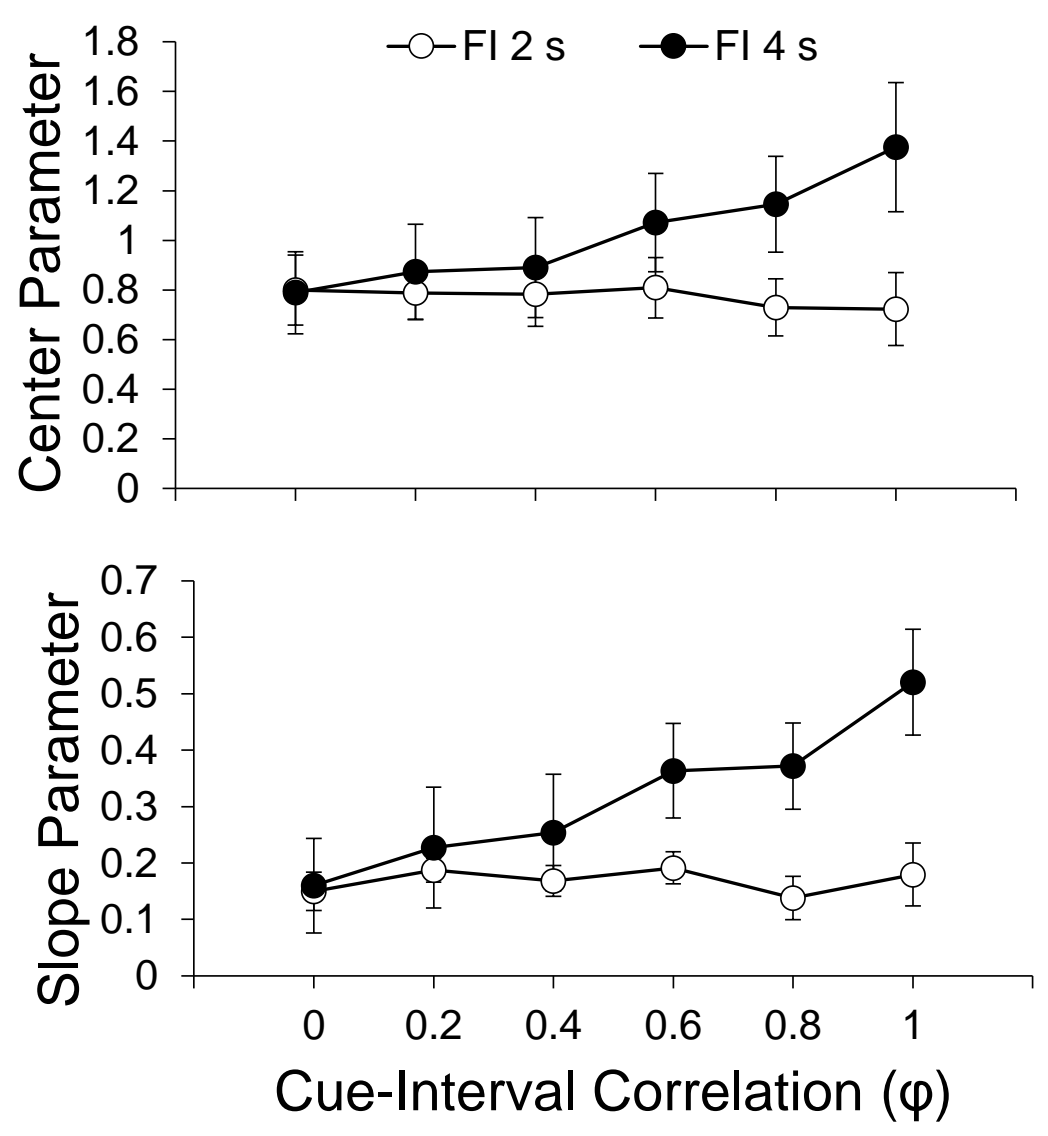

Figure 6. Center and slope parameters of ogives fit to FI response gradients as a function of cueinterval correlation. Parameters are shown separately from ogives fit to response gradients in FI 2-s (unfilled) and FI 4-s (filled) trials. Error bars are standard error. 


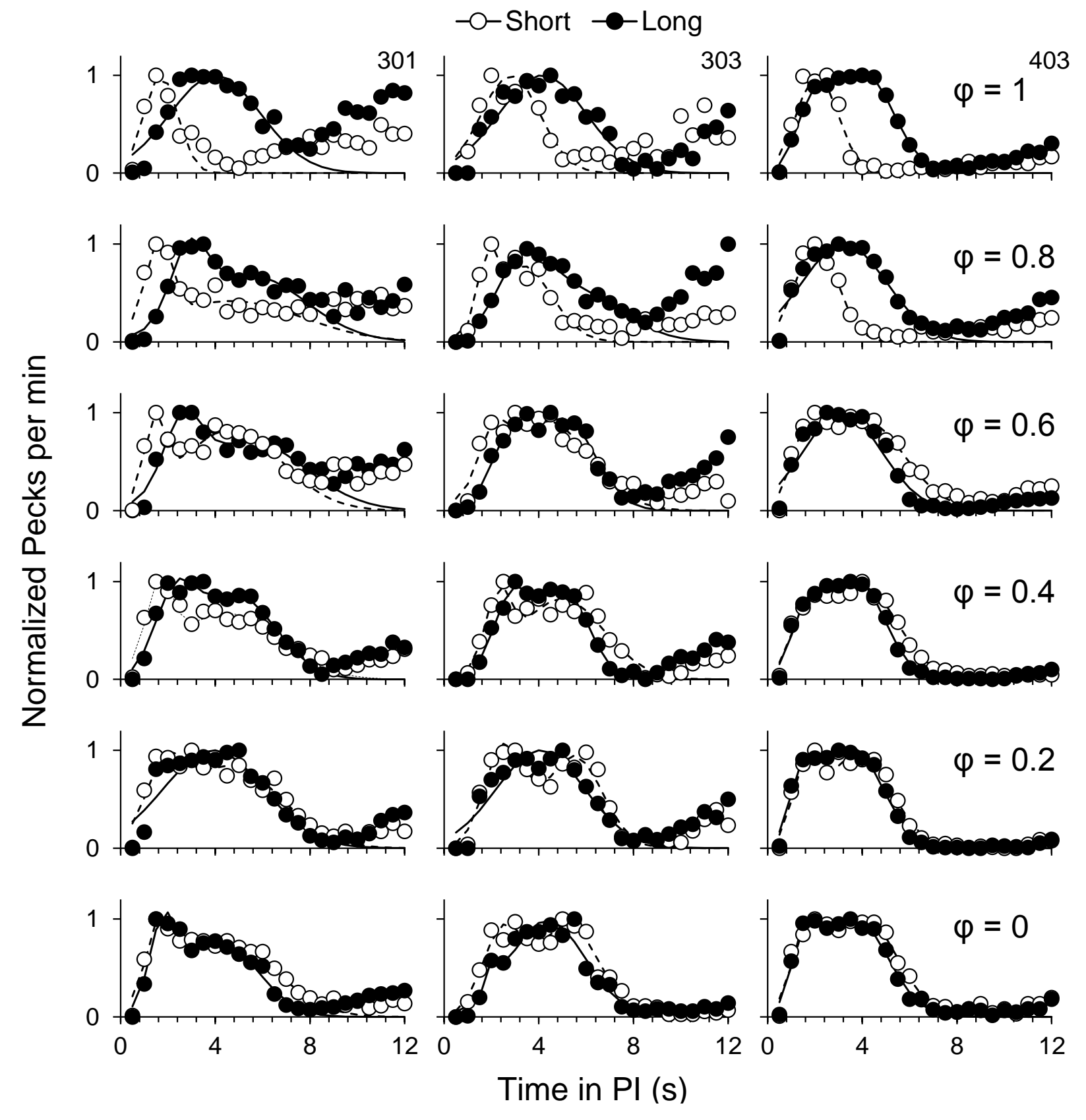

Figure 7. PI response distributions for Pigeons 301, 303, and 403 showing normalized pecks per min as a function of time for the short (unfilled) and long (filled) key color (when $\varphi=1$ ) for each cue-informativeness condition. Dashed and straight lines are fits of Gaussian curves. Conditions are ordered by row and labeled by phi correlation. 

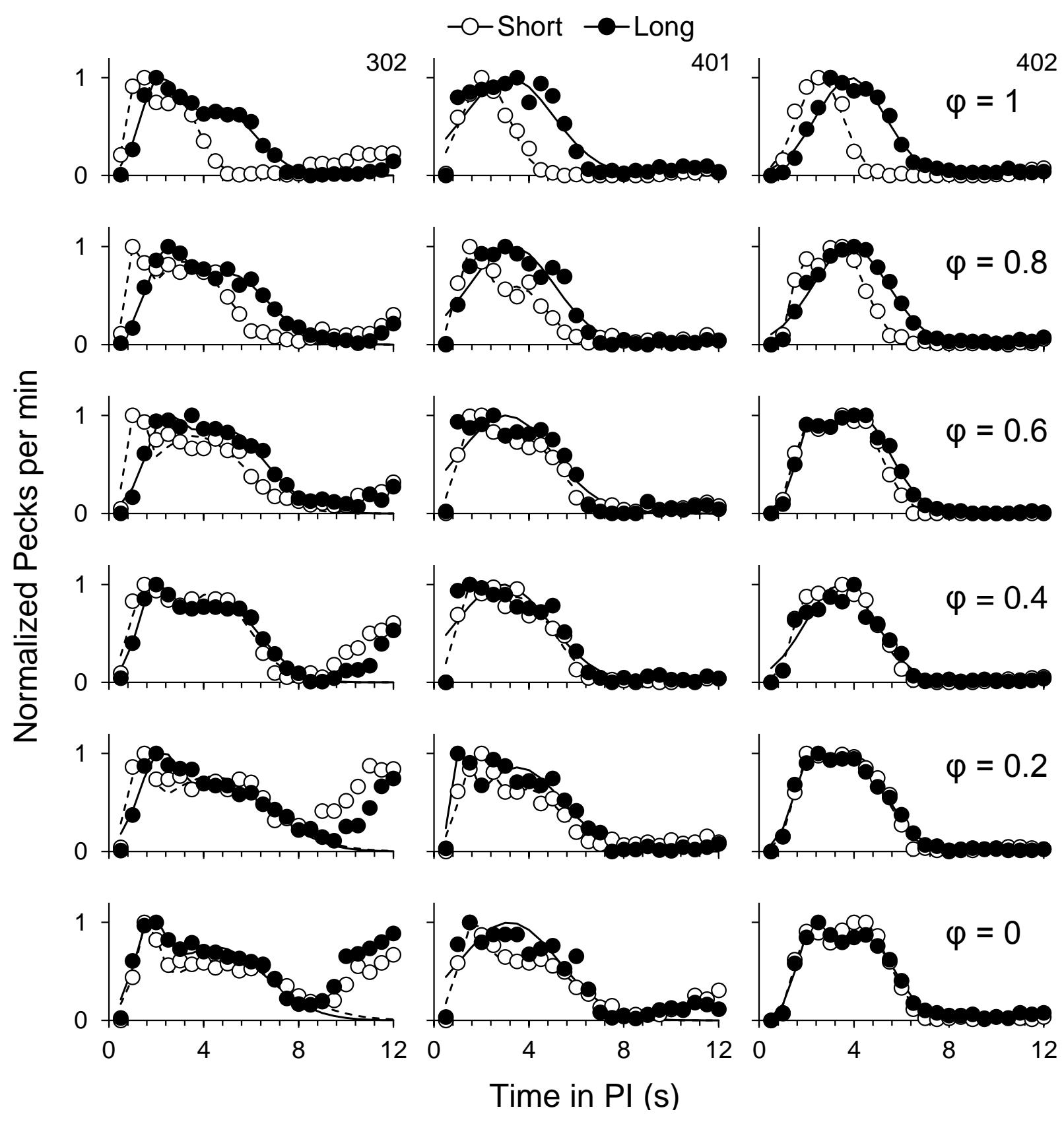

Figure 8. PI response distributions for Pigeons 302, 401, and 402 showing normalized pecks per min as a function of time for the short (unfilled) and long (filled) key color (when $\varphi=1$ ) for each cue-informativeness condition. Dashed and straight lines are fits of Gaussian curves. Conditions are ordered by row and labeled by phi correlation. 

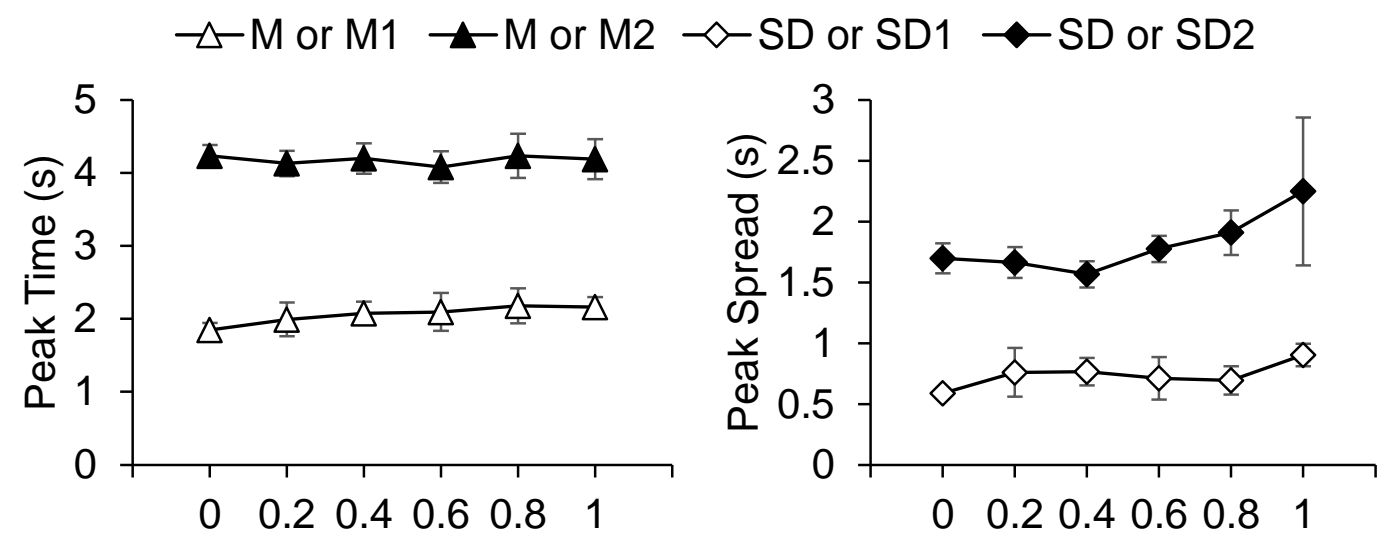

\section{Cue-Interval Correlation $(\varphi)$}

Figure 9. Peak time and spread (s) obtained from Gaussian curves fit to response distributions aggregated across the last six sessions of each condition. Parameter estimates of the first and second Gaussian are graphed as a function of cue-interval correlation averaged across pigeons and key colors. The triangles are mean $M_{1}$ (unfilled) or $M_{2}$ (filled) and the diamonds are $S D_{1}$ (unfilled) or $S D_{2}$ (filled) from Equation 2 fit to red and green PI response distributions from individual pigeons. The error bars are standard error. 


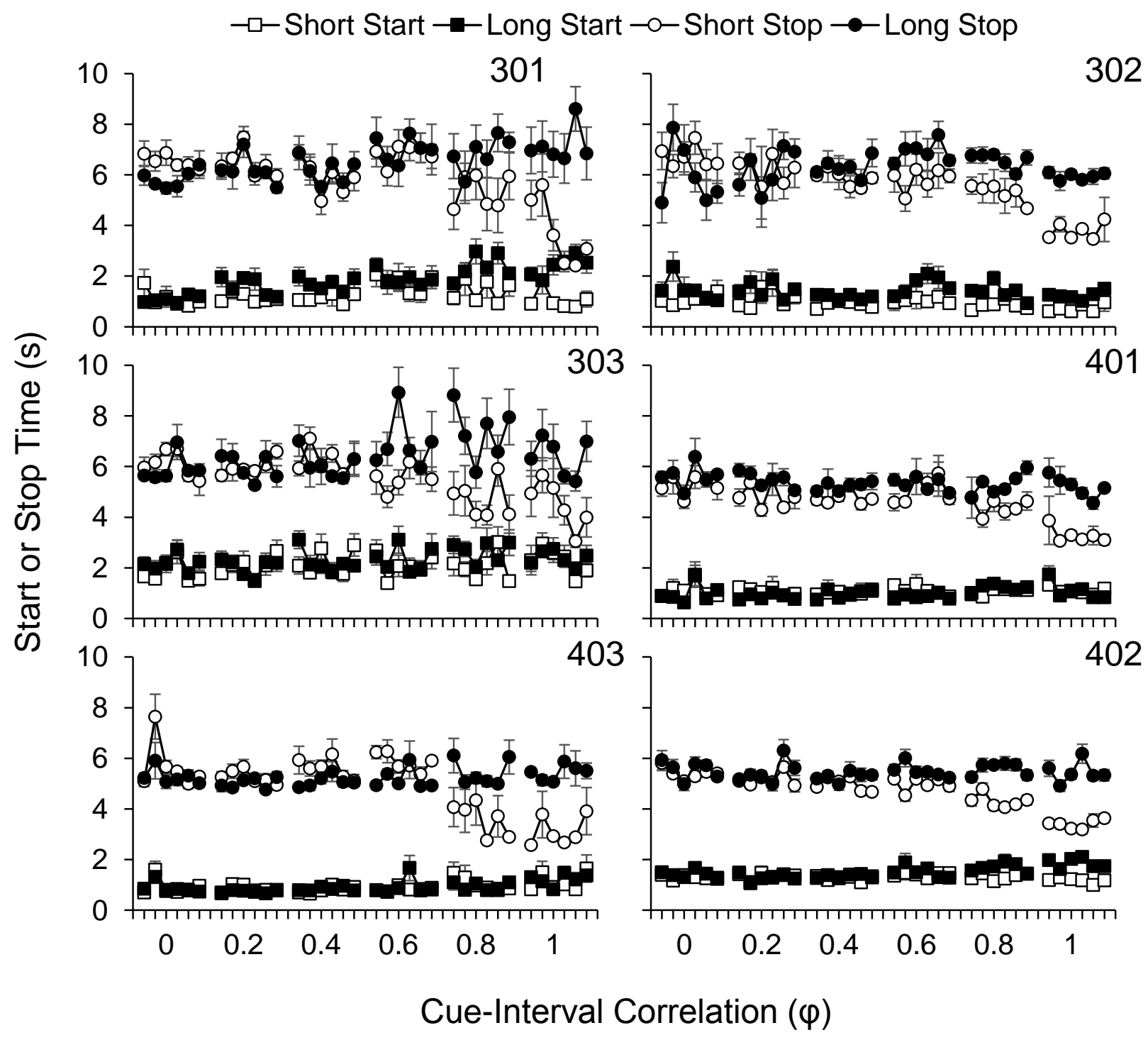

Figure 10. Mean start (squares) and stop (circles) times (s) over the last six sessions in each cueinformativeness condition, indicated by the phi correlation, for each individual pigeon. The filled data points are start or stop times in the presence of the long key color and the unfilled data points are start or stop times in the presence of the short key color $($ when $\varphi=1)$. Error bars are standard deviation. 


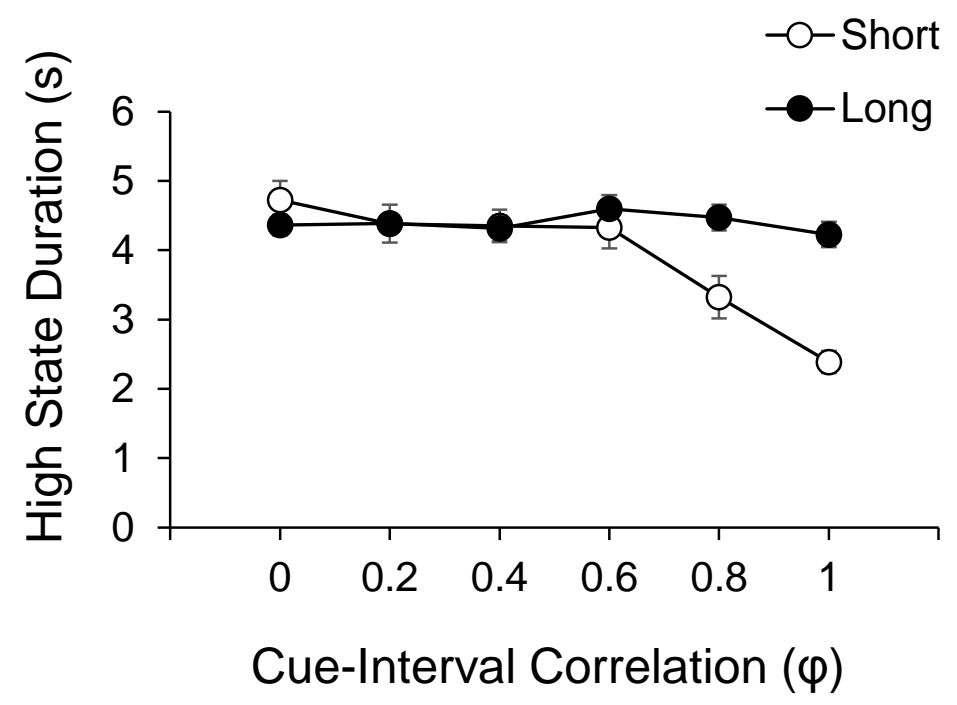

Figure 11. High state duration, or the difference between the start and stop time in the presence of the short (unfilled) or long (filled) key color (when $\varphi=1$ ) averaged across the last six sessions in each cue-informativeness condition, indicated by the phi correlation. High state duration is averaged across all six pigeons and error bars denote standard error. 

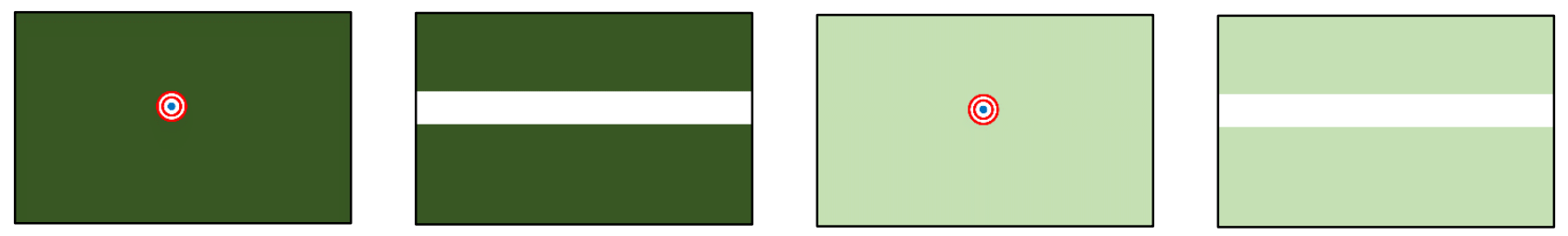

Points Earned this Trial:

Total Points Earned this Session:

19

262

Press the Spacebar to Begin the Next Trial

Figure 12. Screenshots of PI procedure with humans. The top row shows regular and PI trials and the bottom panel shows how the participant viewed their points during the ITI. 


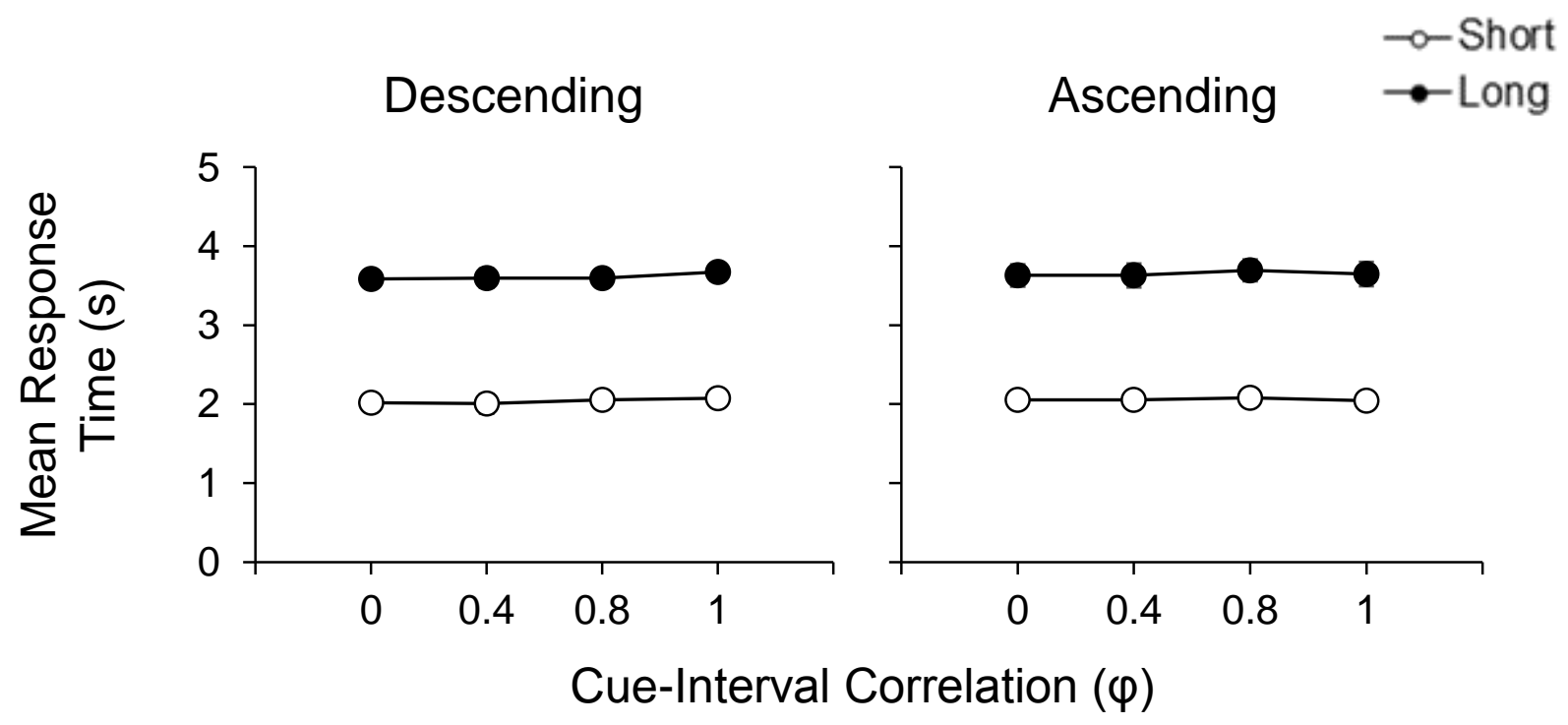

Figure 13. Time (s) of the mean response since the start of the regular trial in each cueinformativeness condition. Response times are averaged across all 30 short (unfilled circles) and 30 long-target trials (filled circles) and across participants receiving cue-interval correlations in descending (left) or ascending (right) order. Error bars are standard error. 


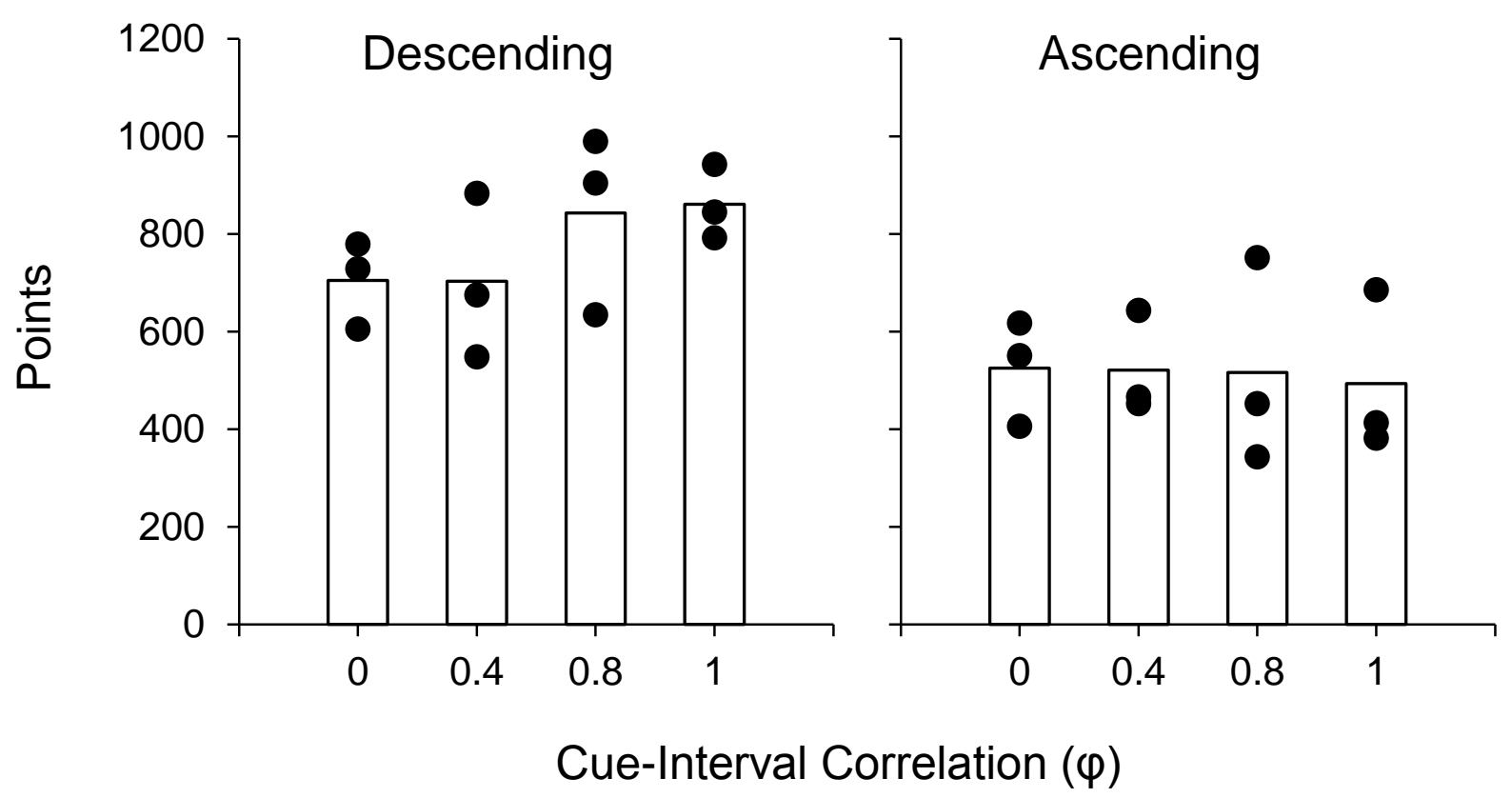

Figure 14. Bars are average number of points earned in each cue-informativeness condition in Experiment 2. Filled circles are points earned by individual participants with descending (left) or ascending (right) cue informativeness. Cue-interval correlations for each condition are labeled using phi coefficients. 


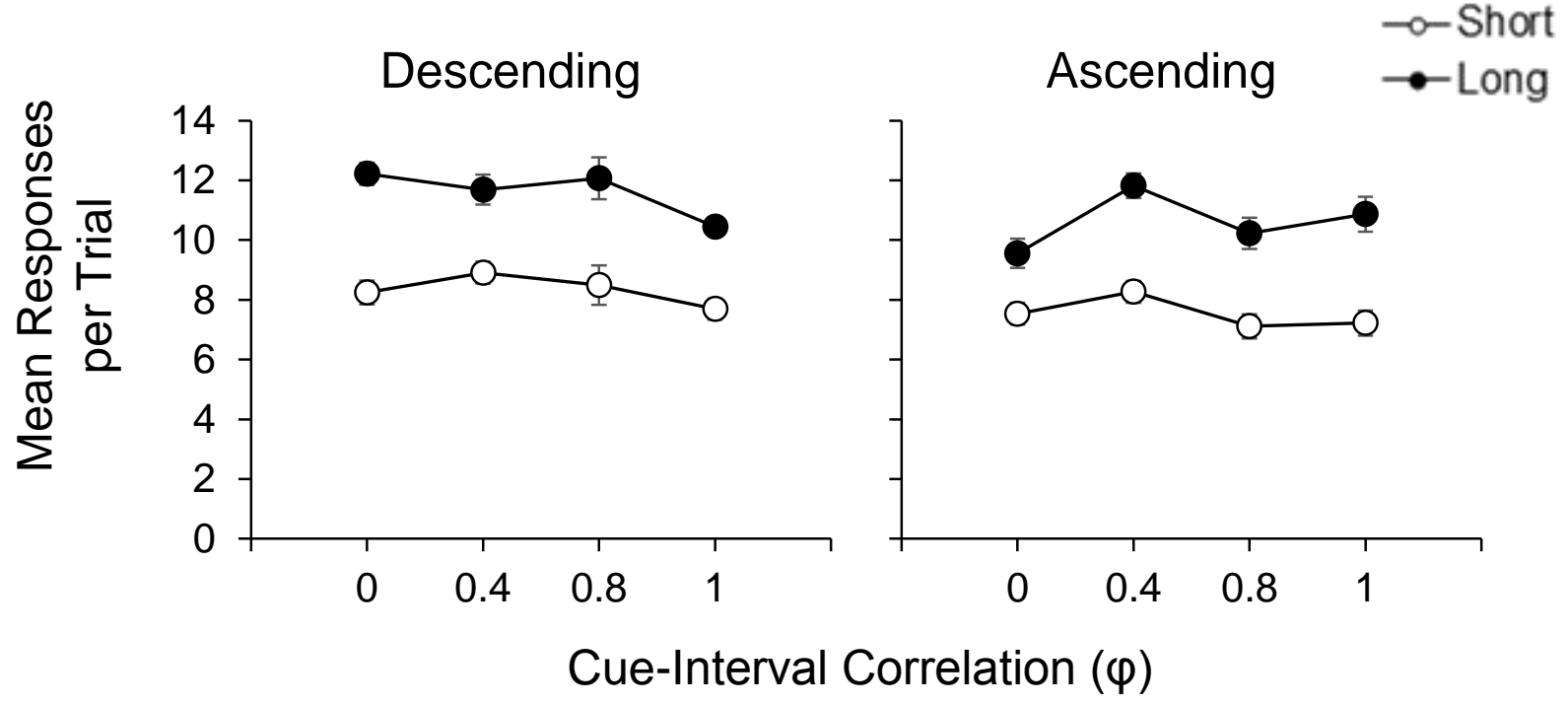

Figure 15. Mean number of responses in regular trials in each cue-informativeness condition.

Responses are averaged across all 30 short (unfilled circles) and 30 long-target trials (filled circles) and across participants receiving cue-interval correlations in descending (left) or ascending (right) order. Error bars are standard error. 


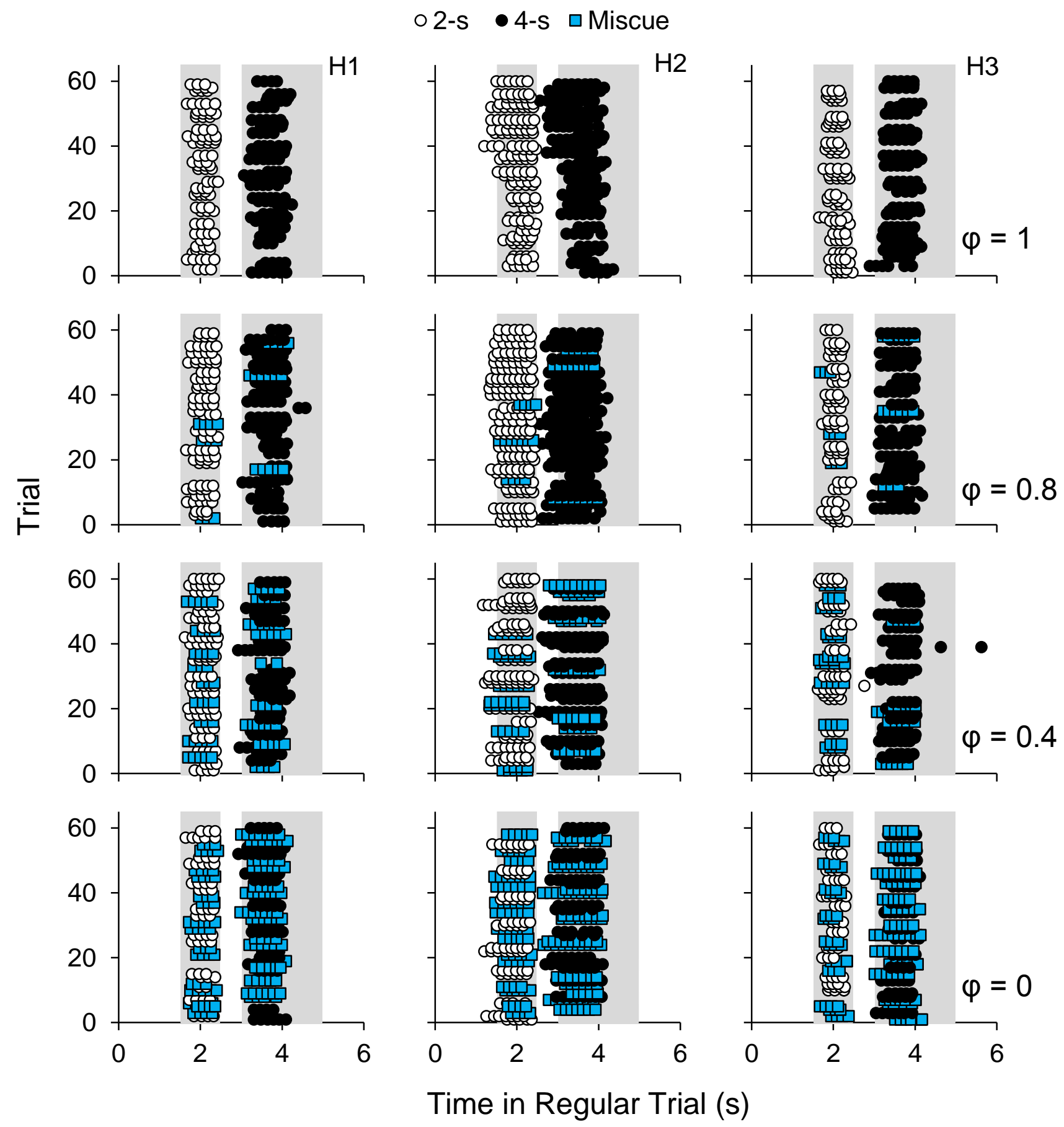

Figure 16. Each data point is the time of each enter-key press in regular trials for participants with descending cue informativeness ( $\mathrm{H} 1, \mathrm{H} 2$, and $\mathrm{H} 3)$. Responses in miscued trials are blue squares. The shaded area is the window in which points were available. Cue-interval correlations for each condition are labeled using phi coefficients. 
०2-s • 4-s 口 Miscue

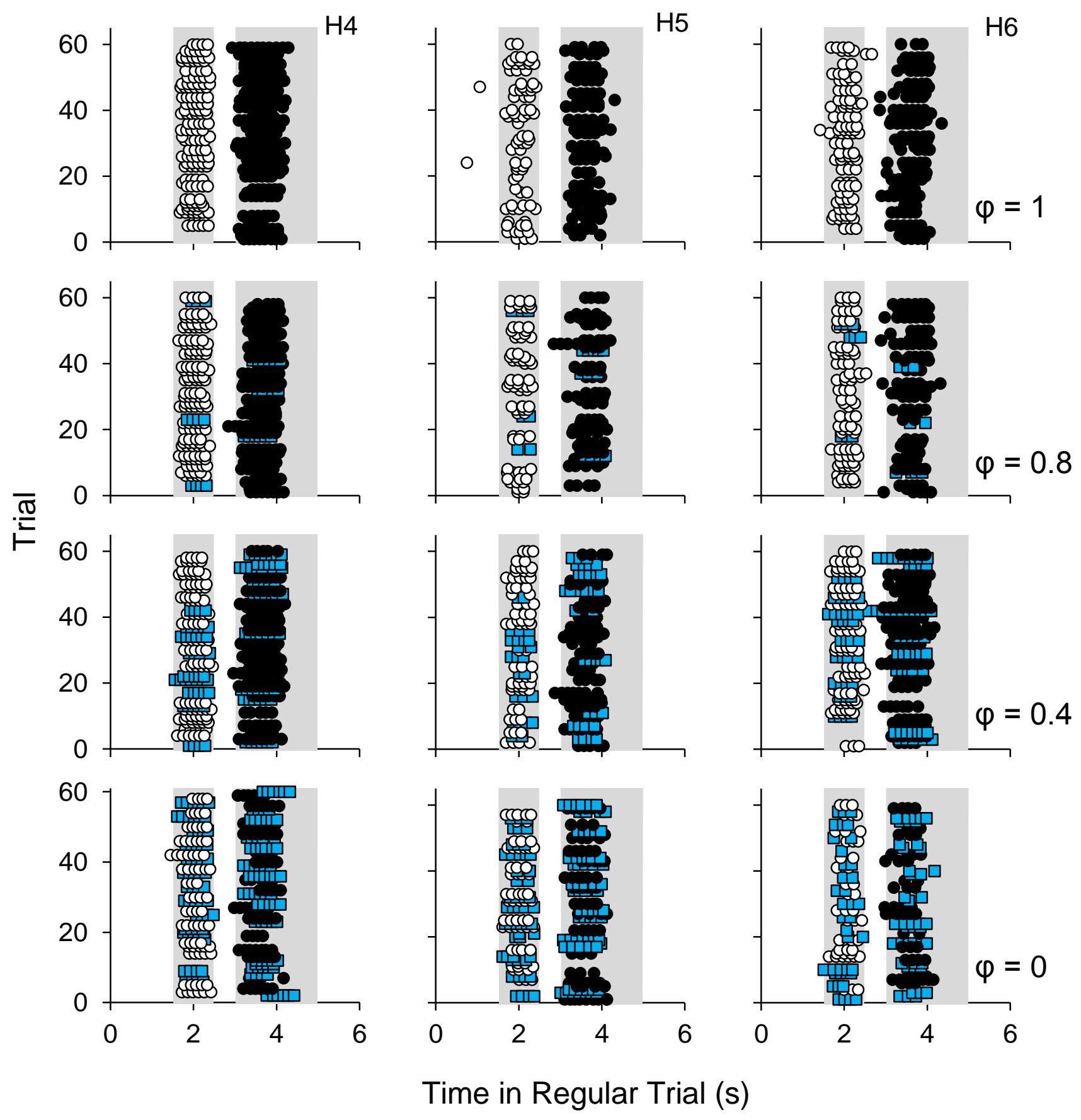

Figure 17. Each data point is the time of each enter-key press in regular trials for participants with ascending cue informativeness (H4, H5, and H6). Responses in miscued trials are blue squares. The shaded area is the window in which points were available. Cue-interval correlations for each condition are labeled using phi coefficients. 

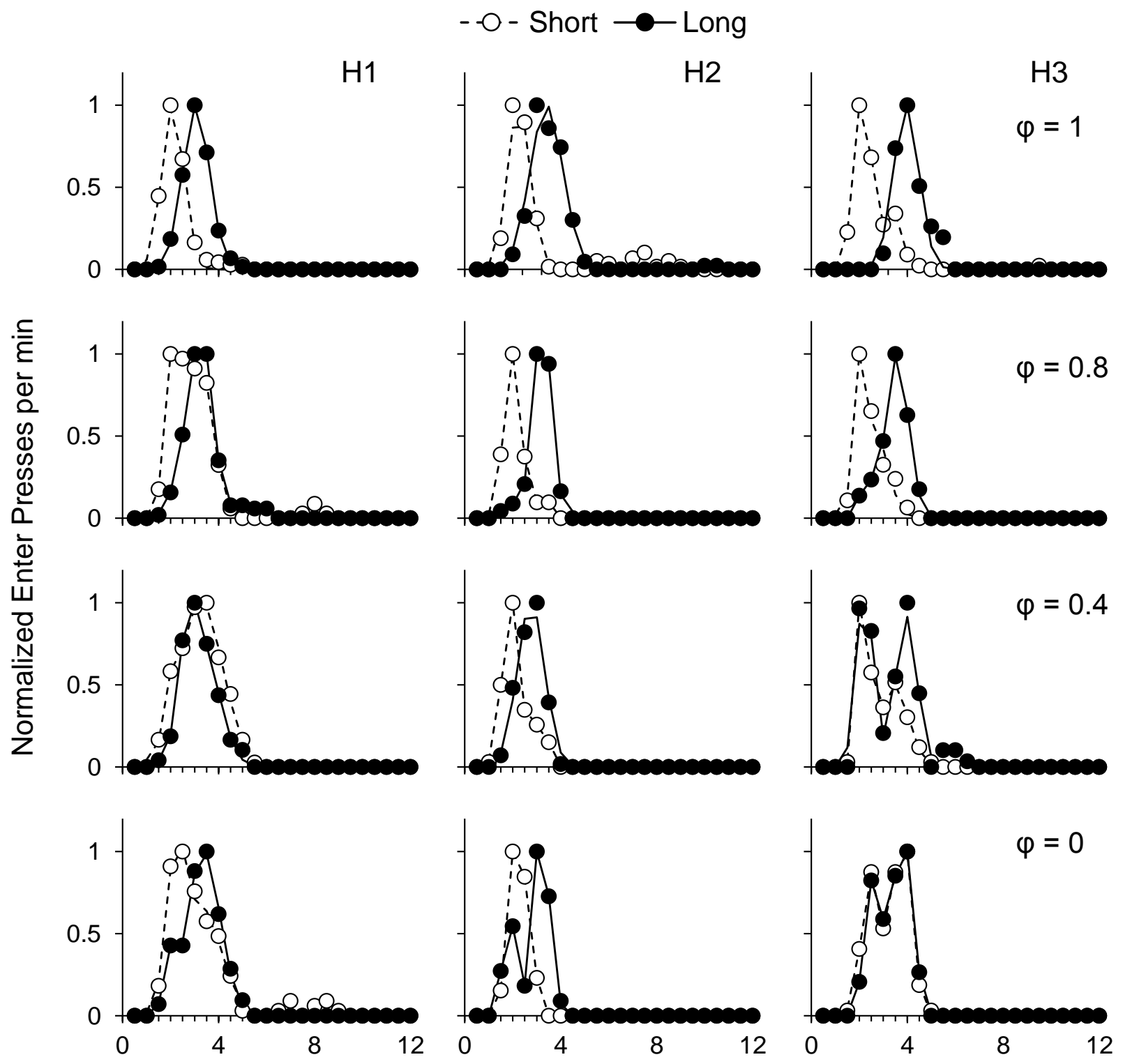

Time in $\mathrm{PI}(\mathrm{s})$

Figure 18. PI response distributions, enter presses per min as a function of time, for the short (unfilled) and long (filled) background color, when $\varphi=1$, for each participant experiencing descending cue informativeness (H1, H2, H3). PI responding is averaged across all PI trials of each background color. Dashed and solid lines are fits of Equation 2 or single Gaussians to the PI response distributions. Each condition, labeled by phi coefficient, is shown on a separate row. 

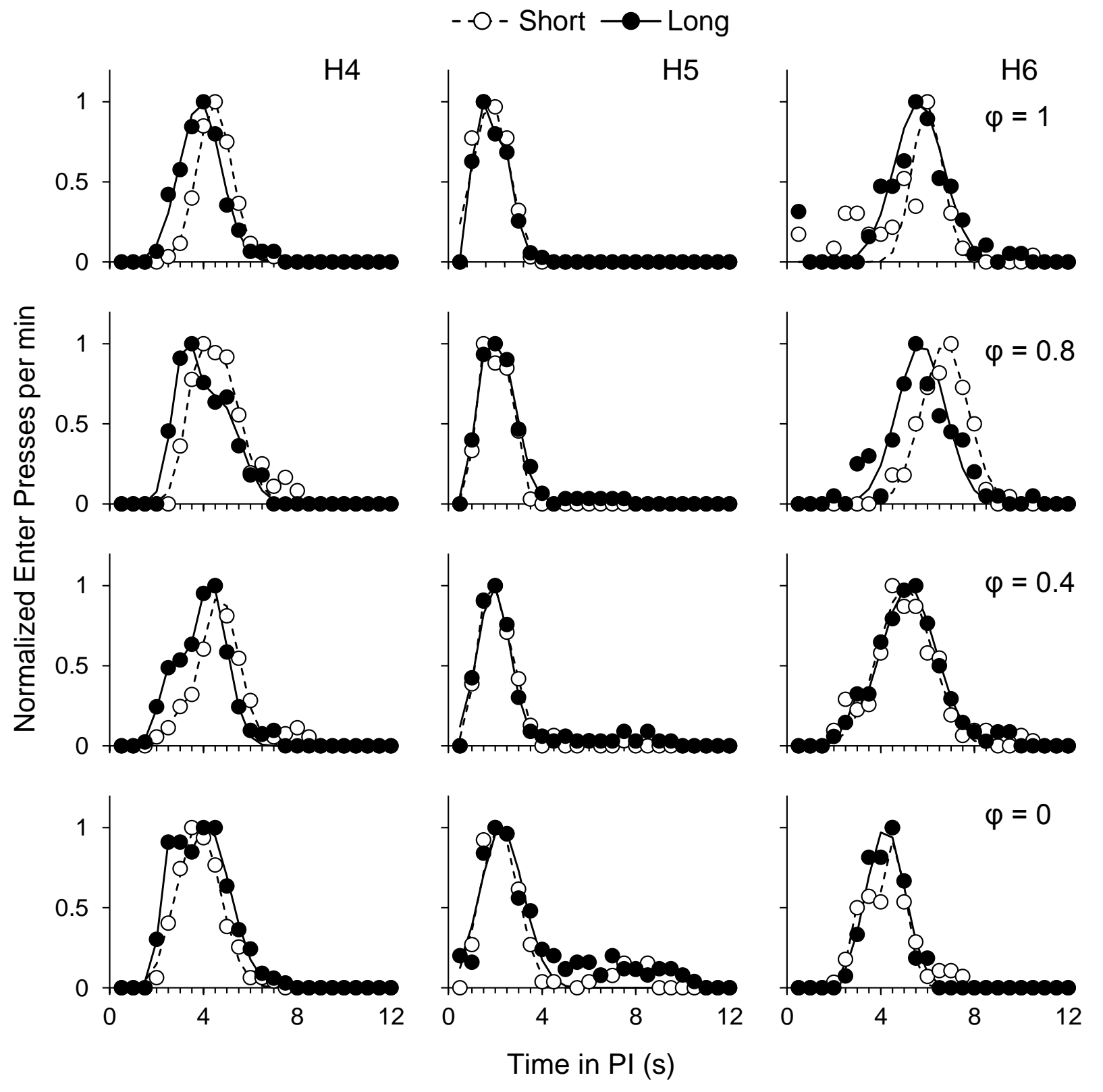

Figure 19. PI response distributions, enter presses per min as a function of time, for the short (unfilled) and long (filled) background color, when $\varphi=1$, for each participant experiencing ascending cue informativeness $(\mathrm{H} 4, \mathrm{H} 5, \mathrm{H} 6)$. PI responding is averaged across all PI trials of each background color. Dashed and solid lines are fits of Equation 2 or single Gaussians to the PI response distributions. Each condition, labeled by phi coefficient, is shown on a separate row. 


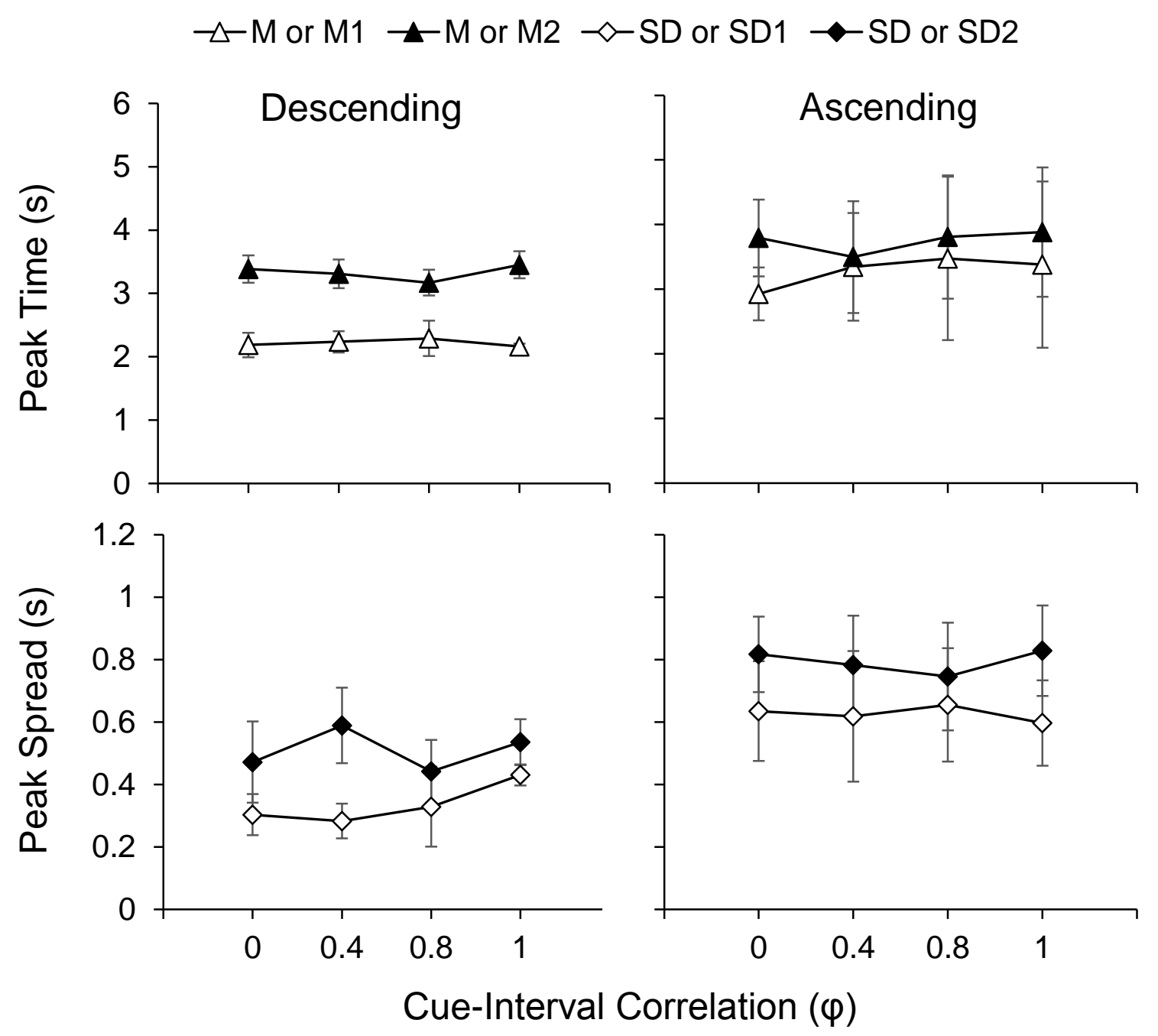

Figure 20. Peak time and spread (s) obtained from all PI trials in each condition as a function of cue-interval correlation, averaged across participants and background colors. The left graphs are peak times and spreads for participants with descending cue informativeness, and the right graphs are peak times and spreads for participants with ascending cue informativeness. The triangles are mean $M_{1}$ (unfilled) or $M_{2}$ (filled) and the diamonds are $S D_{1}$ (unfilled) or $S D_{2}$ (filled) from single Gaussians or Equation 2 fit to short and long background color PI response distributions from individual participants. The error bars are standard error. 

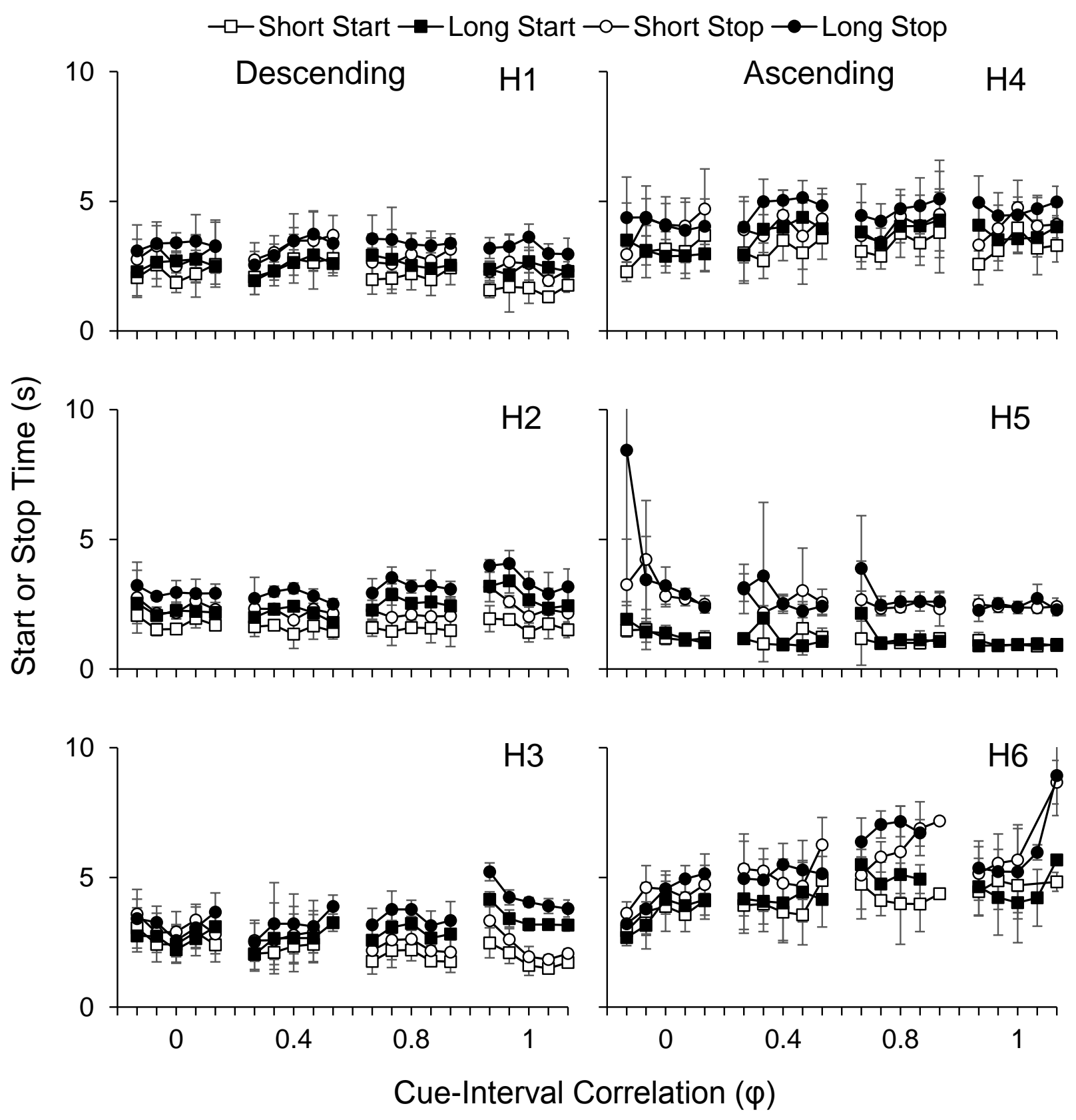

Figure 21. Start (squares) and stop (circles) times as a function of cue-interval correlation. Each data point is the average start or stop time across a block of $6 \mathrm{PI}$ trials. The filled data points are the long background color PI and the unfilled data points are the short background color PI when $\varphi=1$. Error bars are standard deviation. 


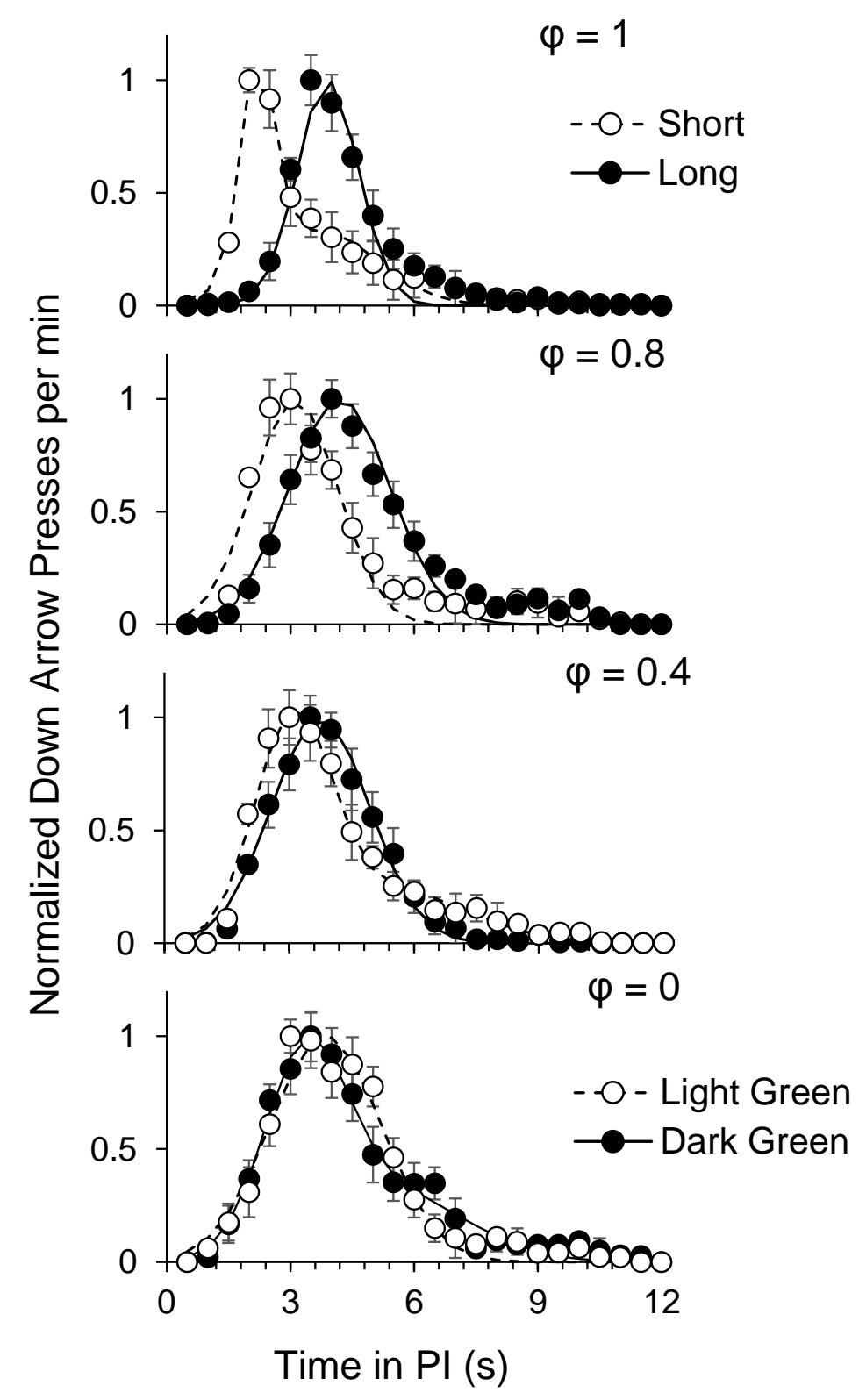

Figure 22. PI response distributions, down arrow key presses per min as a function of time, for the short (unfilled) and long (filled) background color when $\varphi=1,0.8$, or 0.4 . Unfilled circles are light green and filled circles are dark green background PI trials for participants in the $\varphi=0$ condition. Averaged distributions across groups of 12 participants in each condition $(\varphi=1,0.8$, $0.4,0)$ are graphed separately. Dashed and solid lines are fits of Equation 2 or single Gaussians to the PI response distributions. Error bars are standard error. 


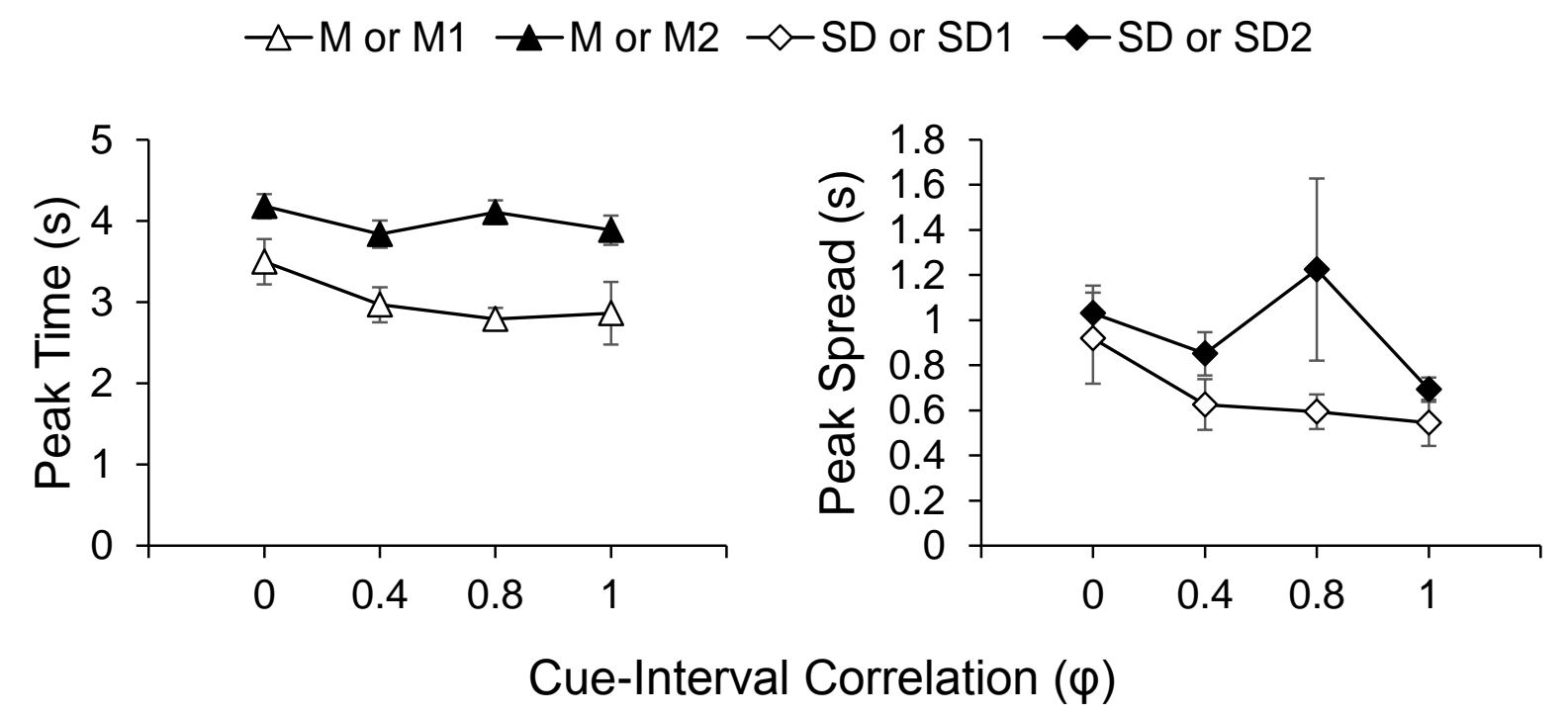

Figure 23. Peak time and spread (s) obtained from all PI trials of each condition as a function of cue-interval correlation, averaged across participants in each group and across background colors. The triangles are mean $M_{1}$ (unfilled) or $M_{2}$ (filled) and the diamonds are $S D_{l}$ (unfilled) or $S D_{2}$ (filled) from single Gaussians or Equation 2 fit to short and long background color PI response distributions from individual participants. The error bars are standard error. 
$-\square-$ Short Start $\rightarrow$-Long Start - - - Short Stop $-\bullet-$ Long Stop

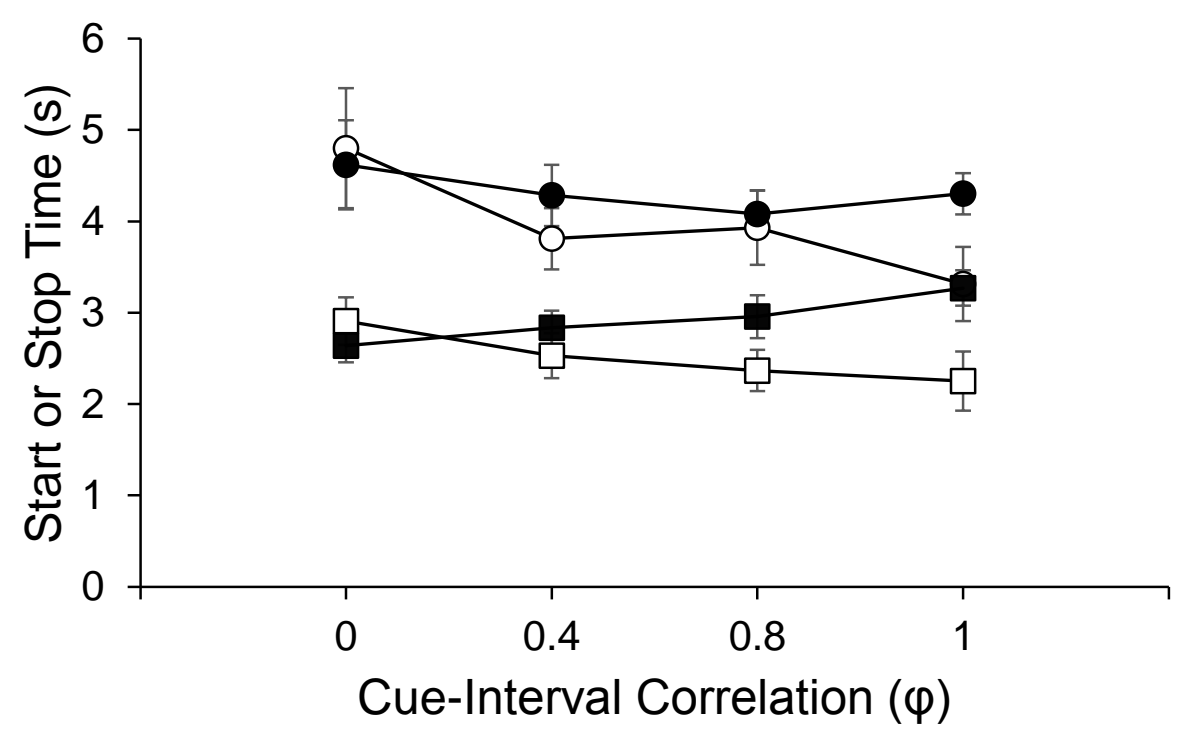

Figure 24. Start (squares) and stop (circles) times as a function of cue-interval correlation, indicated by the phi coefficient. Each data point is the average start or stop time across the last six PI trials and across participants in each condition. The filled data points are the long background color PI and the unfilled data points are the short background color PI when $\varphi=1$. 


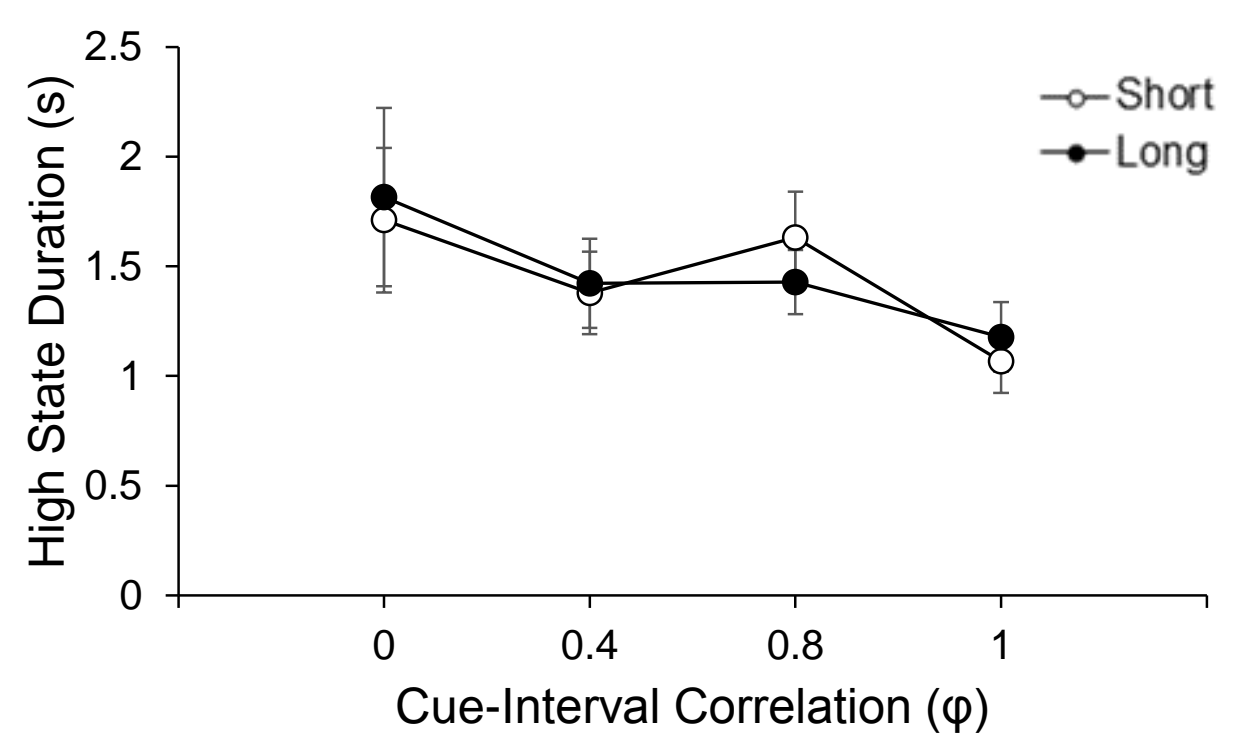

Figure 25. High state duration, or the difference between the start and stop time in the presence of the short (unfilled) or long (filled) background color (when $\varphi=1$ ) averaged across all PI trials in a session and across participants in each cue-informativeness condition group, indicated by the phi coefficient. Error bars denote standard error. 